\title{
Characterising the Biological Activity of a Trichlorovinyl Cysteine-Containing Mycothiol Analogue
}

\author{
By Phoebe Harmos
}

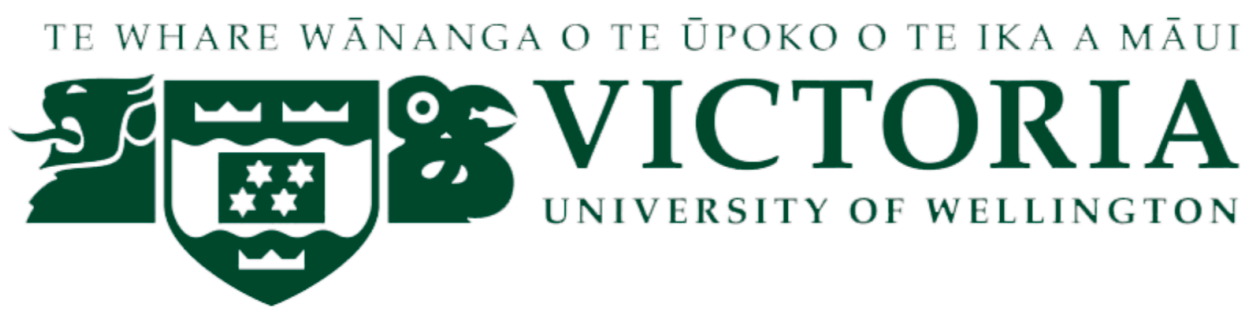

A thesis submitted to

Victoria University of Wellington

In fulfillment of the requirements for the degree of Master of Drug Discovery and Development

Victoria University of Wellington

2018 


\section{Abstract}

Cancer is a disease characterised by the uncontrolled growth of mutated cells, and is one of the leading causes of death worldwide, with over a third of people diagnosed with cancer in their lifetime. Despite extensive investment of both time and money in cancer research, poor patient outcomes and quality of life, and the evolution of treatment resistant cancers indicates that continued research, and more efficacious therapies are required. A recent investigation identified a mycothiol analogue which displayed significant toxicity in the promyelocytic leukemia cell line (HL60). Designed as a negative control, no biological activity was expected from this compound and its cellular target and mode of action are unknown.

This thesis describes the synthesis of a toxic trichlorovinyl cysteine-containing analogue of mycothiol, and the attempted synthesis of a propynylated and fluorescent derivative of this. The research also details immunomodulatory investigations, which were undertaken to probe the mode of action of the lead compound, and to determine whether its precursor, $N$-Boc- $S$-trichlorovinyl cysteine, induced toxicity through the same mechanism. The lead compound demonstrated mild immunomodulatory activity in splenocytes isolated from euthanised C57BL/6 mice, and enzyme linked immunosorbent assays revealed a likely Th2 mediated response, induced by the production of IL-4. The precursor however appears to promote a strong pro-inflammatory response, by inducing IL-17a production, which is widely considered a deleterious immune response in cancer. Whilst further work is required to determine the cellular target of the lead compound, the research described demonstrates the potential for this compound as an anti-cancer agent, while the precursor appears inappropriate for further development. 


\section{Graphical Abstract}

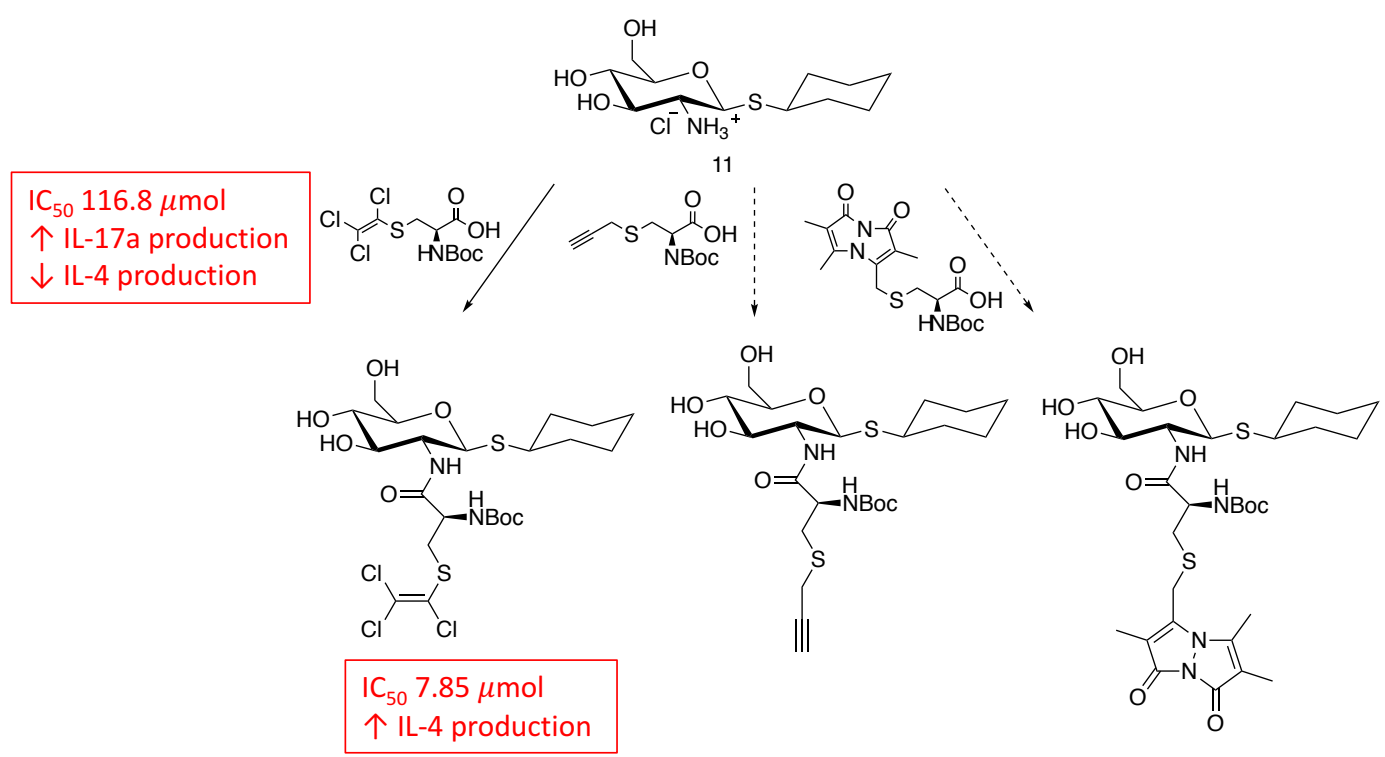




\section{Acknowledgements}

Paul, thank you so much for all of your help over the past year. Your encouragement, and enthusiasm for research has kept me going, and no problem was ever too small or too big for your attention. And thank you to Joanne, your positivity, good humour and intimidatingly vast knowledge of chemistry made group meetings and working in the lab a joy.

To my lab mates Sophie, Jamie, Claire and Matt F, although we only briefly overlapped in the lab, you all welcomed me and made me feel at home in the lab, thank you. Amira. You're the best b. I couldn't have done this without you, your encouragement to keep trying when it was worthwhile, and to move on (to Hunter lounge) when it wasn't got me through. So glad you're my lab mum! And to my lab dad, Tao, thank you for all your advice throughout the year, and for humouring my feeble attempts at speaking Mandarin. Ethan, thank you of course for running the mass specs! But mainly for your creativity and playfulness in the lab. Jordan/ Jason, I'm so glad you were Jordan most of the time, getting to know both of you has made this research a lot more fun! And Paris, sharing that fumehood with you was such a blessing, you have become a real friend over the past year. Thanks also to our neighbours, the Fulton Coles group. Lastly, and even though you're not in the lab group, to Mat Anker. You have been my personal trainer, nutritionist, and according to some, father. Thank you for keeping me sane throughout this process!

Huge thank you to everyone in biology. Vimal, you were endlessly helpful and I am so grateful for all the time you sacrificed to help me. Also to Palak, Georgina, Sam Lee and Rose, thank you for always making bio a welcoming and fun place. I've been so lucky to get to know all of you throughout the last year.

Tania and Emily Bambi Bedward. You guys have been there throughout the entire of my university life. Tania, I'm so lucky to have you in my life! You're always there for me, and I could not imagine not having you as my best friend. Emily, I may complain about you, to you, all the time, but I appreciate every distraction you've provided me. You've been there throughout every panic attack and you've been so encouraging and supporting. I love you both!

To Nick, Soph and G. Thank you for always being there for me, and always making me laugh. You guys are the best. Finally, to mum and dad, you have supported me throughout everything I do, you're both so thoughtful and I am constantly learning from both of you. I love you guys so much. Thank you. 


\section{Table of Contents}

Table of Contents $\quad$ v

List of Figures $\quad$ vi

List of Tables $\quad$ viii

$\begin{array}{ll}\text { List of Abbreviations } & \text { ix }\end{array}$

$\begin{array}{lr}\text { Chapter } 1 & 1\end{array}$

1. Introduction 1

1.1 Mycothiol
1.2 Halogenated Alkenes

1.2 Halogenated Alkenes
2

1.3 Mycothiol Conjugates as Therapeutics 4

$\begin{array}{ll}1.4 \text { Cancer } & 6\end{array}$

1.4.1 Targeting Cancer Through Sugar Conjugation 6

1.4.2 Targeting Cancer with Immunomodulatory Therapeutics 8

1.5 Target Identification and Mode of Action 9

$\begin{array}{lr}1.6 \text { Aims and Objectives } & 10\end{array}$

$\begin{array}{lr}1.7 \text { Structure Design } & 10\end{array}$

$\begin{array}{ll}\text { 1.7.1 Cell Line Selection } & 11\end{array}$

$\begin{array}{ll}\text { 1.7.2 Structure Selection } & 11\end{array}$

$\begin{array}{lr}\text { 1.7.3 Alkyne Conjugate } & 12\end{array}$

$\begin{array}{ll}\text { 1.7.4 The Fluorescent Conjugate } & 12\end{array}$

$\begin{array}{ll}1.8 \text { Biological Investigations } & 13\end{array}$

1.8.1 Enzyme Linked Immunosorbent Assay (ELISA) 13

$\begin{array}{lr}\text { 1.8.2 Phagocytosis Assay } & 14\end{array}$

$\begin{array}{lr}\text { Chapter } 2 & 14\end{array}$

2. Synthesis of Cysteine Derivatives $\quad 15$

2.1 Synthesis of N-Boc-S-trichlorovinyl Cysteine 15

$\begin{array}{ll}2.1 .1 \mathrm{~N}-B o c \text { Protection of Cysteine } & 15\end{array}$

2.1.2 S-alkylation with Tetrachloroethylene 16

2.2 Synthesis of N-Boc-S-propynyl-L-Cysteine 16

2.2.1 S-alkylation of L-cysteine $\quad 16$

2.2.2 S-propynylation of N-Boc-L-Cysteine $\quad 17$

2.2.3 S-alkylation and N-Boc Protection of L-cysteine $\quad 17$

$\begin{array}{ll}2.3 \text { Synthesis of a Fluorescent Derivative } & 18\end{array}$

2.3.1 Conjugation of Monobromobimane to Cysteine 18

2.3.2 Conjugation of Monobromobimane to N-Boc-L-Cysteine 19

$\begin{array}{ll}2.4 \text { Summary } & 20\end{array}$

$\begin{array}{lr}\text { Chapter } 3 & 21\end{array}$

3. Synthesis and Attempted Conjugation of Thioglycoside 11

3.1 Synthesis of Thioglycoside $11 \quad 21$

3.2 Conjugation of Thioglycoside 11 and N-Boc TCVC 23

3.3 Conjugation of Thioglycoside 11 and the Fluorescent Cysteine Derivative 24

3.4 Conjugation of Thioglycoside 11 and N-Boc-S-propynyl-L-Cysteine 24

$\begin{array}{ll}3.5 \text { Summary of Chemical Synthesis } & 29\end{array}$

$\begin{array}{ll}\text { Chapter } 4 & \mathbf{3 0}\end{array}$

4. Introduction to Biological Investigations 30

$\begin{array}{ll}\text { Results and Discussion } & 31\end{array}$ 
$\begin{array}{ll}\text { 4.1 MTT Assays } & 31\end{array}$

4.2 Enzyme-linked Immunosorbent Assays $\quad 32$

$\begin{array}{ll}4.2 .1 \quad B \text { cell activity } & 32\end{array}$

$\begin{array}{llr}4.2 .2 & \text { T Cell Activity } & 34\end{array}$

$\begin{array}{lr}4.3 \text { Phagocytosis assay } & 37\end{array}$

$\begin{array}{lr}4.4 \text { Summary } & 38\end{array}$

$\begin{array}{lr}\text { Chapter } 5 & 40\end{array}$

$\begin{array}{ll}5.1 \text { Future Directives } & 42\end{array}$

5.2 Concluding Remarks $\quad 40$

$\begin{array}{lr}\text { Chapter } 6 & 44\end{array}$

6. Experimental $\quad 44$

6.1 General Experimental $\quad 44$

6.2 Experimental Detail for Chemical Synthesis 445

6.3 Experimental Detail for MTT Assay $\quad 50$

6.4 Experimental Detail for ELISAs $\quad 50$

6.5 Experimental Detail for Phagocytosis Assay 152

$\begin{array}{lr}\text { 7. Appendix } & 53\end{array}$

$\begin{array}{lr}\text { 8. References } & 57\end{array}$ 


\section{List of Figures}

Figure 1.1 Mycothiol detoxification pathway

Figure 1.2 Structure of mycothiol (L) and glutathione (R)

Figure 1.3 Glutathione mediated tetrachloroethylene detoxification pathway. (A) Glutathione S-transferase. (B) $\gamma$-glutamyltransferase and dipeptidase. (C) $\beta$-lyase. (D) $\mathrm{N}$-acetyltransferase. 3 Figure 1.4 Compounds synthesised and tested by Riordan

Figure 1.5 Proposed method of dichlorothioketene liberation in Mycobacterium. (A) Mca. (B) $\beta$ lyase.

Figure 1.6 The disaccharide moiety found in bleomycin, which contributes to the cancer specific toxicity of this targeted treatment

Figure 1.7 N-Boc TCVC, precursor to compound 1 10

Figure 1.8 The lead compound to be synthesised for biological investigations 11

Figure 1.9 Proposed structure of the alkyne containing analogue, compound $\mathbf{5}$.

Figure 1.10 Proposed Structure of the fluorophore containing analogue, compound 6.

Figure 2.1 N-Boc TCVC

Figure 2.2 N-Boc-S-propynyl-L-cysteine

Figure 2.3 N-Boc-S-bimane-L- cysteine

Figure 3.2 Compound 11, thioglycoside precursor to 1, 5 and 6

Figure 3.2 Synthesis of thioglycoside 11, and attempted conjugations to compounds 7,8 and 9. aby weight, from unpurified 11.

Figure 3.3 Pathway to the expected products of conjugation of $\mathbf{1 1}$ and N-Boc-S-propynyl-Lcysteine. (A) O-acylisourea. (B) N-acylurea. (C) Compound 5. (D) Urea.

Figure 4.1 The amount of IL-10 and IgM production in LPS stimulated splenocytes treated with compound 1, compared to \% vehicle control

Figure 4.2 The amount of IL-10 and IgM production in LPS stimulated splenocytes treated with TCVC, compared to \% vehicle control.

Figure 4.3 The amount of IL-10, IF- $\gamma$, IL-4 and IL-17a production in conA stimulated splenocytes treated with compound $\mathbf{1}$, compared to \% vehicle control.

Figure 4.4 The amount of IL-10, IF- $\gamma$, IL-4 and IL-17a production in conA stimulated splenocytes treated with $\mathrm{N}-\mathrm{Boc}$ TCVC, compared to \% vehicle control.

Figure 4.5 The phagocytotic ability of RAW264.7 cells treated with compound 1, compared to \% vehicle

Figure 4.6 The phagocytotic ability of RAW264.7 cells treated with TCVC, compared to \% vehicle. 


\section{List of Tables}

Table 2.1. Species formed during the one-pot propynylation and Boc protection of cysteine ...18

Table $3.1{ }^{1} \mathrm{H}$ NMR shifts of protons in the uncoupled compound 8 and the product of the second attempt at HBTU coupling.......

Table 3.2 Reaction conditions and results of attempted conjugations to thioglycoside $11 \ldots \ldots . .28$

Table 6.1 ELISA reagents and conditions

.51 


\section{List of Abbreviations}

\begin{tabular}{|c|c|}
\hline$\left(\mathrm{CH}_{3} \mathrm{CO}\right)_{2} \mathrm{O}$ & acetic anhydride \\
\hline${ }^{13} \mathrm{C}$ NMR & carbon nuclear magnetic resonance \\
\hline${ }^{1} \mathrm{H}$ NMR & proton nuclear magnetic resonance \\
\hline Ac & acetyl \\
\hline $\mathrm{ACT}$ & adoptive cellular therapy \\
\hline app & apparent \\
\hline Aq. & aqueous \\
\hline $\mathrm{BF}_{3} \cdot \mathrm{OEt}_{2}$ & boron trifluoride etherate \\
\hline Boc & tert-butyloxycarbonyl protecting group \\
\hline $\mathrm{Boc}_{2} \mathrm{O}$ & di-tert-butyl dicarbonate \\
\hline br & broad \\
\hline C57BL/ 6 mice & C57 Black 6 mice, an inbred strain of laboratory mice \\
\hline $\mathrm{CH}_{3} \mathrm{NaO}$ & sodium methoxide \\
\hline ConA & concanavalin A \\
\hline CTCM & complete tissue culture medium \\
\hline $\mathrm{CuAAC}$ & copper(I)-catalyzed alkyne-azide cycloaddition \\
\hline $\mathrm{d}$ & doublet \\
\hline $\mathrm{DBN}$ & 1,5-diazabicyclo(4.3.0)non-5-ene \\
\hline DCM & dichloromethane \\
\hline DMAP & 4-dimethylaminopyridine \\
\hline $\mathrm{DMF}$ & dimethylformamide \\
\hline DMSO & dimethyl sulfoxide \\
\hline EDC & 1-ethyl-3-(3-dimethylaminopropyl)carbodiimide \\
\hline ELISA & enzyme linked immunosorbent assay \\
\hline EPA & Environmental Protection Authority \\
\hline eq. & equivalents \\
\hline Et & ethyl \\
\hline EtOAc & ethyl acetate \\
\hline FCS & foetal calf serum \\
\hline FDA & Food and Drug Administration \\
\hline GlcN-Ins & glucosamine-inositol \\
\hline
\end{tabular}




\begin{tabular}{|c|c|}
\hline GST & Glutathione- $S$-transferase \\
\hline h2so4 & sulfuric acid \\
\hline \multirow[t]{2}{*}{ HBTU } & $N, N, N^{\prime}, N^{\prime}$-tetramethyl- $O-(1 H$-benzotriazol-1-yl)uronium \\
\hline & hexafluorophosphate \\
\hline $\mathrm{HCl}$ & hydrochloric acid \\
\hline HL60 & human promyelocytic leukemia cells \\
\hline $\mathrm{HOBt}$ & hydroxybenzotriazole \\
\hline HRMS & high resolution mass spectrometry \\
\hline IARC & International Agency for Research on Cancer \\
\hline \multirow[t]{2}{*}{$\mathrm{IC}_{10}$} & the concentration of an inhibitor required to inhibit cellular growth by \\
\hline & $10 \%$ \\
\hline \multirow[t]{2}{*}{$\mathrm{IC}_{50}$} & the concentration of an inhibitor required to inhibit cellular growth by \\
\hline & $50 \%$ \\
\hline IFN- $\gamma$ & interferon gamma \\
\hline $\operatorname{IgM}$ & immunoglobulin $\mathrm{m}$ \\
\hline IL-10 & interleukin 10 \\
\hline IL-17a & interleukin $17 \mathrm{a}$ \\
\hline IL-4 & interleukin 4 \\
\hline IR & infrared radiation \\
\hline LC-MS/MS & liquid chromatography-tandem mass spectrometry \\
\hline LPS & lipopolysaccharide \\
\hline $\mathrm{m}$ & multiplet \\
\hline $\mathrm{mAb}$ & immune-cell-targeted monoclonal antibody \\
\hline Mca & mycothiol- $S$-conjugate amidase \\
\hline $\mathrm{Me}$ & methyl \\
\hline $\mathrm{MgSO}_{4}$ & magnesium sulfate \\
\hline MNIC & minimum non-inhibitory concentration \\
\hline MTT & 3-(4,5-dimethylthiazol-2-yl)-2,5-diphenyltetrazolium bromide \\
\hline $\mathrm{Na}_{2} \mathrm{HPO}_{4}$ & disodium phosphate \\
\hline NTP & National Toxicology Program \\
\hline PAMPs & pathogen associated molecular patterns \\
\hline PBS & phosphate buffered saline \\
\hline PET & positron emission tomography \\
\hline q & quartet \\
\hline
\end{tabular}




$\begin{array}{ll}\text { RAW264.7 } & \text { murine macrophage cell line } \\ \mathrm{R}_{f} & \text { retention factor } \\ \text { RPMI } & \text { media, originally developed to culture human leukemic cells } \\ \mathrm{rt} & \text { room temperature } \\ \mathrm{S} & \text { singlet } \\ \mathrm{t} & \text { triplet } \\ t \text {-BuOK } & \text { potassium tert-butoxide } \\ \text { TCVC } & S \text {-(1,2,2-trichlorovinyl)-L-cysteine } \\ \text { TCVG } & S \text {-(1,2,2-trichlorovinyl) glutathione } \\ \text { TCVSH } & 1,2,2 \text {-trichlorovinylthiol } \\ \text { Th1 } & \text { type } 1 \text { helper T cells } \\ \text { Th17 } & \text { type } 17 \text { helper T cells } \\ \text { Th2 } & \text { type } 2 \text { helper T cells } \\ \text { THF } & \text { tetrahydrofuran } \\ \text { TLC } & \text { thin-layer chromatography } \\ \text { TMB reagent } & 3,3 \text { ',5,5'-Tetramethylbenzidine } \\ \text { Treg } & \text { regulatory t cells } \\ \text { Tris } & \text { trisaminomethane } \\ \text { UV } & \text { ultraviolet } \\ \text { VUW } & \text { Victoria University of Wellington }\end{array}$




\section{Chapter 1}

\section{Introduction}

The aim of the work reported in this thesis is to synthesise a toxic mycothiol analogue, and to investigate its mode of action in the HL60 cell line.

Previous work sought to develop novel agents for the treatment of mycobacterial infection based on a trichlorovinyl cysteine-containing analogue of mycothiol. An unexpected discovery from that work was that a control compound showed promising anti-cancer like activity against the HL60 promyelocytic leukemia cell line. The work reported in this thesis was undertaken to probe the mode of action of this compound. The original intention was to assess pathways affected by the compound based on analysis of proteome responses in HL60 cells. However, a prolonged break-down of the liquid chromatography-tandem mass spectrometry machine (LC-MS/MS) over the final months of this research necessitated a late change of research goals. A set of assays were undertaken to evaluate the immunomodulatory activity of the lead compound, to assess whether its activity was appropriate for an anti-cancer treatment. These assays were also utilised to determine whether the activity of compound $\mathbf{1}$ is distinct from that of a precursor, $N$-Boc- $S$-trichlorovinyl-L-cysteine ( $N$-Boc TCVC).

To explain the background to the discovery of the activity of the lead compound, there follows an introduction to mycothiol, and the role of the $\beta$-lyase enzyme in the biological activity of $\mathrm{N}$-Boc TCVC. This is followed by a description of how target identification was approached in this thesis. The chemical synthesis and biological aims of this investigation, and how they changed during the course of the research are also discussed.

\subsection{Mycothiol}

Mycothiol is a thiol-containing compound with a protective role in the detoxification of electrophilic xenobiotics in actinomycetes bacteria. ${ }^{1}$ Mycothiol is composed of a cysteine conjugated to GlcN-Ins, a glucosamine which is linked to an inositol group at 
the anomeric centre. ${ }^{2}$ Mycothiol functions by binding to exogenous compounds through the cysteine thiol group, and forming mycothiol-toxin conjugates, which can be further metabolised by mycothiol-S-conjugate amidase (Mca) to produce an $N$-acetyl cysteine $S$ conjugate of the toxin (Figure 1.1). ${ }^{1}$
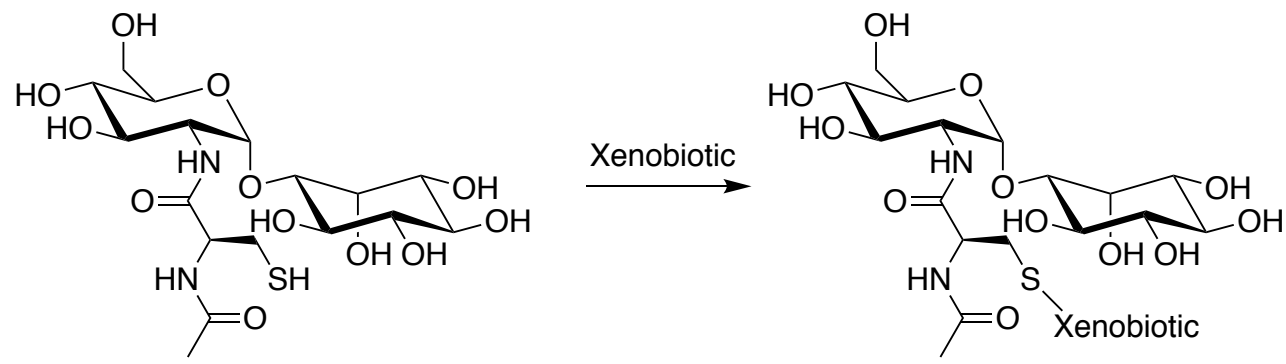

Figure 1.1 Mycothiol detoxification pathway

Mycothiol is not found in human cells, where an analogous peptide glutathione performs a similar role. ${ }^{3}$ Despite their similar function, the structure of glutathione is different to that of mycothiol, and consists of a tripeptide, containing a glutamine, cysteine, and glycine (Figure 1.2). ${ }^{4}$ As mycothiol is an essential peptide for bacteria such as Mycobacterium tuberculosis and is absent in human cells, the mycothiol detoxification pathway has been investigated as a potential target for anti-tuberculosis treatment. ${ }^{5-7}$

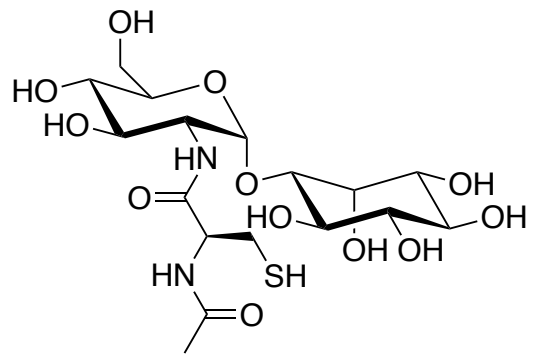<smiles>N[C@@H](CCC(=O)NC(CS)C(=O)NCC(=O)O)C(=O)O</smiles>

Figure 1.2 Structure of mycothiol (L) and glutathione (R)

\subsection{Halogenated Alkenes}

Halogenated alkenes such as tetrachloroethylene and trichloroethylene are commonly used solvents, and have important industrial applications, particularly in dry cleaning, metal degreasing, and in the production of chlorinated chemicals. ${ }^{8,9}$ Human exposure to these chlorinated solvents generally occurs through inhalation, although contamination of drinking water is common. ${ }^{8}$ Recent investigations by the US Environmental Protection 
Agency (US EPA), the International Agency for Research on Cancer (IARC) and the National Toxicology Program (NTP) classified tetrachloroethylene as a probable human carcinogen, with significant non-cancer neuro- and nephrotoxicity. ${ }^{8,10,11}$ Interestingly, the acute toxicity of tetrachloroethylene is primarily associated with its metabolism and attempted detoxification by glutathione, predominantly in the liver and kidney. ${ }^{12}$ Conjugation of tetrachloroethylene to glutathione is catalysed by glutathione $S$ transferase, and leads to the production of $S$-(1,2,2-trichlorovinyl) glutathione (TCVG) (Figure 1.3). ${ }^{13}$ This precursor is then further metabolised by $\gamma$-glutamyltransferase and dipeptidases to form $S$-(1,2,2-trichlorovinyl)-L-cysteine (TCVC). ${ }^{13}$ The majority of TCVC is subsequently detoxified through $\mathrm{N}$-acetylation, and excreted in the urine. A small percentage of TCVC however can act as a substrate for $\beta$-lyase enzymes. ${ }^{13} \beta$-lyases catalyse a $\beta$-elimination, causing the production of 1,2,2-trichlorovinylthiol (TCVSH), pyruvate and ammonia. ${ }^{12,13}$ TCVSH is unstable, and can rearrange to form acylating species, such as dichlorothioketene, which is the likely agent of the associated neuro- and nephrotoxicity. ${ }^{13,14}$

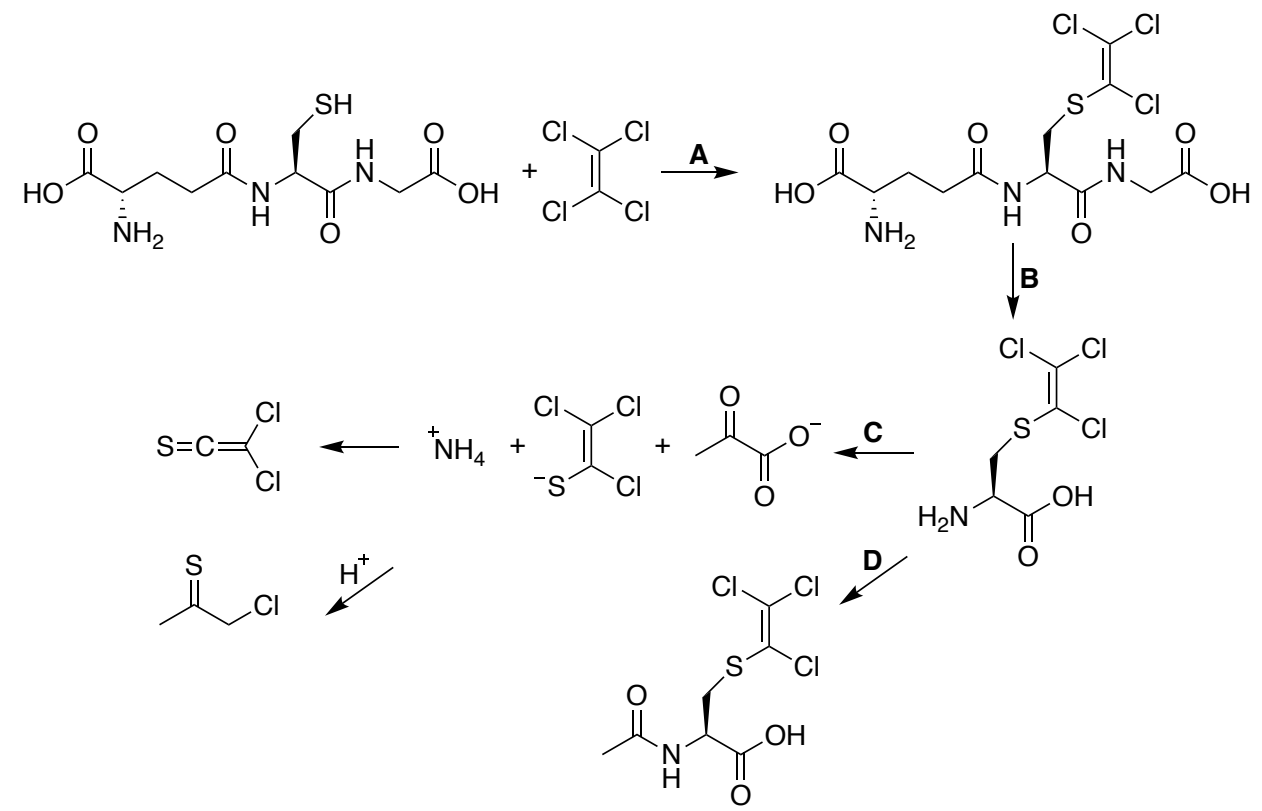

Figure 1.3 Glutathione mediated tetrachloroethylene detoxification pathway. (A) Glutathione S-transferase. (B) $\gamma^{-}$ glutamyltransferase and dipeptidase. (C) B-lyase. (D) N-acetyltransferase

$\beta$-lyase activity is a secondary function of pyridoxal phosphate containing amino acid metabolising enzymes, including aminotransferases. ${ }^{15}$ As transamination is an essential process in all living systems, and aminotransferase enzymes are found in human and Mycobacterium, it is expected that some incidental $\beta$-lyase activity will occur in both 
systems. ${ }^{16}$ It was with the goal of treating tuberculosis by exploiting the ubiquitous nature of the $\beta$-lyases, that a trichlorovinyl conjugated mycothiol analogue was synthesised. ${ }^{5}$

\subsection{Mycothiol Conjugates as Therapeutics}

Due to the substantial structural differences between glutathione and mycothiol, and the inherent substrate specificity of their metabolising enzymes in human cells and Mycobacterium, it is expected that mycothiol conjugates can only be metabolised in the cells of Mycobacterium and not humans. As a result, these compounds have been investigated as potential treatments for tuberculosis. One such investigation explored the effects of conjugating a trichloroethylene group to the thiol of a simplified mycothiol backbone in Mycobacterium smegmatis and Mycobacterium bovis. ${ }^{5}$ Four analogues were synthesised, each containing a trichloroethylene group, but differing in the conformation of the anomeric center, and protection of the cysteine's amine (Figure 1.4). It was hypothesised that within Mycobacterium, compounds $\mathbf{2}$ and $\mathbf{4}$ would be recognised as a substrate for mycothiol metabolism, due to their structural similarity to an endogenous mycothiol, bound to an exogenous toxin. The $\beta$-anomers, compounds $\mathbf{1}$ and $\mathbf{3}$ were designed to act as negative controls within Mycobacterium as it was expected that the differing geometry at the anomeric centre would exclude them as substrates for mycothiol metabolising enzymes.

The $N$-Boc protected precursors, compounds $\mathbf{1}$ and $\mathbf{2}$ were included in biological investigations as it was speculated that the lipophilicity of the Boc group would improve cellular transport of the compounds into the cell. It was expected that once within a Mycobacterium cell, compounds $\mathbf{2}$ and $\mathbf{4}$ would be cleaved by mycothiol $S$-conjugate amidase (Mca) to release an $S$-trichlorovinyl cysteine and a thioglycoside. ${ }^{13} \beta$-lyase cleavage of the cysteine, through the incidental activity of aminotransferase enzymes, would result in the liberation of an unstable $S$-haloalkene, which is subsequently converted into the toxic dichlorothioketene (Figure 1.5). ${ }^{14,15}$ This toxic metabolite could then cause cellular damage to the Mycobacterium, resulting in cell death. ${ }^{13,14}$ As compounds $\mathbf{1}$ and $\mathbf{3}$ were not expected to act as substrates for Mca metabolism, it was expected that only compounds $\mathbf{2}$ and $\mathbf{4}$ could be able to induce toxicity. 


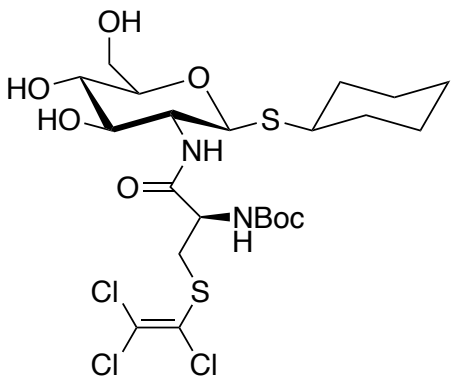

1

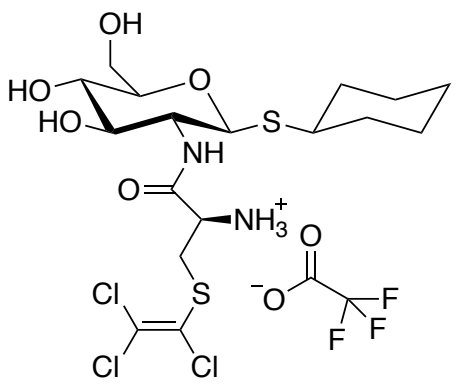

3

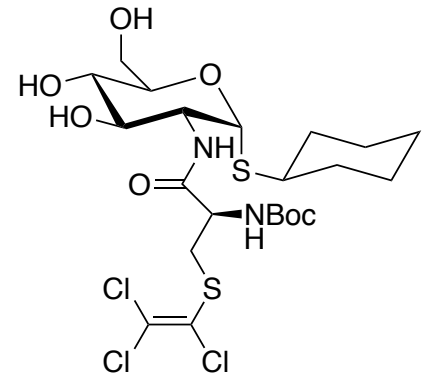

2

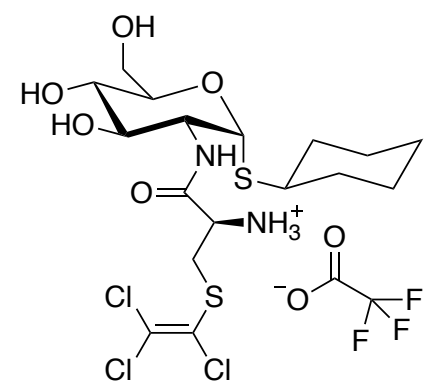

4

Figure 1.4 Compounds synthesised and tested by Riordan

Biological testing of these four compounds indicated that compounds $\mathbf{3}$ and $\mathbf{4}$ had moderate activity against Mycobacterium smegmatis and Mycobacterium bovis. Surprisingly, the highest activity was observed in HL60 cells treated with compound 1 in which an $\mathrm{IC}_{50}$ of $16.5 \pm 0.2 \mu \mathrm{M}$ was recorded. This $\mathrm{IC}_{50}$ indicates that there is reasonable efficacy in human cancer cells, and that compound $\mathbf{1}$ may represent a potential anti-cancer lead compound. ${ }^{5}$ Although the activity of this simplified mycothiol analogue looks promising, the mechanism of its toxicity is unclear. This is especially true when the design of the compound is considered. It was predicted that none of the mycothiol analogues would be active in human cells, as the considerable difference in their structure compared to glutathione should prevent their recognition by glutathione metabolising enzymes. Furthermore, the $\beta$-anomer was designed to cause a reduction in activity even in Mycobacterium, so any activity in human cells is particularly surprising.

Based on the design of compound 1, there are two hypotheses which could explain the toxicity observed in HL60 cells. HL60 cells may be able to process compound 1 and release the known toxic metabolite, dichlorothioketene, which subsequently inhibits cell growth. Alternatively, the toxicity could be caused by a cellular target interaction, which is not mediated by the release of dichlorothioketene. To determine the potential 
usefulness of compound $\mathbf{1}$ as an anti-cancer agent, its mechanism of action must be determined

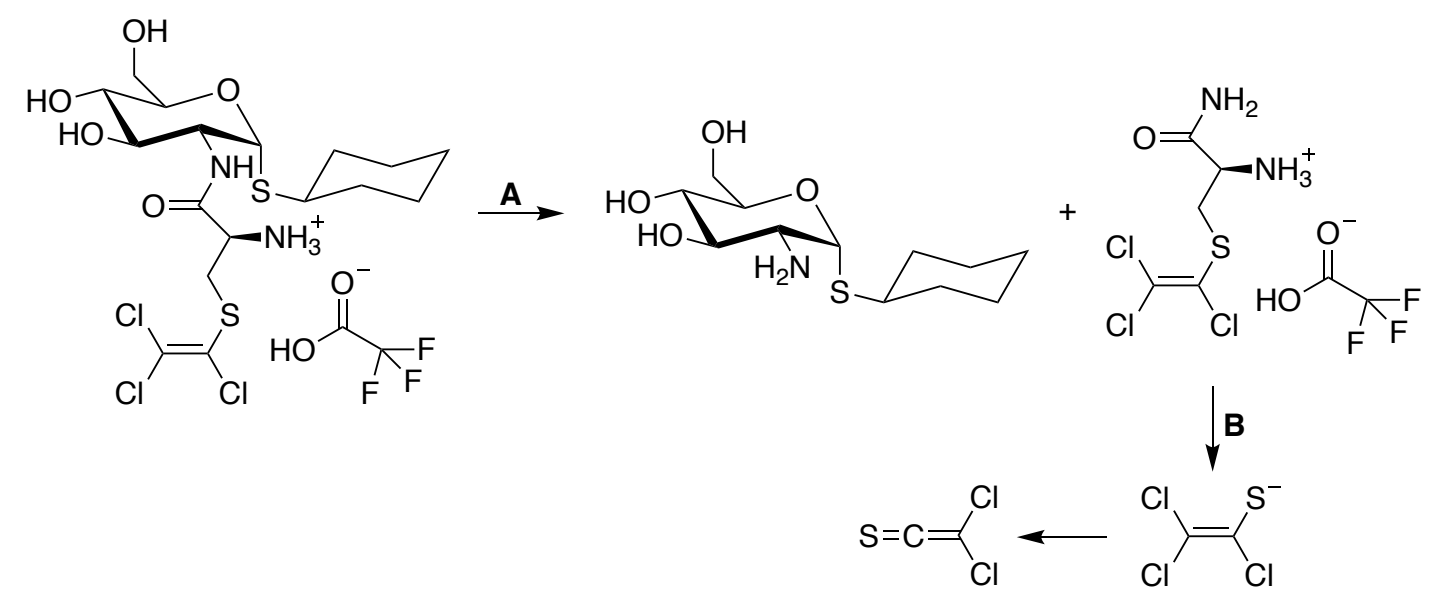

Figure 1.5 Proposed method of dichlorothioketene liberation in Mycobacterium. (A) Mca. (B) B-lyase

\subsection{Cancer}

Cancer is a disease characterised by the uncontrolled growth of mutated cells, and is one of the leading causes of death worldwide, with an estimated $38.5 \%$ of people diagnosed with cancer in their lifetime. ${ }^{17}$ Although advances in treatment have been significant in recent years, necessary improvements in the quality of life and patient outcomes, as well as the evolution of treatment resistant cancers indicates that continued research and new therapies are required. ${ }^{18,19}$ Common cancer treatments options include surgery, radiation therapy, chemotherapy, and targeted therapy. ${ }^{18}$

\subsubsection{Targeting Cancer Through Sugar Conjugation}

Targeted therapy seeks to exploit cancer cell-specific mechanisms to cause selective toxicity or growth inhibition in cancer cells. ${ }^{18}$ While small molecule drugs are commonly administered as a targeted therapy, complete specificity towards cancer cells is rare, and mild to severe side effects are often caused by off target effects in healthy cells. ${ }^{20-22}$ Targeting strategies which seek to exploit the differences between healthy and cancerous cells are varied, and include antibody conjugation, hormone therapies, angiogenesis inhibitors and apoptosis inducers. ${ }^{23,24}$ 
Sugar conjugation is one method of targeting that is rarely utilised in cancer treatments, but which could have significant effects on the specificity of a drug. The Warburg effect was first reported in 1930, and describes the phenomenon by which cancerous cells tend to rely on aerobic glycolysis for energy production, while healthy cells preferentially employ oxidative phosphorylation. ${ }^{25}$ Aerobic glycolysis is a comparatively inefficient process, with oxidative phosphorylation achieving 18 fold more energy production from the same amount of glucose. ${ }^{25}$ Consequently, cancerous cells generally consume significantly more glucose than healthy cells. This trend has been utilised in cancer imaging, through positron emission tomography (PET) scanning. ${ }^{26}$ In PET scanning, a radio-labelled glucose is injected into an individual, and areas of high glucose concentration can be visualised as opaque areas in a translucent image of the body. ${ }^{26}$ Areas of high glucose metabolism indicate potentially cancerous sites. Although the preference of cancer cells for sugar as fuel has already been exploited for cancer imaging, its use as a targeting strategy in drug design is largely unexplored. Conjugation of a chemotherapeutic to a sugar motif may lead to preferential uptake into cancerous cells, and therefore targeted toxicity. PET scanning is used to visualise many different types of cancer including; lung, lymphoma, melanoma, thyroid and pancreatic, and its wide scope indicates the potential for a wide scope of the sugar conjugation strategy. ${ }^{27}$

Bleomycin is an example of an FDA approved targeted anti-cancer therapy which contains a disaccharide moiety. ${ }^{28}$ While research has indicated that the disaccharide component of bleomycin does not contribute to its toxicity, it has been shown to determine the specificity for cancerous cells, where removal of the disaccharide moiety significantly reduces selectivity. ${ }^{29}$ In vitro investigations of existing FDA approved drugs chlorambucil and docetaxel have indicated that conjugation of sugar moiety to the compounds increases specificity to cancer cells. ${ }^{27}$ This indicates the specificity afforded to Bleomycin is not necessarily limited to this drug, but could be exploited in more anticancer agents. ${ }^{27}$ Interestingly, bleomycin is clinically used in the treatment of lymphoma, testicular cancer, ovarian cancer and cervical cancer, all cancers which can be visualised by PET scans. 


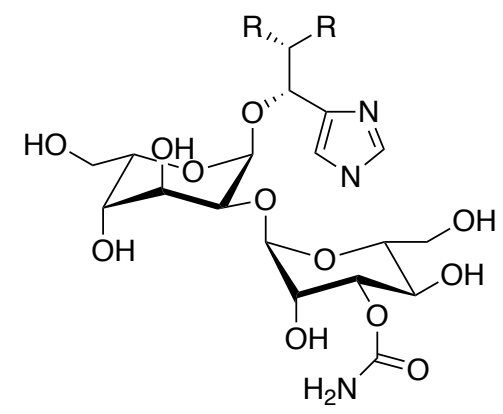

Figure 1.6 The disaccharide moiety found in bleomycin, which contributes to the cancer specific toxicity of this targeted treatment

\subsubsection{Targeting Cancer with Immunomodulatory Therapeutics}

In recent years, significant advances in the use of immunomodulatory therapeutics for cancer treatment has piqued an interest in the unmatched specificity that is afforded by these drugs. ${ }^{30}$ Immunotherapy seeks to treat cancer by generating or improving an existing immune response against cancer cells. ${ }^{30}$ Immune-cell-targeted monoclonal antibody $(\mathrm{mAb})$ and adoptive cellular therapy (ACT) are widely considered to be the most efficacious immunomodulatory treatment strategies. ${ }^{30}$ ACT utilises personalised medicine, by first isolating tumour specific $\mathrm{T}$ cells from a patient, and then stimulating these cells to increase their activity, before injecting the cells back into the patient. ${ }^{31,32}$ In comparison, $\mathrm{mAb}$ therapy utilises antibodies to cause selective toxicity to deleterious cells or proteins specifically. ${ }^{33}$

Although the most successful immunomodulatory drugs are themselves either immune cells, or immune cell-like, immune-stimulatory activity is also observed in many natural products, including extracts from plants such as Viscum album, Panax ginseng, Tinospora cordifolia and Asparagus racemosus. ${ }^{30,34}$ In some cases, such as with Viscum album individual peptides isolated from plant extracts have been identified as the source of the immunomodulatory activity. ${ }^{35}$ While these peptides lack the specificity of other FDA approved immunomodulatory cancer treatments, they have been investigated for their potential use as an adjuvant in combination therapy. ${ }^{35,36}$ Peptides may act to augment the immune response to cancer, which is notoriously suppressed during conventional cancer therapies, such as radiation and chemotherapy. ${ }^{34-36}$ Thus, as the role of immunomodulatory drugs in the treatment of cancer is ever-increasing, the focus on both 
highly specific immune cell mediators and generalised immuno-stimulatory compounds symbolises the potential for substantial improvements in anti-cancer treatments.

\subsection{Target Identification and Mode of Action}

Identifying the cellular target and mode of action of a compound is a vital step in the drug development process, which can determine whether subsequent research is worthwhile. There are both direct and indirect methods of target identification. One direct method of target identification is affinity purification. In affinity purification, the strong interaction between a compound and its cellular target is exploited, to isolate or "pull down" the target from a complex mixture, such as a cell lysate.

When direct methods of target identification fail, indirect methods can be used to gain insight into how the compound of interest is interacting with a cell. In fluorescent imaging, a fluorophore is conjugated to the lead compound, which is then incubated with cells. Fluorescence microscopy can then be used to visualise the colocalisation of the compound of interest, with specific cellular compartments. Another popular method of indirect target identification is proteomics. In proteomics, an entire proteome is analysed by mass spectrometry, both in the presence and absence of test compound. Proteomics enables a broad and comprehensive analysis of the cell, and therefore reveals which cellular pathways are likely to be influenced by the lead compound.

Much insight can also be probed by investigating the immunomodulatory effects of a compound. Like fluorescence microscopy and proteomics, this will not lead to the direct identification of the cellular target of a compound, but can provide insight into some of the activity observed within a cell. In investigating anti-cancer lead compounds, this can be particularly important when considering the widespread suppression of the immune system, which can be induced by the cancerous cells themselves. ${ }^{37}$ Antibodies, such as IgM have been shown to eliminate B cell tumours through the induction of apoptosis and complement. ${ }^{38}$ Pro-inflammatory factors have been implicated in both the prevention and the promotion of cancer. ${ }^{39,40}$ For example, IL-17a is a pro-inflammatory cytokine with tumour enhancing effects in prostate, cervical and breast cancer. ${ }^{41-43}$ Conversely, tumour specific Th1 cells drive inflammation which leads to the eradication of cancer, through the induction of angiostatic chemokines and cytotoxic macrophages. ${ }^{39}$ The immune 
system plays a vast and complex role in the treatment of cancer, and investigating the immunomodulatory effects of a potential anti-cancer compound could indicate any valuable or potentially problematic cellular responses.

\subsection{Aims and Objectives}

The original aim of this thesis was to synthesise a toxic trichlorovinyl cysteinecontaining analogue of mycothiol (compound 1) and investigate its mode of action in HL60 cells. The synthesis of two derivatives of this compound, functionalised with a propynyl or a fluorescent motif was a secondary objective. These were to be utilised in biological assays, towards discerning the cellular target of the toxic mycothiol analogue (compound 1). Unfortunately, due to difficulties associated with the final synthetic step in the synthesis of both functionalised derivatives, the research goals were modified considerably, and are as follows:

1) Synthesise a toxic trichlorovinyl cysteine- containing analogue of mycothiol (compound 1)

2) Determine the toxicity of a precursor to compound 1, $N$-Boc TCVC in HL60 cells

3) Utilise immunomodulatory assays to investigate the underlying cellular response to treatment with both $\mathrm{N}$-Boc TCVC and compound $\mathbf{1}$ and ascertain whether $\mathrm{N}$ Boc TCVC and compound 1 mediate their toxicity through a shared mechanism

4) Determine whether the immunomodulatory activities of $N$-Boc TCVC or compound 1 justify further investigations into their anti-cancer properties<smiles>O=C(O)C(CSC(Cl)=C(Cl)Cl)C(=O)O</smiles>

Figure 1.7 N-Boc TCVC, precursor to compound 1

Both the chemical synthesis and the biological investigations undertaken during this research are described below.

\subsection{Structure Design}

Compound 1 (Figure 1.8) will be synthesised for use in further biological studies. The attempted synthesis of two analogues, one containing a fluorophore, and one containing 
an alkyne moiety will also be described. The chemical synthesis methodology will primarily be sourced from Riordan's masters thesis, with additional methods from Knapp and Hiremathad. ${ }^{5,44,45}$

\subsubsection{Cell Line Selection}

Compound 1 and N-Boc TCVC will be tested in both HL60 and RAW264.7 cell lines. HL60 cells will be utilised for the initial MTT assays, to determine the $\mathrm{IC}_{50}$ of both treatments, while RAW264.7 cells will be treated in a phagocytosis assay. A third cell type, splenocytes isolated from euthanised C57BL/ 6 mice will also be tested. These splenocytes will be utilised in enzyme linked immunosorbent assays (ELISA). Testing compound $\mathbf{1}$ and $\mathrm{N}$-Boc TCVC in three different cell types, including primary cells, allows a more comprehensive investigation into the mechanism of action of each compound.

\subsubsection{Structure Selection}

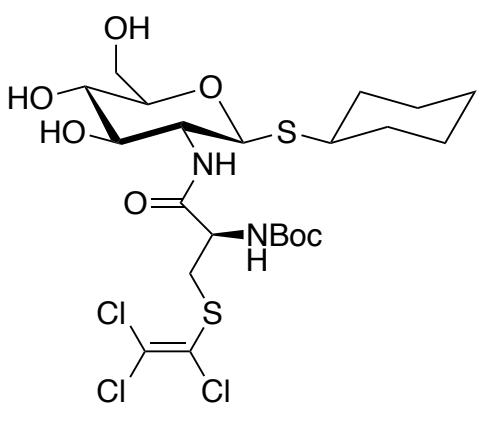

1

Figure 1.8 The lead compound to be synthesised for biological investigations

The proposed structure of compound $\mathbf{1}$ is based on the analogue synthesised and tested by Riordan. ${ }^{5}$ This structure has been selected for further biological analysis, as it demonstrates the greatest activity against human cells, and therefore has the greatest potential as an anti-cancer agent. The structure differs considerably from that of mycothiol. Most notably through the presence of the trichloroethylene group, initially designed to act as the 'warhead' of the compound in Mycobacterium. The structure also deviates from mycothiol in the simplified $\beta$-GlcN-inositol backbone. This was initially reported by Knapp, who replaced the anomeric oxygen linker with a sulfur, and simplified 
the inositol ring, to bypass various complications in the synthesis. ${ }^{44}$ Although $N$-Boc protection of a lead compound is unusual, the significant increase in activity against human cells seen in the MTT results reported by Riordan justifies having the protecting group in the final compound, as it may confer a cellular transportation advantage. ${ }^{5}$

\subsubsection{Alkyne Conjugate}

The attempted synthesis of an analogue containing an alkyne group in place of the trichloroethylene on the cysteine will also be discussed. This analogue was designed for use in affinity purification studies, in an attempt to identify the cellular target of compound 1. Although there are many different methods commonly used to identify a cellular target with affinity purification, it was proposed that employing the copper(I)catalyzed alkyne-azide cycloaddition (CuAAC) reaction would present a particularly elegant solution. ${ }^{46}$ In this reaction, the modified lead compound binds to its cellular target and reacts with an azide coated solid support, to form a stable triazole product. The proteins of the cellular target are then eluted off the solid support, and identified through LC-MS/MS, to reveal the cellular target. Unfortunately, as the synthesis of compound 5 was unsuccessful, affinity purification was not utilised in the biological investigations.

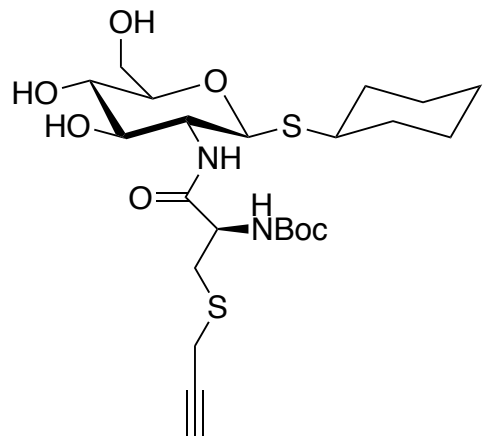

5

Figure 1.9 Proposed structure of the alkyne containing analogue, compound $\mathbf{5}$

\subsubsection{The Fluorescent Conjugate}

The synthesis of an analogue containing a fluorophore in the place of the trichloroethylene on the cysteine was also attempted. In the literature the cellular localisation of mycothiol is most commonly tracked using monobromobimane, which 
alkylates the cysteines thiol to form a fluorescent tag. ${ }^{47}$ Monobromobimane was also chosen as it is a similar size to the trichloroethylene substituent, which may reduce the potential efficacy effects of modifying the structure at the thiol centre. Had the synthesis of this analogue been successful, visualisation through fluorescence microscopy could have provided insight into the cellular localisation of both compounds $\mathbf{1}$ and $\mathbf{6}$.

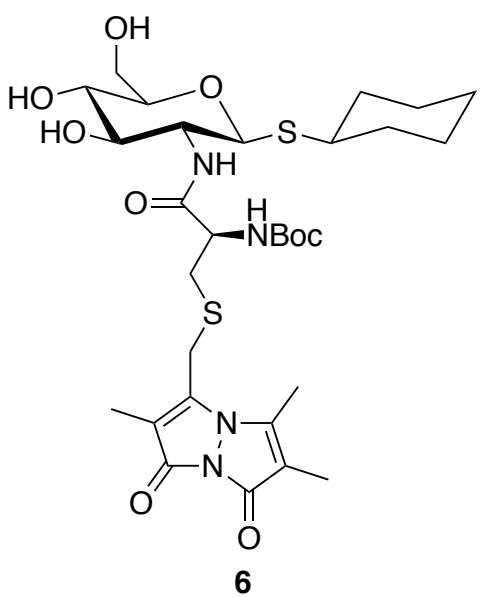

Figure 1.10 Proposed Structure of the fluorophore containing analogue, compound 6

\subsection{Biological Investigations}

Due to the incomplete synthesis of compounds 5 and $\mathbf{6}$ the biological investigations were considerably modified from the original aims of this thesis. Investigations into the immunomodulatory effects of both compound $\mathbf{1}$, and the precursor $\mathrm{N}$-Boc TCVC were undertaken to determine whether the toxicity of compound $\mathbf{1}$ was mediated by the release of the known toxic metabolite dichlorothioketene, or through an unknown cellular target interaction. This also allowed investigations into any deleterious or advantageous immunomodulatory effects of either compound, which could influence their potential as anti-cancer lead compounds.

\subsubsection{Enzyme Linked Immunosorbent Assay (ELISA)}

ELISA investigations allow the quantification of a cellular response to treatment. For the purpose of this research, several ELISAs were carried out. The ELISAs assessed the production of IL-10, IL-4, IFN- $\gamma$, IL-17a and IgM in splenocytes isolated from euthanised C57BL/ 6 mice, and treated with both compound 1, and the precursor $N$-Boc TCVC. Upon exposure to xenobiotics, cells can produce an immunological response, 
which is determined by the specific stimulatory compound. There are three benefits of this assay. Firstly it allows compound $\mathbf{1}$ to be tested in primary cells, which are widely considered to be more physiologically relevant than cell lines. ${ }^{48,49}$ Additionally, by measuring which cytokines are produced in treated cells, a broad understanding of the type of immune response that is occurring can be gained. When considering the ultimate goal of developing an anti-cancer treatment, this insight could be very useful. Finally, it can help to elucidate whether $\mathrm{N}$-Boc TCVC and compound $\mathbf{1}$ are both mediating their effects through the liberation of dichlorothioketene. If this is occurring, then the immunological response should be consistent between the treatments. Conversely, if compound $\mathbf{1}$ is causing toxicity through an unknown target interaction, a different pattern of immune response between the treatments could be expected.

\subsubsection{Phagocytosis Assay}

A phagocytosis assay, which measures the phagocytic ability of cells will also be carried out on RAW264.7 cells, a murine macrophage-like cell line. As phagocytosis a fundamental process for macrophages, any inhibition induced by treatment with compound 1 and $N$-Boc TCVC will be discernable in this cell line. ${ }^{50}$ This highly specific assay was undertaken due to the structural similarity of $N$-Boc TCVC to a known kinesin inhibitor, $S$-trityl-L-cysteine, which has been shown to inhibit tumour growth. ${ }^{51}$ Kinesins are a class of motor protein, which when inhibited by $S$-trityl-L-cysteine, prevent the cytoskeletal organisation required for phagocytosis and formation of the mitotic spindle. ${ }^{51}$ This assay will determine whether either treatment mediates their toxic effects through a similar mechanism as the structurally related kinesin inhibitor, and allows further opportunity to ascertain whether compound $\mathbf{1}$ and $N$-Boc TCVC share the same mechanism of action, or whether compound $\mathbf{1}$ acts through an unknown target interaction. 


\section{Chapter 2}

\section{Synthesis of Cysteine Derivatives}

This chapter outlines the successful synthesis of the functionalised $N$-Boc-Lcysteine derivatives, compounds $\mathbf{7 , 8}$ and $\mathbf{9}$. These compounds were synthesised with the intention of subsequent conjugation to thioglycoside $\mathbf{1 1}$, to form target compounds $\mathbf{1 , 5}$ and $\mathbf{6}$, which could then be utilised in biological investigations, to determine the mode of action of compound $\mathbf{1}$.

\subsection{Synthesis of $\boldsymbol{N}$-Boc-S-trichlorovinyl Cysteine}

\subsubsection{N-Boc Protection of Cysteine}

Synthesis of the $N$-Boc-S-trichlorovinyl-L-cysteine ( $N$-Boc TCVC) initially requires protection of the cysteine by Boc. This is followed by conjugation of trichloroethylene to the thiol center. Previous accounts in the literature have reported successful Boc protection of cysteine, when the thiol group has already been alkylated. ${ }^{52,53}$ Consistent with this, Riordan reported issues with the initial Boc protection of cysteine, due to the propensity of cysteine to dimerise through a disulfide bond, and form cystine, when $S$-alkylation has not yet occurred. ${ }^{5}$ As cystine has two potential sites for $N$-Boc protection, several side products can be produced. This includes $N, N$-diBoc cystine, and both the unprotected and singly protected cystine. As well as sequestering cysteine, and therefore reducing the overall yield of $N$-Boc-L-cysteine these side products can also complicate purification. Although a singly Boc protected cystine is easily separated from the product through aqueous work-up, the $N, N$-diBoc cystine will partition into the organic layer and, as such, a further step of purification is required to remove the side product. Riordan reported that increasing the equivalents of cysteine, relative to ditert-butyl dicarbonate minimises the formation of the completely protected cystine, while the singly protected cystine side-product and any dimer are easily removed during aqueous work up. ${ }^{5}$ Following these conditions Boc protection was carried out with four equivalents of L-cysteine hydrochloride monohydrate, and the reaction proceeded with a $60.1 \%$ yield, without any $N, N$-diBoc cystine impurity. 


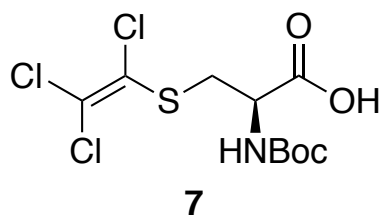

Figure $2.1 \mathrm{~N}-\mathrm{BoC}$ TCVC

The successful synthesis of $N$-Boc TCVC was achieved by utilising the methodology described by Riordan. ${ }^{5}$ Boc protected cysteine was dissolved in acetonitrile and tetrachloroethylene. Following the addition of four equivalents of 1,5diazabicyclo(4.3.0)non-5-ene $(\mathrm{DBN})$, the reaction was stirred for 30 minutes. No modifications of Riordan's method were required, and the thioether bond was installed swiftly, with a yield of $59 \%{ }^{5}$

\subsection{Synthesis of $\mathbf{N}$-Boc-S-propynyl-L-Cysteine}

\subsubsection{S-alkylation of L-cysteine}

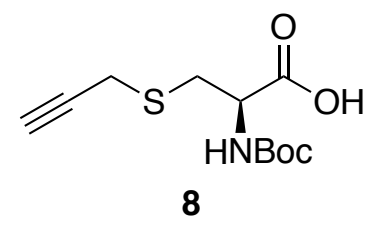

Figure 2.2 N-Boc-S-propynyl-L-cysteine

The attempted synthesis of the propynyl cysteine derivative (compound 8) initially focused on the conjugation of propargyl bromide to the thiol of L-cysteine, and the subsequent Boc protection of the amine. Following a method outlined by Hiremathad, it was proposed that the reaction could take place in basic conditions, with ammonium hydroxide acting as both a base and a solvent for the reaction. ${ }^{54}$ L-cysteine was dissolved in ammonium hydroxide and one and a half equivalents of propargyl bromide added dropwise at $0{ }^{\circ} \mathrm{C}$. The reaction mixture was then brought up to room temperature, and stirred for three hours. Unfortunately, despite several attempts with this procedure, the conjugation of propargyl bromide was consistently incomplete. 


\subsubsection{S-propynylation of N-Boc-L-Cysteine}

A reliable but low yielding method of propynylation was achieved, by carrying out Boc protection of the amine prior to $S$-alkylation. $N$-Boc-L-cysteine was prepared as discussed in section 2.1.1. Following a method reported by Conte et al, the $N$-Boc-Lcysteine was then dissolved in dichloromethane, before the addition of the base triethylamine, which deprotonates the thiol centre. ${ }^{55}$ At room temperature, 1.2 equivalents of propargyl bromide was then added. The reaction proceeded as described, with a yield of $21 \%$.

\subsubsection{S-alkylation and N-Boc Protection of L-cysteine}

In an attempt to increase the yield of the $S$-propynylation of $N$-Boc-L-cysteine, a final alternative method was trialled, which combined both the Boc protection of cysteine, and the $S$-alkylation reaction into a one-pot process. In this method, reported by Curran et al., sodium ethoxide was generated from ethanol and sodium metal, and used to deprotonate the thiol of L-cysteine hydrochloride monohydrate. ${ }^{56}$ Following this, four equivalents of propargyl bromide was added to the reaction mixture dropwise. The excess ethanol was subsequently removed in vacuo, and the propynyl cysteine redissolved in THF. A solution of two equivalents of di-tert-butyl dicarbonate in THF was then added and the reaction stirred overnight.

By essentially combining the propynylation and Boc protection only a single work-up is required for the entire transformation. Aqueous work up of this reaction required a separation at both $\mathrm{pH} 11$ and $\mathrm{pH} 3$, to remove all potential impurities, of which there were many (Table 2.1). Although the organic phase still contains two impurities, $N$-Boc-L-cysteine and $N, N$-di-Boc cystine the formation of these side products was minimised, by using four equivalents of propargyl bromide to ensure almost complete propynylation of the cysteine, which prevents formation of both the cystine dimer, and the free thiol.

By ensuring total $S$-alkylation of cysteine, the number of equivalents of di-tertbutyl dicarbonate could also be increased to two, as Boc protection of the dimer no longer presented with a risk during purification of the reaction mixture. Therefore, the 
production of both $N$-Boc-L-cysteine and $N, N$-di-Boc cystine was minimised. Gratifyingly, the overall yield was greatly improved from that of the independent $N$-Boc protection, followed by propynylation, which had a combined yield of $11.2 \%$, compared to the $64 \%$ yield in this one-pot reaction.

Table 2.1. Species formed during the one-pot propynylation and Boc protection of cysteine

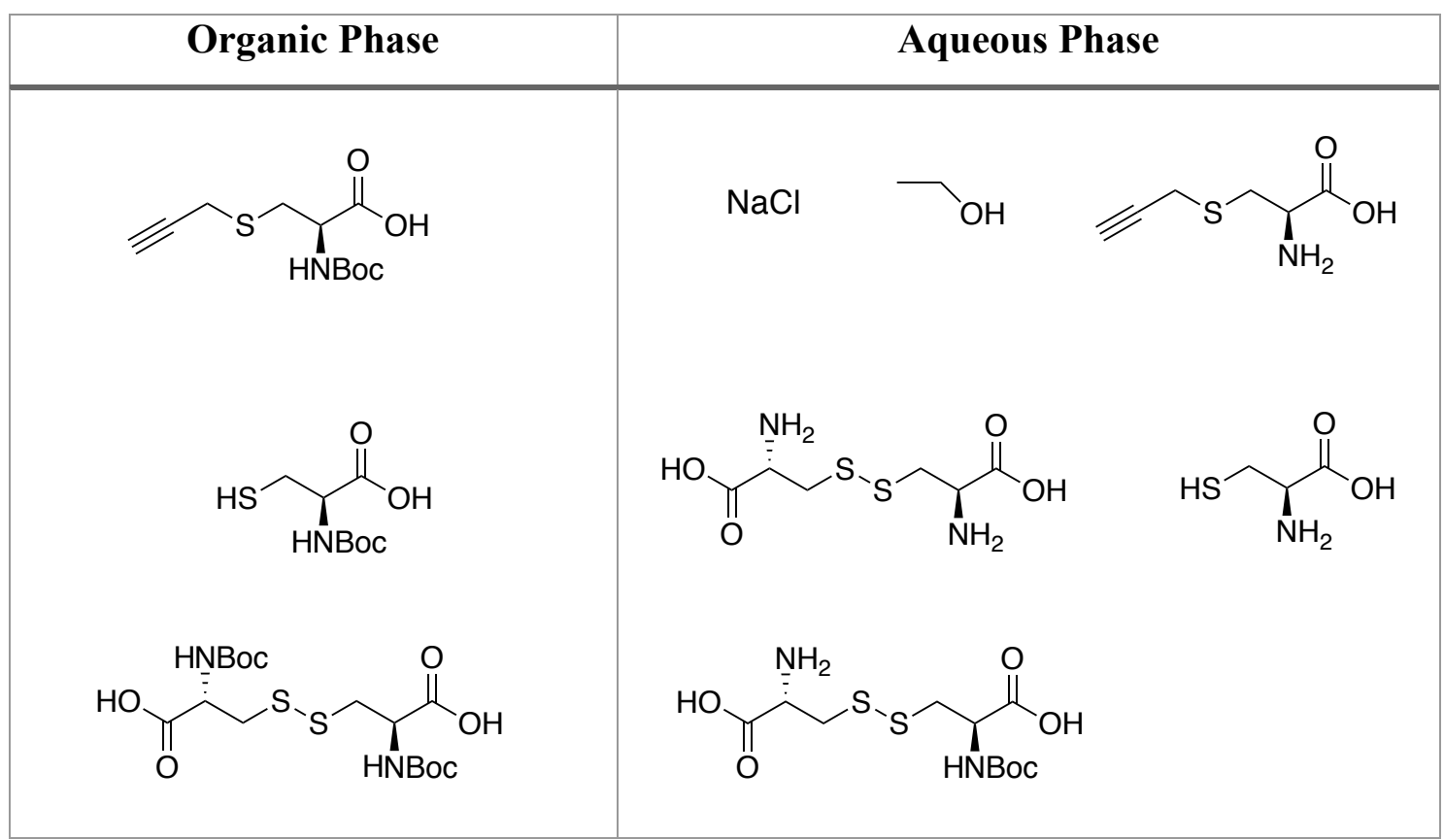

\subsection{Synthesis of a Fluorescent Derivative}

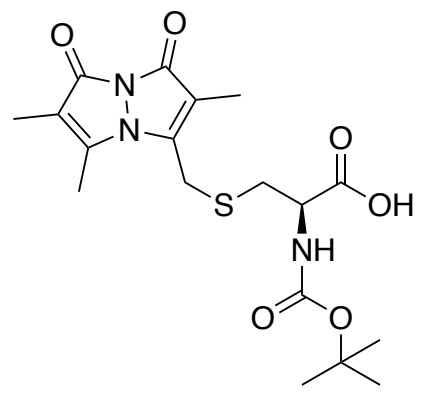

9

Figure 2.3 N-Boc-S-bimane-L-cysteine

\subsubsection{Conjugation of Monobromobimane to Cysteine}

As with the $N$-Boc- $S$-propynyl-L-cysteine, the initial attempts to synthesise $\mathrm{N}$ Boc-S-bimane-L-cysteine focused on first carrying out the $S$-alkylation, before Boc protecting the amine centre. Knapp reported one such method, in which 
monobromobimane was dissolved in trisaminomethane (tris) buffer, and added to a solution of L-cysteine hydrochloride monohydrate in the same buffer. ${ }^{44}$ This reaction was attempted, but purification and work up of the reaction mixture proved troublesome, due to the polarity of the unprotected amine. The bimane derivative partitioned into the aqueous layer during work up. Additionally, the trisaminomethane introduced by the buffer is not removed by aqueous work up. Due to the sensitivity of bimane to light, purification by flash chromatography on silica was not considered an ideal method of removing the buffer salt. Therefore the Boc protection was carried out in the presence of tris.

Despite the presence of trisaminomethane, Boc protection, as outlined in section 2.1.1, was carried out on the $S$-bimane-L-cysteine. This procedure was optimised by Riordan on a gram scale, but due to the expensive of monobromobimane, was being carried out with only $5 \mathrm{mg}$ of material. ${ }^{5}$ Less than ideal reaction conditions, combined with the small amount of starting material meant only trace amounts of product were obtained, and a secondary route was explored.

\subsubsection{Conjugation of Monobromobimane to N-Boc-L-Cysteine}

A second method was subsequently attempted, in which cysteine hydrochloride monohydrate was $N$-Boc protected prior to $S$-alkylation with monobromobimane. The benefits of this reversal of procedure were two-fold. Firstly, completing the $N$-Boc protection of cysteine monohydrate hydrochloride allowed the large-scale synthesis of $\mathrm{N}$ Boc-L cysteine. This increased the yield of the reaction, as it was carried out at the scale for which it was optimised, and meant that the first synthetic step for both compounds 9 and 7 was completed with only one reaction. Secondly, carrying out the $S$-alkylation with monobromobimane after $N$-Boc protection minimised the loss of the more expensive reagent. As Boc protection has less than perfect yields, even under ideal reaction conditions, up to $50 \%$ of the fluorescent conjugated product could be lost during this step, representing a significant waste of material. By reversing the procedures, this loss was minimised, as the fluorescent conjugate needs only undergo a single additional conversion, which is conjugation to thioglycoside $\mathbf{1 1}$ to complete the synthesis of the final compound (compound 6). 
In this secondary procedure, Boc protection of of L-cysteine hydrochloride monohydrate was carried out as outlined in section 2.1. Following this, a solution of monobromobimane, in Tris buffer, was added to a solution of $N$-Boc-L-cysteine in the same buffer and stirred for 20 minutes. Unfortunately, thin layer chromatography (TLC) analysis indicated that once again the cysteine derivative separated into the aqueous layer, during work-up with dichloromethane. Acidification of the reaction mixture to $\mathrm{pH} 3$ with $1 \mathrm{M}$ sulfuric acid resulted in protonation of the carboxylic acid group, and a subsequent separation with dichloromethane saw partition of the product into the organic layer, as visualised with UV light $(366 \mathrm{~nm})$. The product was a bright green oil, and was synthesised with a $60 \%$ yield.

\subsection{Summary}

The successful synthesis of all three functionalised cysteine derivatives signaled a half-way point towards completion of both of the chemical synthesis objectives originally outlined in this thesis. Synthesis of the thioglycoside backbone, and its subsequent conjugation to each of these cysteine derivatives is required to fulfill the objectives. 


\section{Chapter 3}

\section{Synthesis and Attempted Conjugation of Thioglycoside 11}

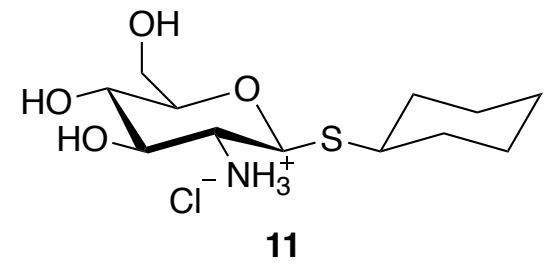

Figure 3.2 Compound 11, thioglycoside precursor to 1, 5 and 6

This chapter outlines the successful synthesis of the thioglycoside backbone, compound 11, and its subsequent conjugation to $\mathrm{N}$-Boc-TCVC, to fulfill the first synthetic aim of this thesis, the synthesis of compound $\mathbf{1}$. The attempted conjugation of $N$-Boc- $S$-propynyl-L-cysteine and $N$-Boc- $S$-bimane-L-cysteine to thioglycoside $\mathbf{1 1}$ is also described. This was undertaken in an attempt to synthesise two analogues of compound 1, for use in biological investigations. Unfortunately, despite many attempts and the use of a range of reaction conditions, successful conjugation of the two analogues was not achieved, and biological investigations were commenced with only the use of compound $\mathbf{1}$, and its precursor $N$-Boc TCVC.

\subsection{Synthesis of Thioglycoside 11}

The synthesis of compound $\mathbf{1 1}$ followed methods outlined by Riordan. ${ }^{5}$ The first step in the synthesis of the thioglycoside backbone was pentaacetylation of Dglucosamine to form $\alpha$-D-glucosamine pentaacetate (compound 13, Figure 3.2). This was achieved by dissolving one equivalent of D-glucosamine in pyridine, and adding excess acetic anhydride. The reaction proceeded smoothly without production of any $\beta$ glucosamine pentaacetate.

The subsequent step was formation of thioglycoside 14. Compound 13 was dissolved in 1,2-dichloroethane, and three equivalents of cyclohexanethiol added. The reaction was then cooled to $0{ }^{\circ} \mathrm{C}$, before the addition of two equivalents of the Lewis acid boron trifluoride etherate $\left(\mathrm{BF}_{3} \cdot \mathrm{OEt}_{2}\right)$. The reaction was subsequently heated to $55^{\circ} \mathrm{C}$ for four and a half hours. The reaction proceeded through a Lewis acid catalysed nucleophilic substitution mechanism, whereby $\mathrm{BF}_{3}$ binds to the oxygen of the acetyl group, thereby 
withdrawing electron density, and promoting nucleophilic attack from the sulfur of cyclohexanethiol at the anomeric centre. Riordan noted that the $\alpha$ and $\beta$ anomer are formed in a 2:1 ratio under these reaction conditions. As Riordan was synthesising both the $\alpha$ and $\beta$ anomers of the final compound, and the 1,2- $\alpha$-cis glycosidic linkage was considered one of the most difficult linkages to install, this conversion was considered advantageous. ${ }^{5}$ The $\alpha$ anomer was not considered valuable in the biological investigations for this thesis, and therefore minimal formation was preferable. Interestingly, under nearly identical reaction conditions as those utilised by Riordan, a 1:5 ratio of the $\alpha / \beta$ anomers was obtained. The single difference between the two methods was an increased reaction time; Riordan's reaction ran for 3 hours, compared to the 4.5 hours reported here. Although the reaction was overall lower yielding than reported by Riordan $(21.8 \%$ yield vs. 33\%), the total yield of the $\beta$ anomer was improved. ${ }^{5}$ Any $\alpha$ anomer that was produced was easily separated during flash chromatography on silica, either immediately, or after the subsequent Boc protection step.

After installation of the thioglycoside, activation at the amine deacetylation, was achieved through the addition of a Boc group. Following the procedure outlined by Riordan, compound $\mathbf{1 4}$ was dissolved in THF, and di-tert-butyl dicarbonate (8 equivalents) and catalytic amounts of 4-dimethylaminopyridine (DMAP) were added. ${ }^{5}$ The reaction mixture was refluxed at $66{ }^{\circ} \mathrm{C}$ for 16 hours, to afford the Boc protected thioglycoside, compound 15. ${ }^{1} \mathrm{H}$ NMR of this compound consistently revealed the presence of rotamers in a 1:1 ratio, which was also observed by Riordan. ${ }^{5}$

The final step in the synthesis of the thioglycoside backbone was deacetylation and $N$-Boc deprotection of compound 15. Compound $\mathbf{1 5}$ is dissolved was methanol, and through the addition of sodium metal, sodium methoxide was generated, which subsequently nucleophilically attacks at the acetylated centers. The addition of excess concentrated hydrochloric acid was followed by concentration of the reaction mixture, in vacuo, to afford compound 11. This was utilised in the coupling reaction without any work up step, or removal of the sodium chloride generated in the reaction. 

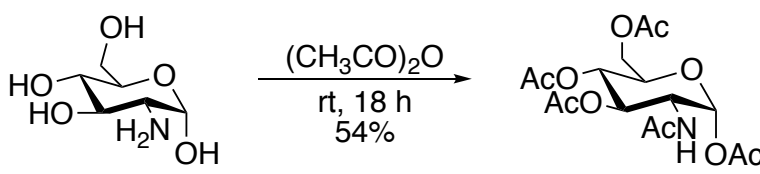

13

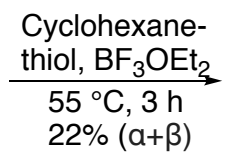

$22 \%(a+\beta)$

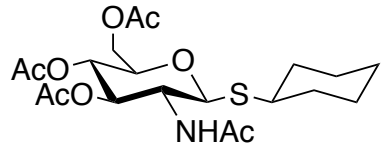

14

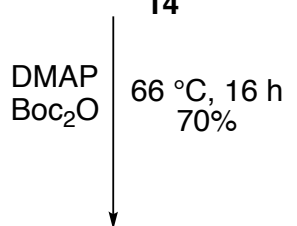

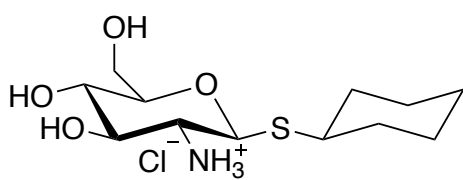

11
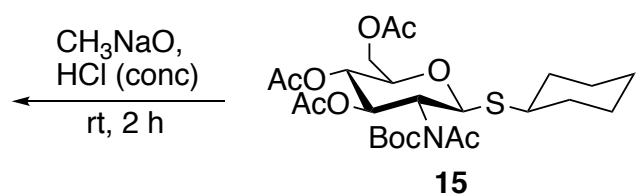
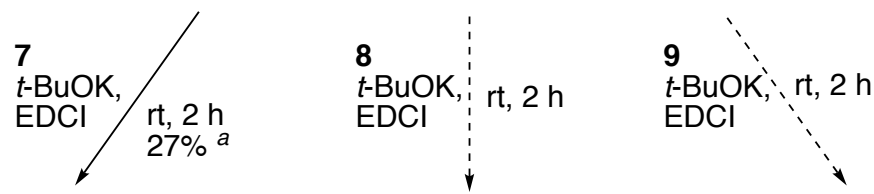<smiles>CC(C)(C)N[C@@H](CSC(Cl)=C(Cl)Cl)C(=O)N[C@H](OC1CCCCC1)[C@H](O)C(O)CO</smiles>

1

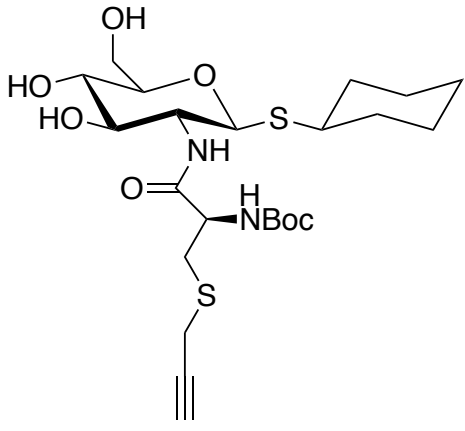

5

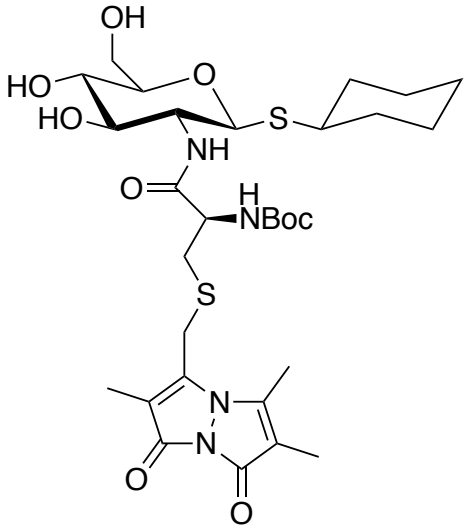

6

Figure 3.2 Synthesis of thioglycoside 11, and attempted conjugations to compounds 7, 8 and 9. ${ }^{a}$ by weight, from unpurified 11

\subsection{Conjugation of Thioglycoside 11 and N-Boc TCVC}

The one successful conjugation of thioglycoside 11 to compound 7 was achieved following the methods outlined by Riordan. ${ }^{5}$ Initially the amine of the thioglycoside was deprotonated by one equivalent of potassium-tert butoxide, in DMF. This solution was then added to the carboxylic acid, which is premixed with two equivalents of EDC in $\mathrm{DMF}$, at $0{ }^{\circ} \mathrm{C}$. The reaction mixture is stirred at room temperature for two hours, before the DMF was distilled off the crude product, which was subsequently purified by flash chromatography, to afford compound $\mathbf{1}$ as a white powder, with a 27\% yield. As $\mathbf{1 1}$ was 
carried through to the conjugation without any further purification, the yield was calculated from the combined mass of $\mathbf{1 1}$ and any impurities present. Completion of this conjugation was the final step in the synthesis of compound 1, and allowed biological testing to commence.

\subsection{Conjugation of Thioglycoside 11 and the Fluorescent Cysteine Derivative}

After the successful conjugation of cysteine derivative 7 to thioglycoside 11, the same reaction conditions were utilised in an attempt to conjugate the fluorescent cysteine derivative, compound $\mathbf{9}$, to the thioglycoside $\mathbf{1 1}$ backbone. It was hypothesised that the modified substituents around the sulfur group would not affect the coupling reaction. The reaction did not proceed, with no evidence of coupling evident by ${ }^{1} \mathrm{H}$ NMR. Additionally, neither thioglycoside $\mathbf{1 1}$ nor the fluorescent cysteine derivative $\mathbf{9}$ were isolated during purification.

Only one attempt at the fluorescent conjugation was made, due to the relative expensive of monobromobimane, and the small-scale synthesis of compound 9. Instead the focus turned to coupling the propynylated cysteine derivative, with the intention of discovering a successful and robust coupling procedure which could subsequently be applied to the fluorescent analogue or to generate a product that could be coupled to an azide-derivatised fluorophore through $\mathrm{CuAAC}$ chemistry.

\subsection{Conjugation of Thioglycoside 11 and N-Boc-S-propynyl-L- Cysteine}

Despite the failure of the attempted conjugation of the fluorescent cysteine analogue to thioglycoside 11, the same reaction conditions were utilised in the initial attempted conjugation of $N$-Boc-S-propynyl-L-cysteine to the thioglycoside backbone. The hypothesis that the modifications on the sulfur group would not affect the coupling reaction was quickly disproven, when multiple attempts to conjugate compound 7 to thioglycoside 11, failed.

The difficulties associated with the conjugation of thioglycoside $\mathbf{1 1}$ to the functionalised $N$-Boc TCVC were initially reported by Riordan. ${ }^{5}$ Installation of an amide 
bond is generally considered a straightforward reaction, and is possible under relatively mild conditions. This bond however proved especially problematic. Riordan noted that neither of the two most commonly used bases in amide bond formation, trimethylamine and DMAP, were able to effectively deprotonate the thioglycoside hydrochloride. ${ }^{5}$ Instead a much stronger base, potassium-tert butoxide was required. While the reaction proceeded successfully under these conditions, the yield of $35 \%$ was low, given coupling reactions of this kind often report yields of up to $75 \%{ }^{57,58}$ Riordan indicated that there was room for optimisation of this reaction, but this was not achieved. ${ }^{5}$

Initial attempts focused on utilising near identical reaction conditions to those reported by Riordan, in which the amine of the thioglycoside was deprotonated by one equivalent of potassium-tert butoxide, in DMF, and then added to $N$-Boc-S-propynyl-Lcysteine, which is premixed with EDC in DMF at $0{ }^{\circ} \mathrm{C} .{ }^{5} \mathrm{H}$ NMR of this first conjugation attempt showed only degradation of the thioglycoside and the cysteine derivative $\mathbf{8}$, and no indication of any product formation. Somewhat surprisingly, there was also no recovery of unreacted starting materials. This observation led to the hypothesis that the product was lost during the work up. As DMF is miscible with water and many organic solvents, an aqueous work-up is not sufficient to completely remove the solvent. Furthermore, the product is likely to be water soluble. In the synthesis of $\mathbf{1}$, this problem was avoided by distilling DMF off the product, under house vacuum. Although the distillation was carried out under reduced pressure, significant heating was required to remove all of the solvent, given its boiling point of $153{ }^{\circ} \mathrm{C}$.

Thus, to circumvent the use of high temperatures during a DMF distillation in the second coupling attempt, the distillation was carried out under reduced pressure on the high vacuum, with only very mild heating required. The second coupling attempt also utilised $N, N, N^{\prime}, N^{\prime}$-Tetramethyl-O-(1H-benzotriazol-1-yl)uronium hexafluorophosphate (HBTU), a coupling reagent, in place of the EDC, as well as trimethylamine. Triethylamine, HBTU and $N$-Boc- $S$-propynyl-L-cysteine were premixed in DMF at $0{ }^{\circ} \mathrm{C}$ for 30 minutes. Thioglycoside $\mathbf{1 1}$ was premixed for 15 minutes with one equivalent of potassium-tert butoxide in DMF, before dropwise addition to the $N$-Boc-S-propynyl-Lcysteine solution. It was envisioned that the addition of trimethylamine would ensure deprotonation of the carboxylic acid, while the use of HBTU in amide couplings was supported in the literature. ${ }^{59}$ 
This reaction was trialled twice. There was no evidence of either starting material in ${ }^{1} \mathrm{H}$ NMR analysis of the initial attempt, nor was there any indication that the coupling had occurred. The second attempt presented more interesting ${ }^{1} \mathrm{H}$ NMR data. The ${ }^{1} \mathrm{H}$ NMR data for the second HBTU attempt correlates strongly to that which is seen for compound 1. This is especially clear in the regions that correspond to the thioglycoside. Two diagnostic shifts which are a good indication of whether or not coupling has occurred, are those which correspond to $\mathrm{H}-1$ and $\mathrm{H}-2$ of the uncoupled thioglycoside. In the uncoupled thioglycoside, $\mathrm{H}-1$ is seen as a doublet at $4.90 \mathrm{ppm}$, while $\mathrm{H}-2$ is seen as a triplet at 3.14 ppm. In the coupled product, compound 1, these peaks shifted to 4.70 and $3.53 \mathrm{ppm}$ respectively. Importantly, these diagnostic peaks at 4.70 and 3.53 are also seen in the ${ }^{1} \mathrm{H}$ NMR of the second HBTU attempt, while the peaks corresponding to the uncoupled starting material at 4.90 and $3.14 \mathrm{ppm}$ are not apparent. The ${ }^{1} \mathrm{H}$ NMR spectra also corresponds well for the cyclohexane peaks, although these are considerably less diagnostic than the $\mathrm{H}-1$ and $\mathrm{H}-2$ peaks, as they shift only slightly once the coupling has taken place.

While the spectra of the second HBTU attempt does establish that coupling of the thioglycoside has occurred, the spectra of the product does not correspond well to that which is expected for a propynylated cysteine. There are five hydrogen environments that should be discernable in the coupled product, which correspond to: The 9 Boc hydrogens, the single $\alpha$-hydrogen, two $\beta$-hydrogens, $\mathrm{C}_{2}-\mathrm{CCH}$, and the $\mathrm{CCH}$ hydrogen. Although formation of the amide bond should result in a more shielded chemical environment around the $\alpha$-proton, which is expected to shift upfield as a result, the other protons are not expected to experience a significant change, and therefore the chemical shifts in the ${ }^{1} \mathrm{H}$ NMR spectra should be relatively consistent between the uncoupled $N$-Boc- $S$ propynyl-L-cysteine and the coupled product. Both the Boc and the $\beta$-protons correspond well to the expected chemical shifts, based upon the ${ }^{1} \mathrm{H}$ NMR of compound 8, but unfortunately the expected peaks for both the $\alpha$-proton and the $\mathrm{C}_{2}-\mathrm{CCH}$ are obscured by solvents in the spectra. Furthermore, the $\mathrm{CCH}$ peak appears to have shifted to $2.61 \mathrm{ppm}$, which is a considerable downfield shift, given the consistency seen with the Boc and $\beta$-protons. 
Table $3.1^{l} H$ NMR shifts of protons in the uncoupled compound 8 and the product of the second attempt at HBTU coupling

\begin{tabular}{|c|c|c|c|c|c|}
\hline & $\begin{array}{c}\text { Boc } \\
\text { protons }\end{array}$ & $\alpha$-proton & $\beta$-protons & $\mathrm{CH}_{2}-\mathrm{CCH}$ & $\mathrm{CCH}$ \\
\hline $\begin{array}{c}\text { Compound } \\
8\end{array}$ & $1.46 \mathrm{ppm}$ & $4.58 \mathrm{ppm}$ & $\begin{array}{c}\text { 3.25- } 3.11 \\
\text { ppm }\end{array}$ & $3.32 \mathrm{ppm}$ & $2.29 \mathrm{ppm}$ \\
\hline $\begin{array}{c}\text { HBTU } \\
\text { attempt } 2\end{array}$ & $1.47 \mathrm{ppm}$ & Obscured & $\begin{array}{c}3.20-3.12 \\
\text { ppm }\end{array}$ & Obscured & $2.61 \mathrm{ppm}$ \\
\hline
\end{tabular}

Due to the small amount of compound isolated from flash chromatography, the ${ }^{13} \mathrm{C}$ NMR spectra was incomprehensible. It was proposed that while conjugation between a cysteine and the thioglycoside backbone has likely taken place, the cysteine could be any one of $N$-Boc- $S$-propynyl-L-cysteine, $S$-propynyl-L-cysteine, $N$-Boc-L-cysteine, or cysteine, through degradation of the compound. Unfortunately, mass spectrometry did not identify any compounds which corresponded to any of these potential conjugations.

The evidence of formation of compound $\mathbf{5}$ was therefore inconclusive, and the reaction was attempted again, this time utilising hydroxybenzotriazole ( $\mathrm{HOBt}$ ) as an alternative auxiliary coupling reagent. HOBt is one of the most commonly used additives in EDC coupling reactions, and functions to reduce the formation of an undesirable side product, $N$-acylurea. ${ }^{60}$ In coupling reactions activated with a carbodiimide, an intermediate, $O$-acylisourea, is formed when the carboxylic acid nucleophically attacks the carbodiimide (Figure 3.3, A). This $O$-acylisourea can act as a leaving group, and therefore enable nucleophilic attack at the carbonyl carbon by the amine of thioglycoside 11, resulting in formation of the desired amide bond between cysteine derivative $\mathbf{8}$ and the thioglycoside (Figure 3.3, C). Expulsion of the leaving group during formation of the amide bond results in the production of a urea byproduct (Figure 3.3, D). The $O$ acylisourea can also undergo a rearrangement, whereby an $\mathrm{N}$-acylurea is formed, and aceylated by another equivalent of the carboxylic acid (Figure $3.3 \mathrm{~B}$ ). This is an irreversible side reaction, which can significantly reduce the yield of the reaction. Unfortunately, the use of solvents with a high dielectric constant, such as DMF, can result in stabilisation of the $\mathrm{N}$-acylurea transition state, and therefore favour the formation of this undesired side product. ${ }^{61,62} \mathrm{HOBt}$ is utilised as a coupling reagent, partially due to 
its ability to minimise this side reaction, as its oxygen engages in nucleophilic attack of the activated carboxylic acid and subsequently forms an activated ester. ${ }^{63}$ Following this, the amine can couple with the ester, and form the desired amide. ${ }^{63}$

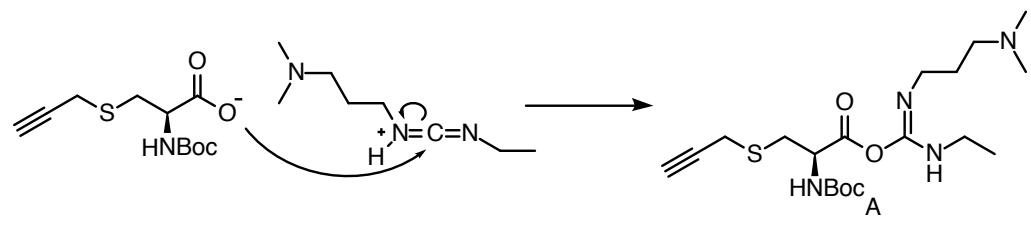
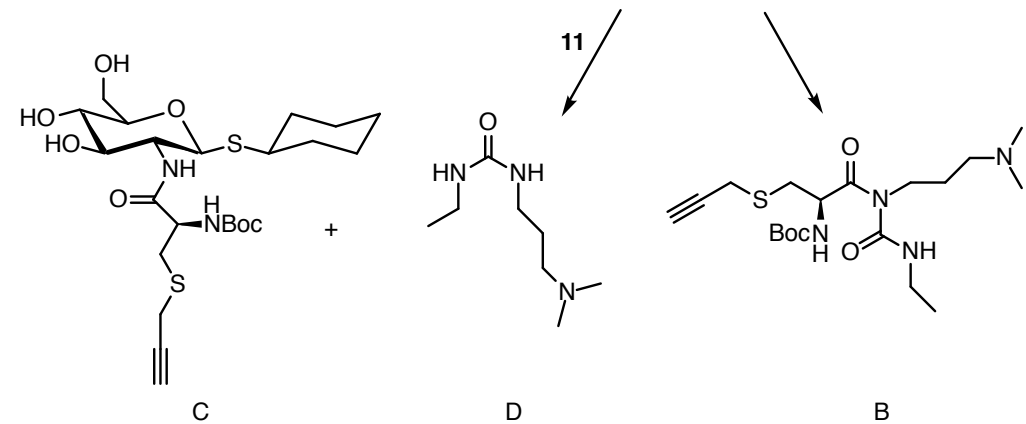

Figure 3.3 Pathway to the expected products of conjugation of 11 and N-Boc-S-propynyl-L-cysteine. (A) Oacylisourea. (B) N-acylurea. (C) Compound 5. (D) Urea

${ }^{1} \mathrm{H}$ NMR of this fourth coupling attempt clearly indicated that the reaction was unsuccessful. For the first time, unreacted starting material was isolated during flash chromatography. Only the $N$-Boc-S-propynyl-L-cysteine was isolated, while the thioglycoside 11 appears to have either reacted or degraded entirely. Unlike the third attempt, there was no evidence of coupling.

Table 3.2 Reaction conditions and results of attempted conjugations to thioglycoside 11

\begin{tabular}{|c|c|c|c|}
\hline Entry & Coupling Reagent & $\begin{array}{l}N \text {-Boc- } S \text {-propynyl- } \\
\text { L-cysteine Premix } \\
\text { Conditions }\end{array}$ & Results \\
\hline 1 & EDC (2 equivalents) & DMF & $\begin{array}{l}\text { Degradation, no } \\
\text { starting materials } \\
\text { present. }\end{array}$ \\
\hline 2 & $\begin{array}{l}\text { HBTU (1.1 } \\
\text { equivalents) }\end{array}$ & $\begin{array}{l}\text { Trimethylamine (1.3 } \\
\text { equivalents), DMF }\end{array}$ & $\begin{array}{c}\text { Degradation, no } \\
\text { starting materials } \\
\text { present. }\end{array}$ \\
\hline 3 & $\begin{array}{l}\text { HBTU (1.1 } \\
\text { equivalents) }\end{array}$ & $\begin{array}{l}\text { Trimethylamine (1.3 } \\
\text { equivalents), DMF }\end{array}$ & $\begin{array}{l}\text { Some evidence for } \\
\text { coupling, inconclusive. }\end{array}$ \\
\hline 4 & $\begin{array}{l}\text { HOBT (1.3 } \\
\text { equivalents) }\end{array}$ & $\begin{array}{c}\text { EDC (1.3 equivalents) } \\
\text { DMF }\end{array}$ & $\begin{array}{c}\text { Some propargyl } \\
\text { cysteine, no evidence } \\
\text { of coupling }\end{array}$ \\
\hline
\end{tabular}




\subsection{Summary of Chemical Synthesis}

The successful synthesis of thioglycoside 11 and its conjugation to $N$-Boc- $S$ trichlorovinyl-L-cysteine signaled completion of the first synthetic target of this thesis, and commencement of biological investigations. Unfortunately, the conjugation of both the propynylated and the fluorescent cysteine analogue was not achieved. This was particularly surprising, given the extensive literature supporting the use of HOBT, HBTU and EDC mediated amide bond formation, in both fast and high yielding reactions. Despite motivation to complete the synthesis of these two analogues, the conjugation attempts were ceased, as the research focus shifted to biological investigations. 


\section{Chapter 4}

\section{Introduction to Biological Investigations}

In pursuance of investigating the mechanism of action of compound $\mathbf{1}$, biological investigations were commenced, despite the failed attempted synthesis of compounds 5 and 6. Given that direct target identification through affinity purification was no longer possible, the research goal of this thesis shifted focus, to investigate whether compound 1 mediates its cellular inhibition through the release of the toxic dichlorothioketene, as is expected for the precursor $N$-Boc TCVC, or through an alternative cellular target interaction. It was originally intended to focus biological investigations on proteomic analysis. HL60 cells were treated with either compound 1 or $N$-Boc TCVC at both the $\mathrm{IC}_{10}$ and $\mathrm{IC}_{50}$ concentrations, as determined by prior MTT assays. The cells were then processed, and proteins prepared for proteomic analysis. Unfortunately, due to the prolonged ( $>4$ month) break down of the LC-MS/MS instrument, these samples could not be analysed before the end of this research.

An alternative strategy for the biological investigations was devised. This focused on investigating the biological activity of both compound $\mathbf{1}$ and $N$-Boc TCVC in the hopes of determining whether the compounds act through a shared mechanism of action. At the time when it became apparent that the LC-MS/MS instrument would not be available, a fellow research student, Vimal Patel in the School of Biological Sciences, had developed a set of assays chosen to evaluate the biological activity of new compounds. These assays primarily assess the immunomodulatory effect of treatments within a cell. As immune function depends on many fundamental cellular processes including translation, protein trafficking, protein processing for production and release of cytokines and cytoskeletal function required for endocytosis, the information gained from these assays could provide useful insight into the mechanism of action of both compound $\mathbf{1}$ and $N$-Boc TCVC.

Investigations therefore turned to exploring the immunomodulatory activity of compound $\mathbf{1}$ and $\mathrm{N}$-Boc TCVC, particularly through the use of enzyme-linked immunosorbent assays (ELISAs). The ELISAs were undertaken to determine whether compound 1 and $\mathrm{N}$-Boc TCVC have equivalent immunomodulatory effects in cells, and 
thereby help ascertain whether the treatments mediate their toxicity through a shared mechanism.

\section{Results and Discussion}

\subsection{MTT Assays}

MTT assays were carried out to assess the metabolic function of cells treated with both compound 1 and $\mathrm{N}$-Boc TCVC. The $\mathrm{IC}_{50}$ of compound 1 in HL60 cells was found to be $7.8 \pm 0.05 \mu \mathrm{M}$, compared to that of $N$-Boc TCVC, which was found to have an $\mathrm{IC}_{50}$ of $116.8 \pm 0.06 \mu \mathrm{M}$. While it is clear that a much greater concentration of $N$-Boc TCVC is required to generate a similar level of toxicity as compound 1 in HL60 cells, the cause of this reduced activity is not as obvious. As both compounds were initially dissolved in $100 \%$ ethanol, to form a $10 \mathrm{mM}$ solution, and diluted to the required concentrations in cell culture medium prior to cell treatment, and no particulates in the solution were observed throughout the biological testing it is unlikely the solubility of the test compounds caused this discrepancy in toxicity. The comparatively high $\mathrm{IC}_{50}$ of $N$-Boc TCVC may indicate that it is unable to enter the cell at an appreciable concentration, and that the thioglycoside backbone of compound $\mathbf{1}$ is acting as a mediator of improved transport. This could be through utilising its amphiphilic properties to aid in passive cellular transport, or through exploiting a a glucose transporter, which tend to be upregulated in cancer cells. ${ }^{64-66}$ The poor activity could also imply that $N$-Boc TCVC has relatively inferior biological activity due to a fundamental difference in the way each of the compounds interacts with the cell. Although it is easy to speculate, the lower $\mathrm{IC}_{50}$ of $\mathrm{N}$-Boc TCVC neither supports nor disputes the hypothesis that both treatments mediate their effects through the same mechanism of toxicity, the release of dichlorothioketene.

While the MTT results alone are not sufficient to confirm any mechanism of toxicity, additional studies such as ELISAs and a phagocytosis assay can provide significantly more information about the cellular response to treatment with both compound 1 and $N$-Boc TCVC. 


\subsection{Enzyme-linked Immunosorbent Assays}

Several ELISAs were carried out on splenocytes isolated from euthanised C57BL/ 6 mice. These assays allowed the compounds to be tested in primary cells, which are known to be more physiologically relevant than immortalised cell lines such as HL60. ${ }^{48}$ These assays also allowed further comparisons of the cellular interactions of compound 1 and $N$-Boc TCVC, to investigate the hypothesis that they cause toxicity through the same mechanism.

The maximum non-inhibitory concentration (MNIC) in murine splenocytes was found to be $10 \mu \mathrm{M}$ for compound 1 and $70 \mu \mathrm{M}$ for $N$-Boc TCVC, Interestingly, the toxicity of both compounds was significantly reduced in splenocytes, compared to HL60s. Only cells treated at concentrations below the MNIC are considered below, to prevent confounding variables such as cell viability. The ELISAs quantified the immune response to compound 1 and $N$-Boc TCVC through measuring the amount of IgM, IL-10, IFN- $\gamma$, IL-4 and IL-17a that was produced by the splenocytes in response to the various treatments.

\subsubsection{B cell activity}

To measure IgM production, splenocytes were stimulated with LPS to activate B cells, which were subsequently treated with either compound $\mathbf{1}$ or $N$-Boc TCVC. IgM is a subset of antibodies produced by the B cells, in response to exposure to an antigen, but unlike many cells of the immune system, has a broad and non-specific substrate recognition. ${ }^{67} \mathrm{IgM}$ is the first antibody produced in an immune response, and is therefore useful when investigating the short term immunomodulatory effect of a drug. ${ }^{68}$ The physiological role of $\operatorname{IgM}$ is activation of the classical complement pathway, and it therefore has pro-inflammatory effects, as well as increasing opsonisation and cell lysis. ${ }^{69}$ Splenocytes treated with compound $\mathbf{1}$ at a concentration of $0.01-10 \mu \mathrm{M}$ did not demonstrate a significant change in IgM production, which remained consistent with the vehicle stimulated cells (Figure 4.1). Some unusual data was recorded in splenocytes treated with $N$-Boc TCVC. The amount of IgM appears to fluctuate significantly between treatment concentrations, initially rising to $128 \%$ of the vehicle control at a treatment concentration of $0.7 \mu \mathrm{M}$, before dropping to $65 \%$ when treated at a concentration of 7 
$\mu \mathrm{M}$ (Figure 4.2). Splenocytes treated at the maximum concentration $(70 \mu \mathrm{M})$ once again produced excess levels of $\operatorname{IgM}$, at $125 \%$ of that of the vehicle control. IgM production is clearly inconsistent between cells treated with compound $\mathbf{1}$ and $\mathrm{N}$-Boc TCVC, indicating that the compounds are interacting with the cell in very different ways, and therefore challenging the hypothesis that compound $\mathbf{1}$ mediates its toxicity through the release of a toxic dichlorothioketene. The unusual fluctuations in $\operatorname{IgM}$ production seen during treatment with $N$-Boc TCVC however cast doubt on the reliability of this data. Despite consistency within the replicates of this experiment, data from a biological repeat could be useful to determine whether this effect is reproducible. Time and resource constraints prevented the collection of replicate data.

IL-10 is an anti-inflammatory cytokine, which is produced by T cells, B cells, macrophages, and dendritic cells. ${ }^{70}$ The role of IL-10 during infection is to suppress the immune system, and this cytokine is considered vital to prevent the immunopathology associated with an unchecked immune response. ${ }^{71}$ In splenocytes stimulated with LPS, the production of IL-10 remained consistent during treatment with both $N$-Boc TCVC and compound $\mathbf{1}$, albeit at a slightly lower average concentration than in vehicle treated cells (Figures 4.1 and 4.2). Very little can be inferred from this data, although it does appear that cells treated with both compound 1 and $N$-Boc TCVC have a similar IL-10 response, indicating that the immunomodulatory effect, and therefore mechanism of action, of these compounds may be similar.

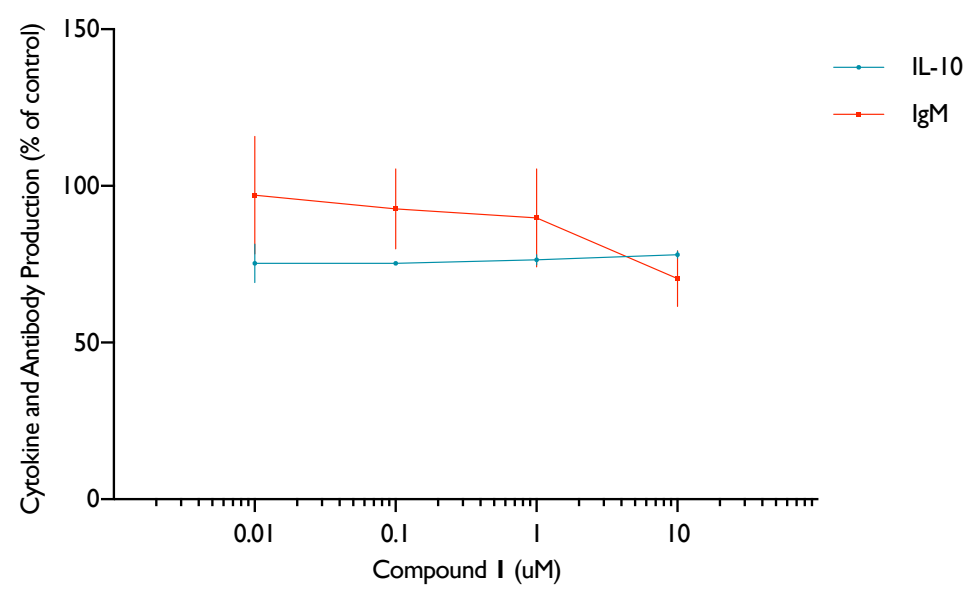

Figure 4.1 The amount of IL-10 and IgM production ( \pm SEM) in LPS stimulated splenocytes treated with compound 1, compared to \% vehicle control (performed in triplicate from splenocytes isolated from two mice) 


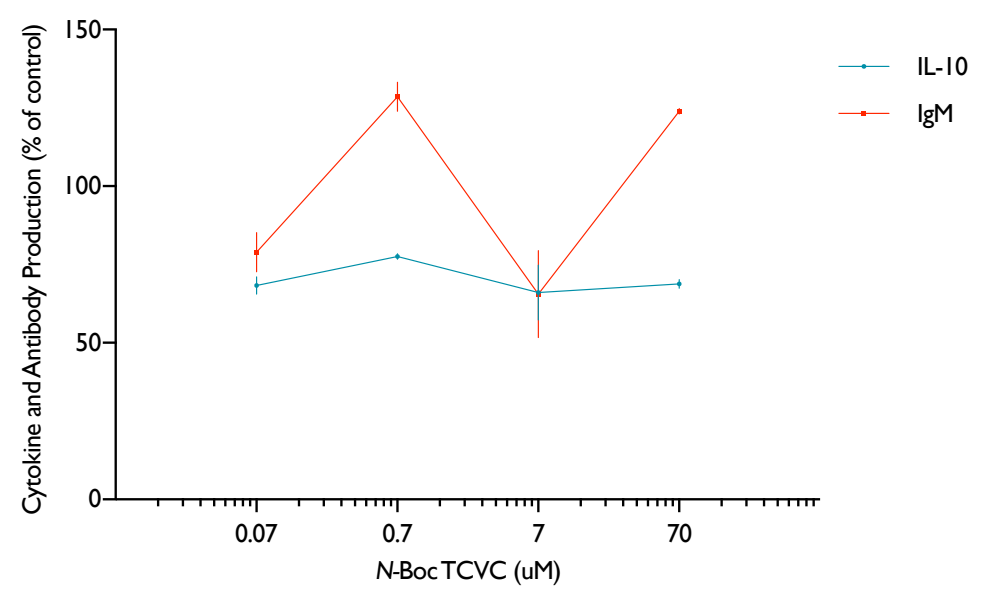

Figure 4.2 The amount of IL-10 and IgM production ( \pm SEM) in LPS stimulated splenocytes treated with N-Boc TCVC, compared to \% vehicle control (performed in triplicate from splenocytes isolated from two mice)

\subsubsection{TCell Activity}

To measure the production of cytokines IL-10, IFN- $\gamma$, IL-4 and IL-17a, splenocytes were stimulated with ConA, to active $\mathrm{T}$ cells, which were subsequently treated with compound 1 or $N$-Boc TCVC.

The production of IL-10 in cells stimulated with ConA, and treated with $N$-Boc TCVC remains consistent throughout treatment concentrations, at approximately $77 \%$ of the vehicle control (Figure 4.4). The production of IL-10 in T cells treated with compound 1 increases significantly at the greatest treatment concentration, to $230 \%$ of the vehicle (Figure 4.3). Although this appears to be a point of significant difference in the immunomodulatory activity of compound $\mathbf{1}$ and $N$-Boc TCVC, the variation in cells treated with compound 1 at a concentration of $10 \mu \mathrm{M}$ is significant, indicating that the uncertainty in this measurement may be too pronounced for any reliable insights to be gained. As with the IgM, this data would profit from a repeated experiment to determine the reproducibility of the inflated IL-10 production by cells treated with compound $\mathbf{1}$.

IFN- $\gamma$ is a cytokine produced by $\mathrm{T}$ helper 1 (Th1) cells with potent immunomodulatory effects, which have been described as bidirectional, given the propensity for both stimulatory and inhibitory activity. ${ }^{72}$ The bidirectional activity of IFN- $\gamma$ is a result of its many interactions with cells of the immune system. IFN- $\gamma$ can directly inhibit viral replication, stimulate regulatory $\mathrm{T}$ cell (Treg) function, inhibit the production of IL-17a, increase phagocytosis, and increase the production of pro- 
inflammatory cytokines. ${ }^{72,73}$ Throughout treatment with both compound $\mathbf{1}$ and $N$-Boc TCVC, the amount of IFN- $\gamma$ remains relatively consistent, indicating that neither treatments stimulate the production if IFN- $\gamma$. As the immunomodulatory activity is comparable, this finding supports, but does not prove, the hypothesis that $N$-Boc TCVC and compound 1 have the same mechanism of action.

IL-4 is a cytokine secreted by T helper 2 (Th2) cells, which regulates the differentiation of naïve T cells into Th2 effector cells, through a positive feedback loop. ${ }^{74}$ Th2 cells are primarily active against extracellular pathogens, and largely act through the humoral immune system. ${ }^{74}$ The amount of IL-4 produced by ConA-stimulated cells, treated with either compound $\mathbf{1}$ or $\mathrm{N}$-Boc TCVC is one of the most pronounced points of deviation between the two treatment types. IL-4 production decreases consistently in $\mathrm{N}$ Boc TCVC treated cells, from $281 \%$ of the vehicle, to $45 \%$ of the vehicle, with the greatest reduction in IL-4 production observed at the greatest concentration of $N$-Boc TCVC. Interestingly, the amount of IL-4 is substantially higher in cells treated with the lowest concentration of $N$-Boc TCVC compared to vehicle treated cells. Conversely, the production of IL-4 increases steadily with the concentration of compound 1, from 137\% to $307 \%$ of that of the vehicle. the greatest concentration of $N$-Boc TCVC. Interestingly, the amount of IL-4 is substantially higher in cells treated with the lowest concentration of $N$-Boc TCVC compared to vehicle treated cells. Conversely, the production of IL-4 increases steadily with the concentration of compound 1, from $137 \%$ to $307 \%$ of that of the vehicle. The immunomodulatory activity of compound $\mathbf{1}$ is at its most pronounced in this assay. Compound $\mathbf{1}$ appears to stimulate a Th2 cell response, which could in theory bolster the humoral immune response. Further investigations to confirm whether the IL4 is inducing the differentiation of naïve T cells into Th2 effector cells could help to validate this study, and determine whether the increase in IL-4 results in a functional change in the cells.

The final cytokine measured was IL-17a, a pro-inflammatory cytokine produced by T helper 17 cells (Th17). IL-17a induces the production of chemokines, which recruit immune cells to a site of inflammation. ${ }^{75}$ It is in the production of IL-17a that the immunomodulatory activity of compound $\mathbf{1}$ and $N$-Boc TCVC diverge unquestionably. IL-17a production hovers at approximately $171 \%$ of that of the vehicle in cells treated with compound 1 (Figure 4.3). 


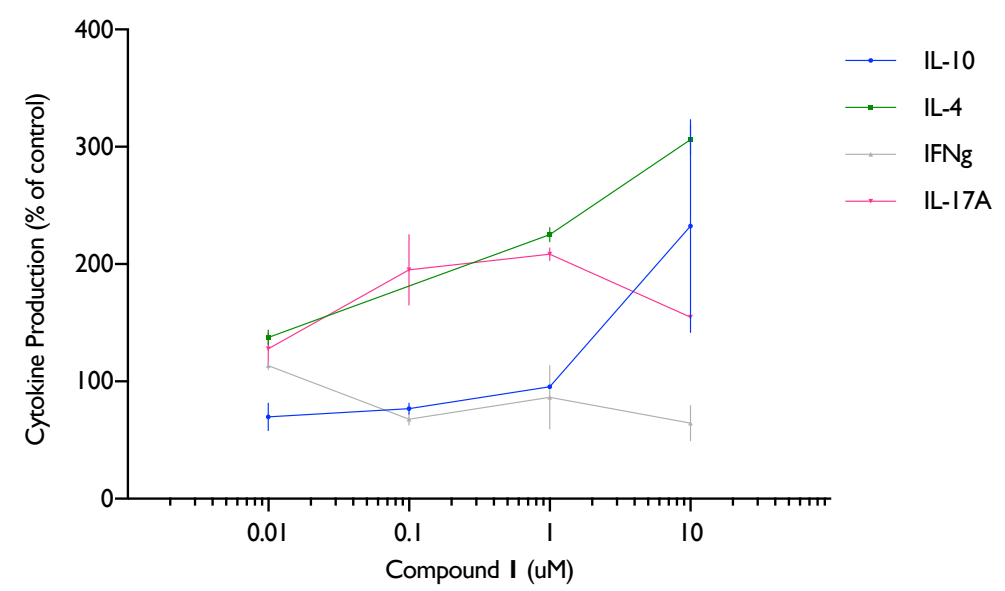

Figure 4.3 The amount of IL-10, IF- $\gamma, I L-4$ and IL-17a production ( \pm SEM) in conA stimulated splenocytes treated with compound 1, compared to \% vehicle control (performed in triplicate from splenocytes isolated from two mice)

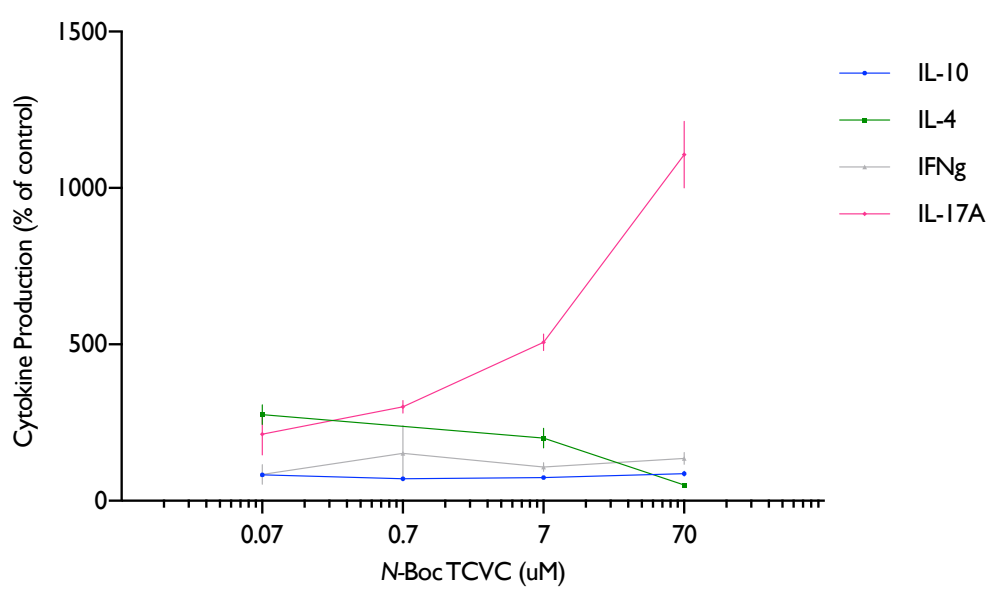

Figure 4.4 The amount of IL-10, IF- $\gamma, I L-4$ and IL-17a production ( \pm SEM) in conA stimulated splenocytes treated with $\mathrm{N}$-Boc TCVC, compared to \% vehicle control (performed in triplicate from splenocytes isolated from two mice)

On the other hand, treatment with $N$-Boc TCVC resulted in an increase of IL-17a production to up to $1100 \%$ of that of the vehicle (Figure 4.4). This is by far the greatest immunomodulatory effect observed throughout all of the ELISAs, and indicates that $\mathrm{N}$ Boc TCVC has a pro-inflammatory effect on splenocytes. Once again, validation of this study by determining whether the observed increase in production of IL-17a translates to a functional change could be very valuable.

The results of the ELISAs reveal much about the immunomodulatory activity of both compound 1 and $N$-Boc TCVC. Not only are the principal effector molecules different with each treatment type, but the strength of the immunomodulation is also considerably different. While $\mathrm{N}$-Boc TCVC appears to promote a strong proinflammatory response, by inducing IL-17a production, compound $\mathbf{1}$ appears to 
preferentially induce a more moderate Th 2 mediated response, induced by the production of IL-4. Given the substantial differences in the immunomodulatory activity of $N$-Boc TCVC and compound 1, it is unlikely that two act through the same mechanism of action.

\subsection{Phagocytosis assay}

The final biological investigation undertaken during this research was a phagocytosis assay, which quantifies the phagocytic ability of a cell, after treatment with either compound 1 or $N$-Boc TCVC. This assay was carried out to determine whether compound 1 or $N$-Boc TCVC were inducing their toxicity through modulation of cytoskeletal functioning or directly through kinesin inhibition. Kinesin is a protein target for a structurally related compound, $S$-trityl-L-cysteine, which blocks mitotic progression by inhibiting the human kinesin Eg5. ${ }^{51}$ Due to the structural similarity of $N$-Boc TCVC and $S$-trityl-L-cysteine, it was hypothesised that a similar interaction could be occurring in cells treated with compound $\mathbf{1}$ or $N$-Boc TCVC. As functional motor proteins are required for phagocytosis, this assay was carried out to determine whether this process was impeded by treatment with compound 1 or $\mathrm{N}$-Boc TCVC. ${ }^{76}$

In this assay RAW264.7 cells, a murine macrophage-like cell line, were treated with either compound $\mathbf{1}$ or $N$-Boc TCVC. The cells were then incubated with pHrodo bioparticles. These particles consist of $E$. coli conjugated to a $\mathrm{pH}$ sensitive fluorophore, which only fluoresces at low $\mathrm{pH}$. The pathogen-associated molecular pattern molecules (PAMPs) of E.coli stimulate phagocytosis of the pHrodo bioparticles by macrophages. ${ }^{77}$

Once within the lysosome of the cell, the low pH enables fluorescence of the fluorophore. The amount of fluorescence, and therefore the amount of phagocytosis, can then be quantified by flow cytometry.

Flow cytometry indicated that neither treatment with compound 1 nor $N$-Boc TCVC caused any discernible effect of the phagocytic ability of the RAW264.7 cells (Figures 4.5 and 4.6). This indicates that despite the structural similarity of the $S$-trityl-Lcysteine and TCVC, the toxicity associated with both of these compounds is unlikely to be mediated by inhibition of microtubule function or kinesins. 


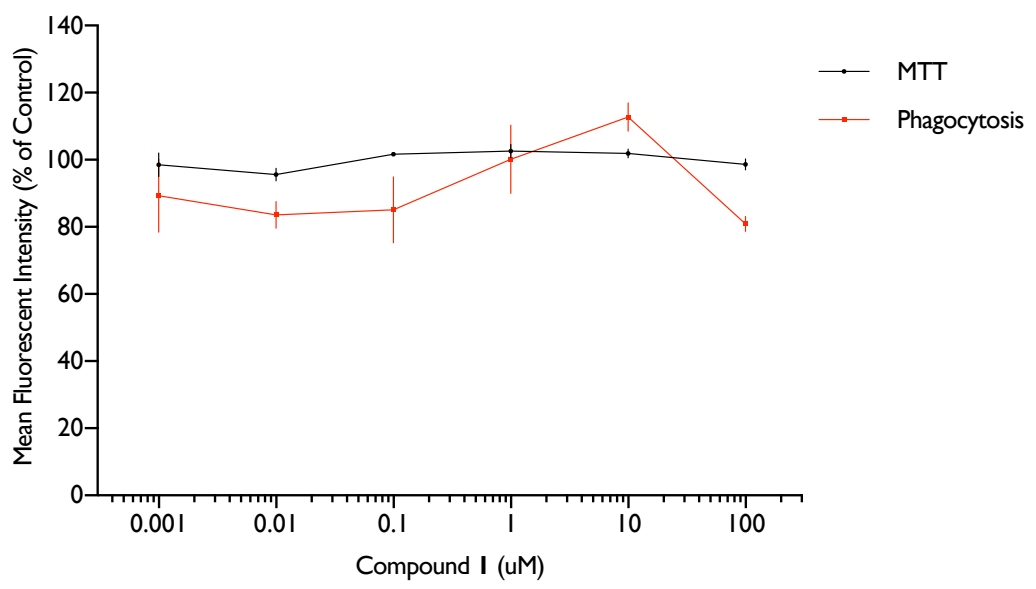

Figure 4.5 The phagocytic ability of RAW264.7 cells ( \pm SEM) treated with compound 1 , as determined by the mean fluorescent intensity, compared to \% vehicle (performed once in triplicate)

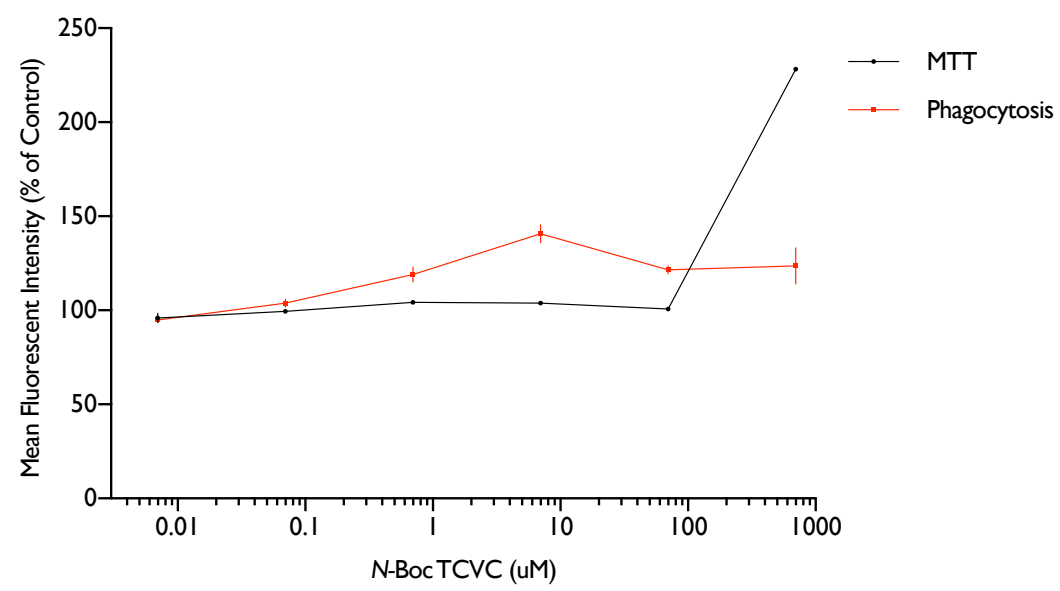

Figure 4.6 The phagocytic ability of RAW264.7 cells ( \pm SEM) treated with N-Boc TCVC, as determined by the mean fluorescent intensity, compared to \% vehicle (performed once in triplicate)

\subsection{Summary}

The biological activity of compound $\mathbf{1}$ and $N$-Boc TCVC was probed through immunomodulatory assays. Neither the splenocytes isolated from euthanised C57BL/ 6 mice, nor the RAW264.7 cells were found to be susceptible to either treatment, with only the highest treatment concentrations resulting in mild cellular inhibition. This indicates that within these cells, the treatment compounds are not reaching the same concentration as in HL60s. This could be a result of defective transport or an increased metabolism of the compounds. The reduced toxicity may also be a result of the different cell types lacking the specific target, which is found in HL60 cells. 
There was no activity for either compound 1 or $N$-Boc TCVC in the IgM, IL-10 or IFN- $\gamma$ assays. Following the revised strategy for biological investigations in this thesis, a major objective was to identify any functional differences between compound $\mathbf{1}$ and $\mathrm{N}$ Boc TCVC, which suggest that the compounds mediate their toxicity through different modes of action. The substantial difference observed in the production of IL-4 and IL17a upon treatment provides two points of validation, that compound $\mathbf{1}$ is not acting as a pro-drug of $\mathrm{N}$-Boc TCVC, and therefore is not inducing toxicity through the liberation of a dichlorothioketene. This signals completion of the third objective of this thesis, to ascertain whether $N$-Boc TCVC and compound $\mathbf{1}$ mediate their toxicity through a shared mechanism.

Insight into the immunomodulatory activities of both $N$-Boc TCVC and compound 1 was also gained. The stimulation of an IL-17a response by $N$-Boc-TCVC indicates this compound is likely an inappropriate anti-cancer lead compound. The proinflammatory activity of IL-17a has implicated this cytokine in tumour development in prostate, cervical and breast cancer and therefore is an undesirable immune response, which anti-cancer therapies would avoid inducing.

The mild induction of a Th2 response by compound $\mathbf{1}$ may also indicate a limitation in its potential as an anti-cancer lead compound. Although the role of Th1 cells in tumour regression is well documented, Th2 cells do not appear to play such a part. Th1 cells are known to enhance cytokine and lymphocyte activity against tumour cells, while Th2 cells are primarily associated with eliminating parasites. ${ }^{78,79}$ By stimulating an inappropriate immune response, $\mathrm{CD} 4{ }^{+} \mathrm{T}$ cells are sequestered for the Th2 lineage, and as a result, the anti-cancer Th1 response may be diminished. This is especially concerning given that the production of IL-4 prevents the repolarisation of Th2 cells towards the Th1 cell lineage. ${ }^{78}$

These results indicate that the immunomodulatory activity of both compound $\mathbf{1}$ and $N$-Boc TCVC may limit their use in anti-cancer investigations. Although the toxicity of compound 1 was found to be substantial in HL60s, the significance of the immune system in the treatment of cancer must also be considered. 


\section{Chapter 5}

\subsection{Concluding Remarks}

The original objective of this thesis was to investigate the mode of action of a toxic $S$-trichlorovinyl-L-cysteine-containing analogue of mycothiol, compound $\mathbf{1}$, in HL60 cells. A secondary aim was the synthesis of two analogues of compound 1, containing a propynyl or a fluorescent group in place of the $S$-trichlorovinyl on compound 1. Compound 1 was successfully synthesised according to the methods described by Riordan, with only one notable deviation in outcomes observed during conjugation of the peracetylated glucosamine to cyclohexanethiol. ${ }^{5}$ Riordan reported a 2:1 ratio of $\alpha / \beta$ anomers, whereas a reproducibly 1:5 ratio of $\alpha / \beta$ anomers was observed during this research, with the salient difference between the reaction conditions being an increase in reaction time. $^{5}$

Following completion of the synthesis of compound 1, and so fulfilment of the first research objective, the attempted synthesis of the two functionalised analogues was attempted. The precursor to the propynyl analogue of compound 1, $N$-Boc-S-propynyl-Lcysteine, was successfully synthesised from cysteine monohydrate hydrochloride in a one-pot reaction, following methods outlined by Curran, with a $64 \%$ yield. ${ }^{56}$ The precursor to the fluorescent analogue of compound 1, $N$-Boc-S-bimane-L-cysteine was synthesised from $N$-Boc-L-cysteine, following a method outlined by Knapp, with a yield of $60 \% .{ }^{44}$ Despite the successful synthesis of all precursors to the two analogues, conjugation was never achieved. The relatively straightforward amide bond was installed in only one circumstance, and characterisation of this conjugated product was complicated due to only trace amounts of product detected.

Due to time constraints, the biological investigations were commenced before either the propynyl or the fluorescent analogue could be successfully synthesised, and as a result the biological objectives had to be modified to allow for testing of only compound 1 and $N$-Boc TCVC. The biological investigations were initially intended to be undertaken through analysis of the proteomic changes in response to the treatment. This was expected to reveal the pathways the cell used in response to the treatment. However, 
the prolonged break down of the LC-MS/MS meant the research objectives once again had to be modified. The first of these new research objectives sought to determine the toxicity of a precursor to compound $\mathbf{1}, N$-Boc TCVC in HL60 cells. This objective was completed through performing MTT assays with $N$-Boc TCVC, which demonstrated a relatively weak toxicity, with an $\mathrm{IC}_{50}$ of $116.8 \pm 0.06 \mu \mathrm{M}$.

The second objective focused on establishing whether $\mathrm{N}$-Boc TCVC and compound 1 mediate their toxicity through a shared mechanism, and thus whether compound 1 primarily acts as a prodrug for TCVC, with enhanced transport into target cells before metabolic transformation to release TCVC as a mediator of function. Immunological investigations which measured the immune response to treatment with either $\mathrm{N}$-Boc TCVC or compound $\mathbf{1}$ were then carried out in splenocytes isolated from euthanised C57BL/6 mice. The results of the biological investigations indicate that compound 1 and $N$-Boc TCVC do not act through the same mechanism. While cells treated with high concentrations of $\mathrm{N}$-Boc TCVC produced up to $1100 \%$ more IL-17a than cells treated with vehicle, the amount of IL-17a produced by cells treated with compound 1 remained relatively consistent, at $171 \%$ of that of the vehicle, even at the highest concentrations of treatment. Conversely, the amount of IL-4 produced in cells treated with compound 1 increased up to $307 \%$ of that of the vehicle, while it decreased to $45 \%$ of that of the vehicle in cells treated with $N$-Boc TCVC. These results indicate that while compound $\mathbf{1}$ is only mildly immunomodulatory it appears to stimulate a Th2 cell response. On the other hand, $N$-Boc TCVC appears to have quite a significant, and specific immuno-stimulatory effect on Th17 cells. Given the substantial differences in the immuno-stimulatory activity of compound $\mathbf{1}$ and $N$-Boc TCVC, the hypothesis that the two act through the same mechanism of action can be tentatively rejected.

The third and final objective was to determine whether the immunomodulatory activities of $\mathrm{N}$-Boc TCVC or compound 1 justify further investigations into their anticancer properties. The strong stimulation of an IL-17a response by $N$-Boc-TCVC demonstrates that it is an inappropriate lead compound for anti-cancer research, given the strong pro-tumour effect this cytokine has in many cancers. While the immunomodulatory effect of compound $\mathbf{1}$ was mild in both its strength and its significance for an anti-cancer lead compound, the production of IL-4 does not indicate any beneficial immunomodulatory activity of this compound. 
Despite the significant adjustments to the objectives of the biological investigations, several valuable outcomes resulted from this research. It was determined that toxicity induced by compound $\mathbf{1}$ is not mediated by the release of dichlorothioketene, and a more specific target interaction is likely the cause of this toxicity. Furthermore, $N$ Boc-TCVC was shown to be an inappropriate anti-cancer lead compound. The potential of compound 1 as an anti-cancer lead compound was neither supported nor entirely undermined by the immunomodulatory investigations.

\subsection{Future Directives}

This thesis describes the synthesis of a toxic $S$-trichlorovinyl-L-cysteinecontaining analogue of mycothiol, and the attempted synthesis of two derivatives of this. This thesis also details immunomodulatory investigations, which were undertaken to probe the mode of action of compound $\mathbf{1}$.

Given that neither functionalised cysteine was successfully conjugated to the thioglycoside backbone, further development of a successful method of conjugation is an obvious area of potential future research. An alternative synthetic route, in which the Boc protected cysteine is conjugated to the thioglycoside backbone before derivatisation could present with more successful results. Carrying out the conjugation reactions on a larger scale would also prove to be a useful undertaking, and could enable comprehensive characterisation of the products of the reaction, and therefore provide a clear insight into why the coupling reactions failed.

Further biological investigations could also be of interest. Whilst useful new information on both $\mathrm{N}$-Boc TCVC and compound $\mathbf{1}$ have been obtained, the original intention of identifying the pathways associated with the action of compound 1 was not addressed. Isolates of the cytosolic proteome were prepared in triplicate for both compound 1 and $N$-Boc TCVC treatments at both $\mathrm{IC}_{50}$ and $\mathrm{IC}_{10}$ concentrations, in HL-60 cells. These isolates are available for analysis when the opportunity arises for further chemical and biological investigations. If successful synthesis of the propynylated derivative is achieved, then carrying out affinity purification as outlined in the original objectives would complement the proteomics research. Proteomics provides a broad perspective on the entire cellular response to treatment, while affinity purification reveals 
a highly specific interaction, which may directly identify the cellular target of the treatment. 


\section{Chapter 6}

\section{Experimental}

\subsection{General Experimental}

The following conditions apply to all subsequent chemical syntheses, unless otherwise stated. Reactions were performed under an inert atmosphere, either with argon by a balloon, or nitrogen delivered via manifold. All reactions were stirred using a magnetic stir bar. Dichloromethane, THF and diethyl ether were used directly from a Pure Solve Md-5 purification system (Innovative Technology). Anhydrous dimethylformamide and acetic anhydride were used without further purification. Triethylamine and acetonitrile were refluxed over calcium hydride, and methanol over sodium before distillation under nitrogen. Boron trifluoride diethyl etherate was distilled over calcium hydride before each use. All reagents were used as received, without further purification.

Reactions were monitored with analytical thin layer chromatography (TLC), using plastic backed pre-coated silica TLC plates (Polygram SilG/ UV254) and visualized with UV irradiation ( $254 \mathrm{~nm}$ or $366 \mathrm{~nm}$ ) and through treatment with potassium permanganate, $\mathrm{p}$ anisaldehyde or ceric ammonium molybdate dips. Purification via flash chromatography utilised silica-gel $60 \AA \AA$ (Pure Science, 40- 63 microns).

${ }^{1} \mathrm{H}$ NMR spectra were obtained using a Varian Unity Inova 500 spectrometer at 500 MHz. The chemical shifts ( $\mathrm{ppm}$ ) are referenced to the residual solvent peak, and are recorded as follows: chemical shifts, multiplicity, integration, peak assignment. ${ }^{13} \mathrm{C} \mathrm{NMR}$ spectra were obtained using a Varian Unity Inova 500 spectrometer at $125 \mathrm{MHz}$. The chemical shifts (ppm) are referenced to the residual solvent peak. Mass spectra were recorded on an Agilent 6530 Accurate-Mass Q-TOF LC/MS high-resolution mass spectrometer (HRMS). Infra-red (IR) spectra were collected from liquid films (chloroform), or neat on a Perkin Elmer Spectrum One FT-IR spectrometer. Melting points were measured on Gallenkamp melting point apparatus.

Cells were cultured in a Logic Labconco ${ }^{\circledR}$ Purifier ${ }^{\circledR}$ Biological Safety Cabinet, and grown in a SANYO Electric Co., Ltd incubator at $37^{\circ} \mathrm{C}$, with $5 \% \mathrm{CO}_{2}$ atmosphere. 


\subsection{Experimental Detail for Chemical Synthesis}

$N$-Boc-L-Cysteine (12)

Water $(45 \mathrm{~mL})$ and THF ( $5 \mathrm{~mL})$ were degassed with nitrogen for 30<smiles>O=C(O)NC(CS)C(=O)O</smiles>
minutes in separate round bottom flasks. L-Cysteine hydrochloride monohydrate $(2.11 \mathrm{~g}, 13.4 \mathrm{mmol})$, sodium bicarbonate $(1.95 \mathrm{~g}, 23.2$ $\mathrm{mmol})$ and di-tert-butyl dicarbonate $(0.67 \mathrm{~g}, 2.1 \mathrm{mmol})$ were placed in a round bottom flask under an argon atmosphere. Degassed water (43 mL) and THF (3 $\mathrm{mL}$ ) were subsequently added, and the reaction stirred under argon for 17 hours. Ethyl acetate $(50 \mathrm{~mL})$ was then added, and the reaction acidified to $\mathrm{pH} 3$ with $\mathrm{H}_{2} \mathrm{SO}_{4}(1 \mathrm{M})$. The organic and aqueous layers were separated, and the organic layer washed with saturated brine $(3 \times 50 \mathrm{~mL})$, dried over anhydrous $\mathrm{MgSO}_{4}$, and concentrated in vacuo to afford a colourless oil (378 mg, 57\%) $\mathrm{R}_{f} 0.69$ (3:1 DCM: EtOAc) ${ }^{1}$ HNMR (500 MHz, $\left.\mathrm{CDCl}_{3}\right) \delta: 5.45$ (br s, 1H), 4.63 (br s, 1H), 2.93-3.1 (m, 2H), 1.47 (s, 9H).

\section{$N$-Boc-S-trichlorovinyl Cysteine (7)}<smiles>O=[R6]([O-])NC(CSC(Cl)=C(Cl)Cl)C(=O)O</smiles>

$N$-Boc-L-cysteine (328 mg, $1.46 \mathrm{mmol}$ ) was dissolved in tetrachloroethylene $(7.7 \mathrm{~mL}, 74.83 \mathrm{mmol})$ and acetonitrile $(4.2 \mathrm{ml})$ and stirred under argon for 45 minutes. DBN $(0.48$ $\mathrm{mL}, 3.86 \mathrm{mmol}$ ) was then added dropwise over 5 minutes, and the reaction stirred for a further 30 minutes. Dichloromethane $(40 \mathrm{~mL})$ and water $(15$ $\mathrm{mL}$ ) were added, and the reaction acidified to $\mathrm{pH} 2$ with $\mathrm{H}_{2} \mathrm{SO}_{4}(1 \mathrm{M})$. The organic and aqueous layers were separated, and the organic layer washed with saturated brine $(40 \mathrm{~mL}$ x 3), dried over $\mathrm{MgSO}_{4}$ and concentrated in vacuo to afford a colourless oil (308 $\mathrm{mg}$, 59\%) $\mathrm{R}_{f} 0.38$ (3:1 n-hexane: EtOAc). ${ }^{1}$ HNMR (500 MHz, $\left.\mathrm{CDCl}_{3}\right) \delta: 5.43$ (br s, 1H), 4.61 (br s, 1H), 3.56 (br d, J=13.7 Hz, 1H), 3.34 (br d, J=13.9 Hz, 1H), 1.46 (s, 9H). 
<smiles>Cc1c(C)n2c(=O)c(C)c(C)n2c1=O</smiles>

Under darkness, monobromobimane $(3.4 \mathrm{mg}$, $12.4 \mu \mathrm{mol})$ was added to $20 \mathrm{mM}$ Tris $\mathrm{HCl}$ buffer $(6.2$ $\mathrm{mL}, \mathrm{pH} 8.0$ ) to produce a $2 \mathrm{mM}$ solution. This was added to a $1 \mathrm{mM}$ solution of $N$-Boc-L-Cysteine $(0.0028$ $\mathrm{g}, 12.65 \mu \mathrm{mol})$ in $20 \mathrm{mM}$ Tris $\mathrm{HCl}$ buffer $(9 \mathrm{~mL}, \mathrm{pH}$ 8.0). The reaction was stirred for 40 minutes in darkness, and then acidified to $\mathrm{pH} 3$ with $1 \mathrm{M}$ sulfuric acid. The organic layer was separated, and concentrated in vacuo to afford a fluorescent green oil $(0.0031 \mathrm{~g}, 60 \%) \mathrm{R}_{f}$ 0.30 (EtOAc, visualized with UV at $366 \mathrm{~nm}$ ) ${ }^{1} \mathbf{H N M R}\left(500 \mathrm{MHz}, \mathrm{CDCl}_{3}\right) \delta: 5.37$ (br s, 1H), 4.57 (br s, 1H, H-1), 3.81(d, $J=14.3 \mathrm{~Hz}, 1 \mathrm{H}, \mathrm{H}-3$ ), 3.71 (d, $J=14.3 \mathrm{~Hz}, 1 \mathrm{H}, \mathrm{H}-3$ ) $3.20(\mathrm{dd}, J=14.1,4.7 \mathrm{~Hz}, 1 \mathrm{H}, \mathrm{H}-2), 2.94$ (dd, $J=14.1,6.1 \mathrm{~Hz}, 1 \mathrm{H}, \mathrm{H}-2), 2.41$ (s, 3H, H5), 1.90 (s, 3H, H-4), 1.83 (s, 3H, H-6), 1.45 (s, 9H)

\section{$N$-Boc-S-propynyl-L-Cysteine (8)}

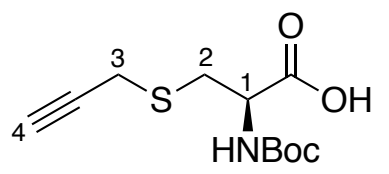

Method 1: Compound 12 (234 mg, $1.05 \mathrm{mM}$ ) was dissolved in $2 \mathrm{M}$ ammonium solution $(0.53 \mathrm{~mL})$, and cooled to $0{ }^{\circ} \mathrm{C}$ with an ice bath. After 30 minutes, propargyl bromide solution $(0.09 \mathrm{~mL}, 1.08 \mathrm{mM})$ was added dropwise, and the reaction stirred for 3.5 hours. The reaction mixture was then concentrated in vacuo, and recrystallised from water-ethanol, to afford a yellow powder ( $82 \mathrm{mg}, 21 \%)$.

Method 2: Sodium metal (507 mg, $22.0 \mathrm{mM})$ was added to ethanol $(30 \mathrm{~mL})$ and stirred under argon until completely reacted, to form sodium ethoxide. L-cysteine hydrochloride monohydrate (1.083 g, $6.2 \mathrm{mM}$ ) was added, and once dissolved, propargyl bromide (2.5 $\mathrm{mL}, 29 \mathrm{mM}$ ) was added dropwise. The reaction was stirred for 2 hours, after which time the reaction mixture was concentrated in vacuo, and redissolved in THF (7.5 mL). Ditert-butyl dicarbonate $(1.22 \mathrm{~g}, 11.2 \mathrm{mM})$ was dissolved in THF $(6.25 \mathrm{~mL})$, and added to the cysteine solution. Triethylamine $(2.5 \mathrm{~mL}, 17.8 \mathrm{mM})$ and distilled water $(6.12 \mathrm{~mL})$ were added, and the reaction stirred overnight. The THF was then removed in vacuo, and the water basified to $\mathrm{pH} 11$ with sodium hydroxide solution (10\%). The aqueous layer was washed three times with ethyl acetate $(20 \mathrm{~mL})$, and acidified to $\mathrm{pH} 3$ with 
concentrated $\mathrm{HCl}$. The acidic aqueous layer was washed three times with ethyl acetate $(20 \mathrm{~mL})$. The ethyl acetate fractions were combined, dried with anhydrous $\mathrm{MgSO}_{4}$, and concentrated in vacuo to afford a tan oil $(463 \mathrm{mg}, 65 \%) \mathrm{R}_{f} 0.63$ (1:1 EtOAc: $\left.\mathrm{MeOH}\right)$ ${ }^{1}$ HNMR $\left(500 \mathrm{MHz}, \mathrm{CDCl}_{3}\right) \delta: 5.39(\mathrm{~d}, J=7.7 \mathrm{~Hz}, 1 \mathrm{H}), 4.58(\mathrm{~d}, J=6.3 \mathrm{~Hz}, 1 \mathrm{H}, \mathrm{H}-1, \mathrm{H}-$ 1), $3.32(\mathrm{dd}, J=12.1,2.6 \mathrm{~Hz}, 2 \mathrm{H} \mathrm{H}-3), 3.25-3.11$ (m, $2 \mathrm{H}, \mathrm{H}-2), 2.29$ (t, $J=2.6 \mathrm{~Hz}, 1 \mathrm{H}$, H-4), 1.46 (s, 9H).

\section{2-Acetamido-2-deoxy-1,3,4,6-tetra-O-acetyl- $\alpha$-D-glucopyranose (13)}

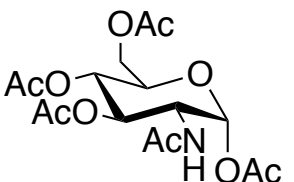

product as a white powder $(3.54 \mathrm{~g}, 54 \%)$. IR: $1735,1672,1363,1217,1111,1018 \mathrm{~cm}^{-1}$. ${ }^{1}$ H NMR $\left(500 \mathrm{MHz}, \mathrm{CDCl}_{3}\right) \delta: 6.17(\mathrm{~d}, J=3.6 \mathrm{~Hz}, 1 \mathrm{H}), 5.56(\mathrm{~d}, J=9.0 \mathrm{~Hz}, 1 \mathrm{H}), 5.29-$ $5.16(\mathrm{~m}, 2 \mathrm{H}), 4.54-4.40(\mathrm{~m}, 1 \mathrm{H}), 4.25(\mathrm{dd}, J=12.5,4.1 \mathrm{~Hz}, 1 \mathrm{H}), 4.06(\mathrm{dd}, J=12.5,2.4$ Hz, 1H), 3.99 (ddd, $J=9.6,4.2,2.4 \mathrm{~Hz}, 1 \mathrm{H}), 2.20$ (s, 3H), 2.09 (s, 3H), 2.05 (d, $J=5.5$ $\mathrm{Hz}, 6 \mathrm{H}), 1.94$ (s, 3H). ${ }^{13} \mathbf{C}$ NMR (125 MHz, $\left.\mathrm{CDCl}_{3}\right) \delta: 171.9,170.9,170.1,169.2,168.8$, $90.8,77.4,77.2,76.9170 .8,69.9,67.6,61.7,51.2,23.2,21.1,20.9,20.9,20.7$.

\section{Cyclohexyl 2-Acetamido-2-deoxy-1-thio-3,4,6-tri-O-acetyl- $\beta$-D-glucopyranoside} (14)

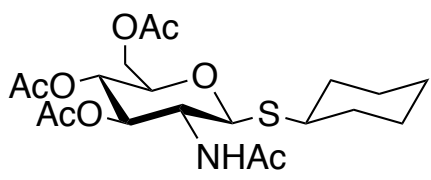

Compound 13 (2.4 g, $6.16 \mathrm{mM})$ was dissolved in $70 \mathrm{~mL}$ of 1,2-dichloroethane under an argon atmosphere. Cyclohexanethiol ( $3 \mathrm{~mL}, 24.5 \mathrm{mM})$ was added, and the reaction stirred for 30 minutes. The reaction mixture was cooled to $0{ }^{\circ} \mathrm{C}$ in an ice bath, and $\mathrm{BF}_{3} \mathrm{OEt}_{2}(1.5 \mathrm{~mL}, 12.15 \mathrm{mM})$ was added dropwise. The reaction was subsequently heated to $55^{\circ} \mathrm{C}$, and stirred for 4.5 hours. The reaction was quenched with the addition of saturated sodium bicarbonate solution, and the organic and aqueous layers were separated. The aqueous layer was washed twice with dichloromethane $(60 \mathrm{~mL})$, and the organic fractions with saturated brine $(150 \mathrm{~mL})$. The organic fraction was then dried over anhydrous $\mathrm{MgSO}_{4}$, and the solvent evaporated with a stream of compressed air. The resulting oil was purified by flash chromatography on silica, with 1:2 petroleum ether: ethyl acetate, to afford the product as a white powder. 
The product was obtained as a mixture of anomers $(\alpha: \beta, 1: 5,0.60 \mathrm{~g}, 21.8 \%) \mathrm{R}_{f} 0.60$ (EtOAc) IR: 3295, 2929, 2853, 1741, 1659, 1541, 1369, 1220, $1035 \mathrm{~cm}^{-1}$. ${ }^{\mathbf{1}}$ HNMR (500 $\left.\mathrm{MHz} \mathrm{CDCl}_{3}\right) \delta: 5.44(\mathrm{~d}, J=9.1 \mathrm{~Hz}, 1 \mathrm{H}), 5.23(\mathrm{dd}, J=10.2,9.3 \mathrm{~Hz}, 1 \mathrm{H}), 5.06(\mathrm{t}, J=10$ $\mathrm{Hz}, 1 \mathrm{H}), 4.76$ (d, $J=10.4 \mathrm{~Hz}, 1 \mathrm{H}), 4.20$ (dd, $J=12.3,5.5 \mathrm{~Hz}, 1 \mathrm{H}), 4.13$ (dd, $J=12.2,2.4$ $\mathrm{Hz}, 1 \mathrm{H}), 3.97(\mathrm{td}, J=10.3,9.1 \mathrm{~Hz}, 1 \mathrm{H}), 3.68(\mathrm{ddd}, J=10.0,5.5,2.5 \mathrm{~Hz}, 1 \mathrm{H}), 2.92(\mathrm{~m}$, $1 \mathrm{H}), 2.07$ (s, 3H), 2.05- $2.01(\mathrm{~m}, 6 \mathrm{H}), 1.95(\mathrm{~m}, 5 \mathrm{H}), 1.73(\mathrm{~m}, 2 \mathrm{H}), 1.40-1.20(\mathrm{~m}, 7 \mathrm{H})$. ${ }^{13}$ C NMR (125 MHz, $\left.\mathrm{CDCl}_{3}\right) \delta: 171.2,170.8,170.2,169.5,83.8,75.9,73.8,68.7,62.7$, 54.0, 43.7, 34.2, 34.0, 25.8, 23.5, 20.9, 20.8. HRMS (ESI): $m / z \mathrm{C}_{22} \mathrm{H}_{35} \mathrm{Cl}_{3} \mathrm{~N}_{2} \mathrm{O}_{7} \mathrm{~S}_{2}$ calculated 445.1770 found 445.17975

\section{Cyclohexyl 2-( $N$-tert-butyloxycarbonylacetamido)-2-deoxy-3,4,6-tri- $O$-acetyl-1- thio- $\beta$-D- glucopyranoside (15)}

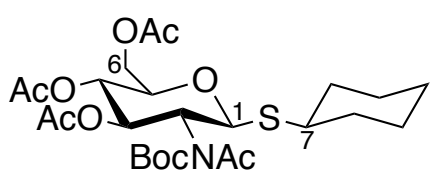

Compound 14 (0.304 g, $0.56 \mathrm{mM})$ was dissolved in THF (4 mL). DMAP (12.6 mg, $0.10 \mathrm{mM})$ and di-tertbutyl dicarbonate $(0.9480 \mathrm{~g}, 4.3 \mathrm{mM})$ were added. The reaction mixture was refluxed at $66^{\circ} \mathrm{C}$ for 16 hours. The solvent was then removed in vacuo, and the product purified by flash chromatography on silica with petroleum ether: ethyl acetate 4:1. (213 mg, 70\%) $\mathrm{R}_{f} 0.66\left(\mathrm{CHCl}_{3}\right)$ IR: 2929 , 2854, 1740, 1696, 1237, 1141, 1045, $1012 \mathrm{~cm}^{-1} .{ }^{1}$ HNMR (500 MHz, $\left.\mathrm{CDCl}_{3}\right) \delta: 5.82$ (dd, $J=10.1,8.8 \mathrm{~Hz}, 1 \mathrm{H}, \mathrm{H}-3), 5.71$ (dd, $J=10.3,8.9 \mathrm{~Hz}, 1 \mathrm{H}, \mathrm{H}-3$ '), 5.59 (d, $J=10.1 \mathrm{~Hz}, 1 \mathrm{H}$, H-1), 5.34 (d, $J=10.2$ Hz, 1H, H-1'), 5.08 (dd, $J=10.2,8.9$ Hz, 1H, H-4'), 5.03 (dd, $J=10.2,8.8 \mathrm{~Hz}, 1 \mathrm{H}, \mathrm{H}-4), 4.91$ (t, $J=10.3 \mathrm{~Hz}, 1 \mathrm{H}, \mathrm{H}-2$ '), 4.23 (m, 3H, H-2, H-6a, H-6a'), 4.11 (m, 3H, H-6b and H-6b'), 3.78 (ddd, $J=10.3,5.8,2.4$ Hz, 1H, H-5), 3.69 (ddd, $J=$ 10.2, 5.4, 2.4 Hz 1H, H-5'), 2.84 (m, 2H, H-7, H-7'), 2.42 (s, 3H, acetyl), 2.34 (s, 3H, acetyl), 2.07 (s, 3H, acetyl), $2.06(\mathrm{~s}, 3 \mathrm{H}$, acetyl), 2.01 (s, 6H, 2 x acetyl), 1.89- 1.99 (m, $10 \mathrm{H}, 2 \mathrm{x}$ acetyl and cyclohexane), 1.73 (m, 5H, cyclohexane), 1.50- 1.60 (m, 20H, Boc and cyclohexane 1.26- 1.40 (m, 10H, cyclohexane). 


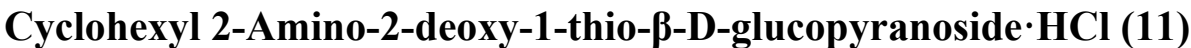

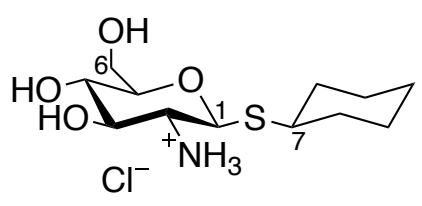

Compound 15 (210 mg, $0.38 \mathrm{mM})$ was dissolved in methanol $(2 \mathrm{~mL})$ under an argon atmosphere. Sodium metal (9.6 $\mathrm{mg}, 0.42 \mathrm{mM}$ ) was added, and the solution stirred for 2 hours. Concentrated aqueous hydrochloric acid $(0.5 \mathrm{~mL}, 5.8 \mathrm{mM})$ was added, and the solution stirred for 18 hours. The solvent was removed in vacuo to afford the product as a yellow solid (127 mg, $0.46 \mathrm{mM})$. IR: 3360, 2923, 2851, 1611, 1505, 1447, $1060 \mathrm{~cm}^{-1}$. ${ }^{1}$ HNMR (500 MHz, D $\left.2 \mathrm{O}\right) \delta: 4.89$ (d, $J=10.4$ Hz, 1H, H-1) 3.87 (d, $J=12.3$ Hz, H-6), 3.71 (dd, $J=12.5,5.1 \mathrm{~Hz}, 1 \mathrm{H}, \mathrm{H}-6$ '), 3.60 (t, $J=$ $9.3 \mathrm{~Hz}, 1 \mathrm{H}, \mathrm{H}-3), 3.49$ (m, 2H, H-4, H-5), 3.11 (t, J=10.3 Hz, 1H, H-2), 3.05 (m, 1H, H7), 1.97 (br s, 2H, cyclohexane), 1.71 (d, J=15 Hz, 2H, cyclohexane), 1.56 (d, J=15 Hz, $1 \mathrm{H}$, cyclohexane), 1.15- 1.45 ( $\mathrm{m}, 5 \mathrm{H}$, cyclohexane).

\section{Cyclohexyl 2-Amino-2-N-(N-tert-butylcarbonyl-S-trichlorovinyl -L-cysteinyl)-2- deoxy-1- thio- $\beta$-D-glucopyranoside (1)}

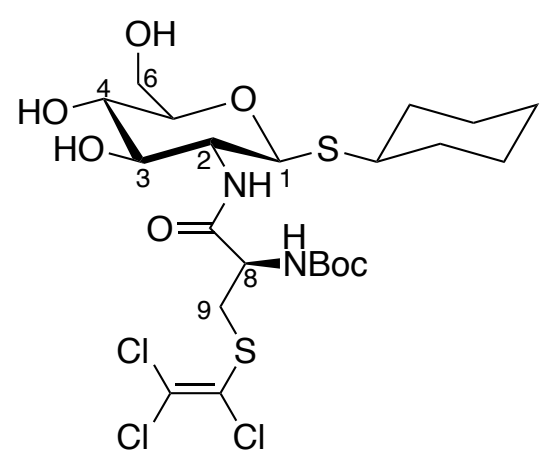

Compound 11 (21 mg, $0.07 \mathrm{mM})$ was dissolved in DMF $(0.5 \mathrm{~mL})$. Once fully dissolved, potassium tertbutoxide (7.5 mg, $0.07 \mathrm{mM}$ ) was added and the solution stirred under argon. In a separate round bottom flask, compound 7 (40 $\mathrm{mg}, 0.11 \mathrm{mM})$ was dissolved in DMF $(0.5 \mathrm{~mL})$, and the solution cooled to $0{ }^{\circ} \mathrm{C}$ in an ice bath. EDC (25 mg, $\left.0.16 \mathrm{mM}\right)$ was added,

and the solution premixed for 10 minutes. The thioglycoside solution was added dropwise to the cysteine solution, and the reaction mixture stirred for 2 hours. The DMF was distilled off under reduced pressure, and the resulting oil purified by flash chromatography on silica, using stepwise elution with petroleum ether, dichloromethane, diethyl ether, ethyl acetate and dichloromethane: methanol $(3: 2)$. The product was isolated as a white powder (11 mg, 27\%). $\mathrm{R}_{f} 0.31$ (EtOAc). M.p. 196-200 ${ }^{\circ} \mathrm{C}$. ${ }^{1}$ HNMR (500 MHz, CD $\left.\mathrm{CD}_{3} \mathrm{OD}\right) \quad 4.72$ (d, $\left.J=10,1 \mathrm{H}, \mathrm{H}-1\right), 4.25$ (m, 1H, H-8), 3.86 (dd, $J=12.1$, $2.0 \mathrm{~Hz}, 1 \mathrm{H}, \mathrm{H}-6), 3.66$ (dd, J=12, $5.5 \mathrm{~Hz}, 1 \mathrm{H}, \mathrm{H}-6$ '), 3.53 (m, 2H, H-2 and H-3), 3.47 (dd, $J=14.2,4.3 \mathrm{~Hz}, 1 \mathrm{H}, \mathrm{H}-9), 3.21-3.31$ (m, 2H, H-4 and H-5), 3.10 (dd, $J=5,10 \mathrm{~Hz}$, 
1H, H-9’) 2.93 (m, 1H, H-12), 2.00 (m, 1H, cyclohexane), 1.91 (m, 1H, cyclohexane), $1.70(\mathrm{~m}, 2 \mathrm{H}$, cyclohexane) $1.56(\mathrm{~m}, 1 \mathrm{H}$, cyclohexane) $1.43(\mathrm{~s}, 9 \mathrm{H}, \mathrm{Boc}), 1.36-1.18(\mathrm{~m}$, $5 \mathrm{H}$, cyclohexane). HRMS (ESI): $m / z \quad \mathrm{C}_{22} \mathrm{H}_{35} \mathrm{Cl}_{3} \mathrm{~N}_{2} \mathrm{O}_{7} \mathrm{~S}_{2}$ calculated 608.0951 found 608.0955 .

\subsection{Experimental Detail for MTT Assay}

$100 \mu \mathrm{L}$ of an HL60 cell suspension $\left(1 \times 10^{6}\right.$ cells $\left./ \mathrm{mL}\right)$ was added to a 96 well plate, and treated with either compound 1 or $N$-Boc-TCVC at a concentration range of $200-1.6 \mu \mathrm{M}$. The volume was brought up to $200 \mu \mathrm{L}$ with RPMI 1640 media, and the cells incubated at $37^{\circ} \mathrm{C}$ for 24 hours. Each well was subsequently treated with $20 \mu \mathrm{L}$ of MTT, and incubated for 2 hours at $37^{\circ} \mathrm{C}$, before the addition of $100 \mu \mathrm{L}$ of solubiliser. The cells were incubated overnight at $37^{\circ} \mathrm{C}$. The absorbance was read in a microplate reader at $570 \mathrm{~nm}$.

MTT and solubiliser were prepared according to methods outlined by Berridge. ${ }^{80}$

The MTT assay was performed three times, in triplicate, and the $\mathrm{IC}_{50}$ values determined using GraphPad Prism software.

\subsection{Experimental Detail for ELISAs}

C57BL/6 mice, housed at the Malaghan Institute of Medical Research Animal Facility, were euthanised by carbon dioxide inhalation (VUW, Animal Ethics Committee protocol 25295), and their spleens were placed in a $70 \mu \mathrm{m}$ cell strainer atop a $50 \mathrm{~mL}$ concical tube. Spleens were mashed with a $1 \mathrm{~mL}$ syringe plunger, and cells collected into the tube with $10 \mathrm{~mL}$ CTCM. This single cell splenocyte suspension was centrifuged at $3000 \mathrm{x}$ g for 4 minutes, before resuspending the pellet in $2 \mathrm{~mL} \mathrm{RBC}$ lysis buffer. After 2 minutes incubation, $8 \mathrm{~mL}$ of CTCM was added and cells centrifuged again. This pellet was resuspended to a concentration of $1 \times 10^{7}$ cells/ $\mathrm{mL}$ for use.

Splenocytes were seeded into 96 well plates at $1 \times 10^{6}$ cells per well. Vehicle controls or treatments were added as indicated (Table 6.1), along with $1 \mu \mathrm{g} / \mathrm{mL}$ ConA to activate T lymphocytes, $0.1 \mu \mathrm{g} / \mathrm{mL}$ LPS to activate B cells, or media for unstimulated controls. After 48 hours of incubation, plates were spun at $300 \mathrm{x}$ g for 4 minutes, and 
supernatants collected for ELISA analysis. Cells viability was determined through an MTT assay.

96-well ELISA plates were coated overnight at $4{ }^{\circ} \mathrm{C}$ with a capture antibody, which was removed after incubation. Plates were then blocked with 5\% FCS in PBS for 2 hours, before being washed three times with $0.05 \%$ tween in PBS. The plates were then loaded with $50 \mu \mathrm{L}$ of cell supernatant or standards, and washed four times, before the addition of $50 \mu \mathrm{L}$ of detection antibody. Plates were then incubated at room temperature for 1 hour and washed eight times. $100 \mu \mathrm{L}$ of TMB reagent (BD Bioscience) was then added into each well. After colour development, the reaction was stopped with $100 \mu \mathrm{L}$ of stop solution, and absorbance was read at $460 \mathrm{~nm}$.

CTCM media was prepared with 86\% DMEM, 10\% FCS, 1\% NEAA, 1\% HEPES, 1\% PenStrep, 1\% L-Glutamine and 0.01\% 2-Mercaptoethanol.

ELISAs were performed in triplicate, on splenocytes isolated from two C57BL/6 mice.

Table 6.1 ELISA reagents and conditions

\begin{tabular}{|c|c|c|c|}
\hline IFN- $\gamma$ & $\begin{array}{l}\text { Concentration/ } \\
\text { Dilution }\end{array}$ & Diluent & Reagent \\
\hline Capture & $1: 1000$ & $\begin{array}{l}\mathrm{Na}_{2} \mathrm{HPO}_{4}(0.1 \mathrm{M}, \\
\mathrm{pH} 9.0)\end{array}$ & rat anti mouse; BD 551216 \\
\hline Blocking Solution & $5 \%$ FCS & PBS (pH 7.4) & - \\
\hline Top Standard & $1: 100$ & $5 \%$ FCS in PBS & - \\
\hline Detection & $1: 4000$ & $5 \%$ FCS in PBS & rat anti mouse; BD 554410 \\
\hline $\begin{array}{l}\text { Streptavidin horseradish } \\
\text { peroxidase }\end{array}$ & $1: 2000$ & $5 \% \mathrm{FCS}$ in $\mathrm{PBS}$ & BD 554066 \\
\hline \multicolumn{4}{|l|}{$I L-4$} \\
\hline Capture & $1: 1000$ & PBS (pH 7.4) & rat anti mouse; BD 554434 \\
\hline Blocking Solution & $5 \%$ FCS & PBS (pH 7.4) & - \\
\hline Top Standard & $1: 100$ & $5 \% \mathrm{FCS}$ in $\mathrm{PBS}$ & - \\
\hline Detection & $1: 4000$ & $5 \% \mathrm{FCS}$ in $\mathrm{PBS}$ & rat anti mouse; BD 554390 \\
\hline $\begin{array}{l}\text { Streptavidin horseradish } \\
\text { peroxidase }\end{array}$ & $1: 2000$ & $5 \% \mathrm{FCS}$ in $\mathrm{PBS}$ & BD 554066 \\
\hline \multicolumn{4}{|l|}{ IL-10 } \\
\hline Capture & $1: 500$ & $\begin{array}{l}\mathrm{Na}_{2} \mathrm{HPO}_{4},(0.1 \mathrm{M}, \\
\text { pH6.0) }\end{array}$ & rat anti mouse; BD 551215 \\
\hline Blocking Solution & $5 \%$ FCS & PBS & - \\
\hline Top Standard & $1: 40$ & $5 \%$ FCS in PBS & - \\
\hline Detection & $1: 2500$ & $55 \%$ FCS in PBS & rat anti mouse; BD 554465 \\
\hline
\end{tabular}




\begin{tabular}{|c|c|c|c|}
\hline $\begin{array}{l}\text { Streptavidin horseradish } \\
\text { peroxidase }\end{array}$ & $1: 1000$ & $5 \% \mathrm{FCS}$ in $\mathrm{PBS}$ & BD 554066 \\
\hline \multicolumn{4}{|l|}{$I L-17 a$} \\
\hline Capture & $1: 125$ & $\begin{array}{l}\mathrm{Na}_{2} \mathrm{HPO}_{4},(0.1 \mathrm{M}, \\
\text { pH6.0) }\end{array}$ & rat anti mouse; BD 551225 \\
\hline Blocking Solution & $5 \% \mathrm{FCS}$ & PBS & - \\
\hline Top Standard & $1: 100$ & $5 \% \mathrm{FCS}$ in $\mathrm{PBS}$ & - \\
\hline Detection & $1: 500$ & $5 \% \mathrm{FCS}$ in $\mathrm{PBS}$ & rat anti mouse; BD 555067 \\
\hline $\begin{array}{l}\text { Streptavidin horseradish } \\
\text { peroxidase }\end{array}$ & $1: 1000$ & $5 \% \mathrm{FCS}$ in $\mathrm{PBS}$ & BD 554066 \\
\hline \multicolumn{4}{|l|}{$\lg M$} \\
\hline Capture & $1: 500$ & $\begin{array}{l}\mathrm{Na}_{2} \mathrm{HPO}_{4},(0.1 \mathrm{M}, \\
\text { pH6.0) }\end{array}$ & rat anti mouse; BD 553435 \\
\hline Blocking Solution & $5 \%$ FCS & PBS & - \\
\hline Top Standard & $1: 2000$ & $5 \% \mathrm{FCS}$ in $\mathrm{PBS}$ & - \\
\hline Detection & $1: 1000$ & $5 \% \mathrm{FCS}$ in $\mathrm{PBS}$ & rat anti mouse; BD 553406 \\
\hline $\begin{array}{l}\text { Streptavidin horseradish } \\
\text { peroxidase }\end{array}$ & $1: 1000$ & $5 \% \mathrm{FCS}$ in $\mathrm{PBS}$ & BD 554066 \\
\hline
\end{tabular}

\subsection{Experimental Detail for Phagocytosis Assay}

$1 \times 10^{5}$ RAW264.7 cells were seeded into wells of a 96 well plate and treatment or vehicle controls added. After 4 hours incubation at $37^{\circ} \mathrm{C}\left(5 \% \mathrm{CO}_{2}\right), 25 \mu \mathrm{g} / \mathrm{mL}$ pHrodo bioparticles were added, along with treatment or vehicle, to maintain treatment concentration. The cells were incubated for a further 4 hours, and the fluorescence measured with a BD FacsCanto II flow cytometer, to determine the phagocytic ability of cells. Flow cytometry data was analysed using FlowJo v10 (TreeStar LLC, Oregon)

In parallel a second 96 well plate was seeded with 1 x $10^{5}$ RAW264.7 cells, and treatment or controls added. The cells were incubated for 4 hours, before the addition of $\mathrm{lug} / \mathrm{mL}$ of MTT to each well. After 45 minutes, solubilising solution was added and the viability of cells was assessed, measuring formazan formation using a PerkinElmer Enspire plate reader at $560 \mathrm{~nm}$. 


\section{Appendix}

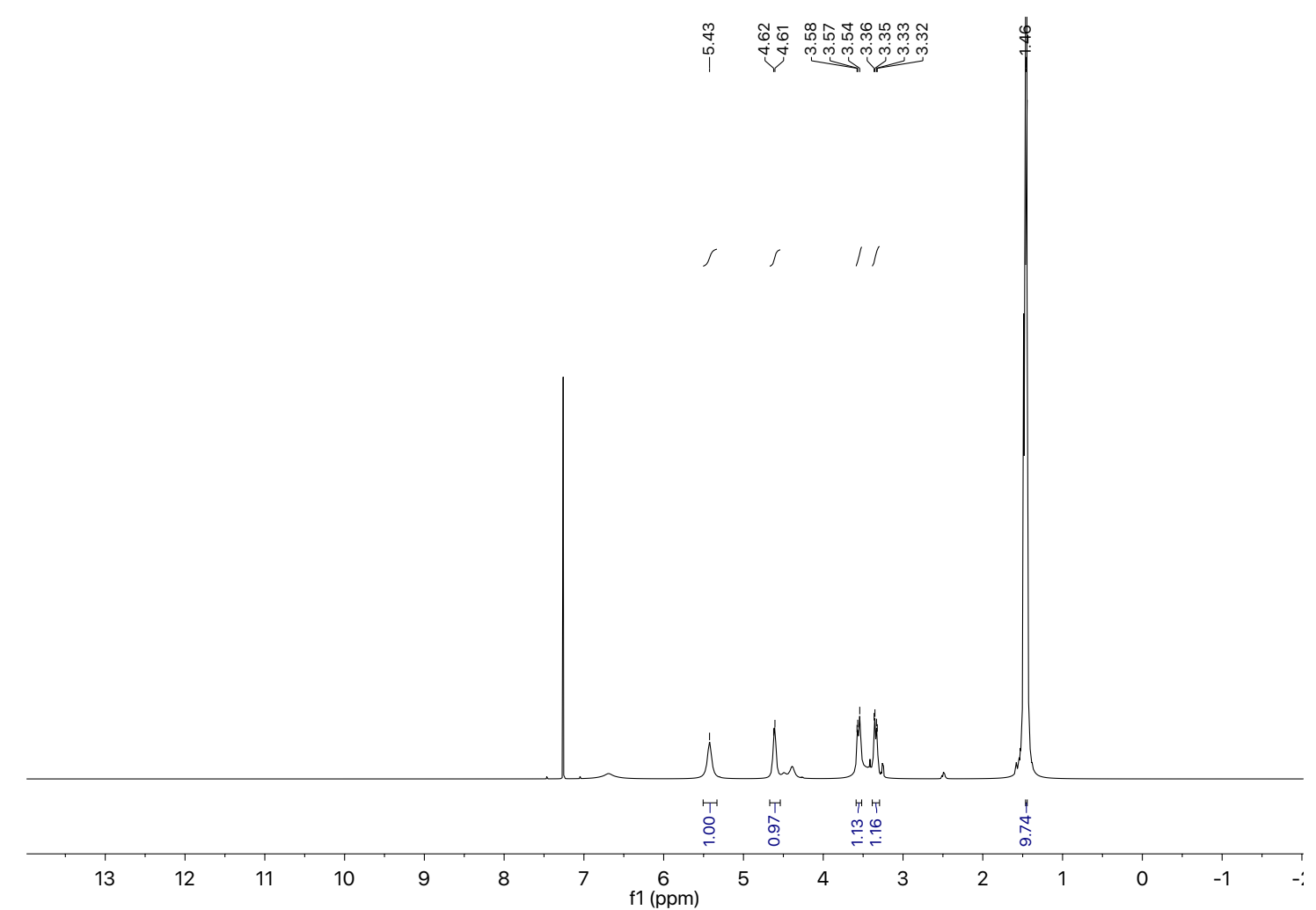

${ }^{1}$ H NMR of N-Boc-S-trichlorovinyl-L-cysteine 7

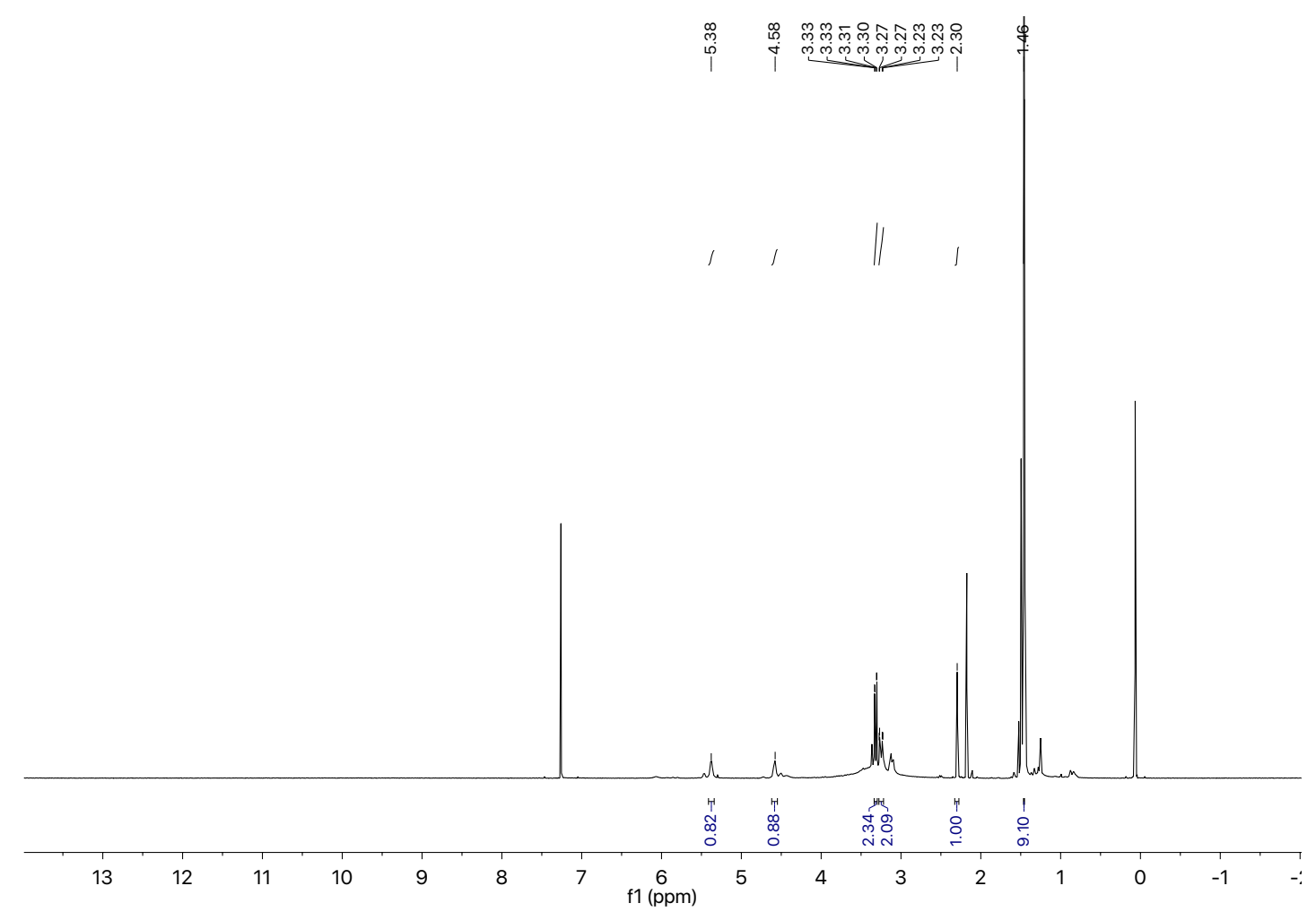

${ }^{1}$ H NMR of N-Boc-S-propynyl-L-cysteine 8 


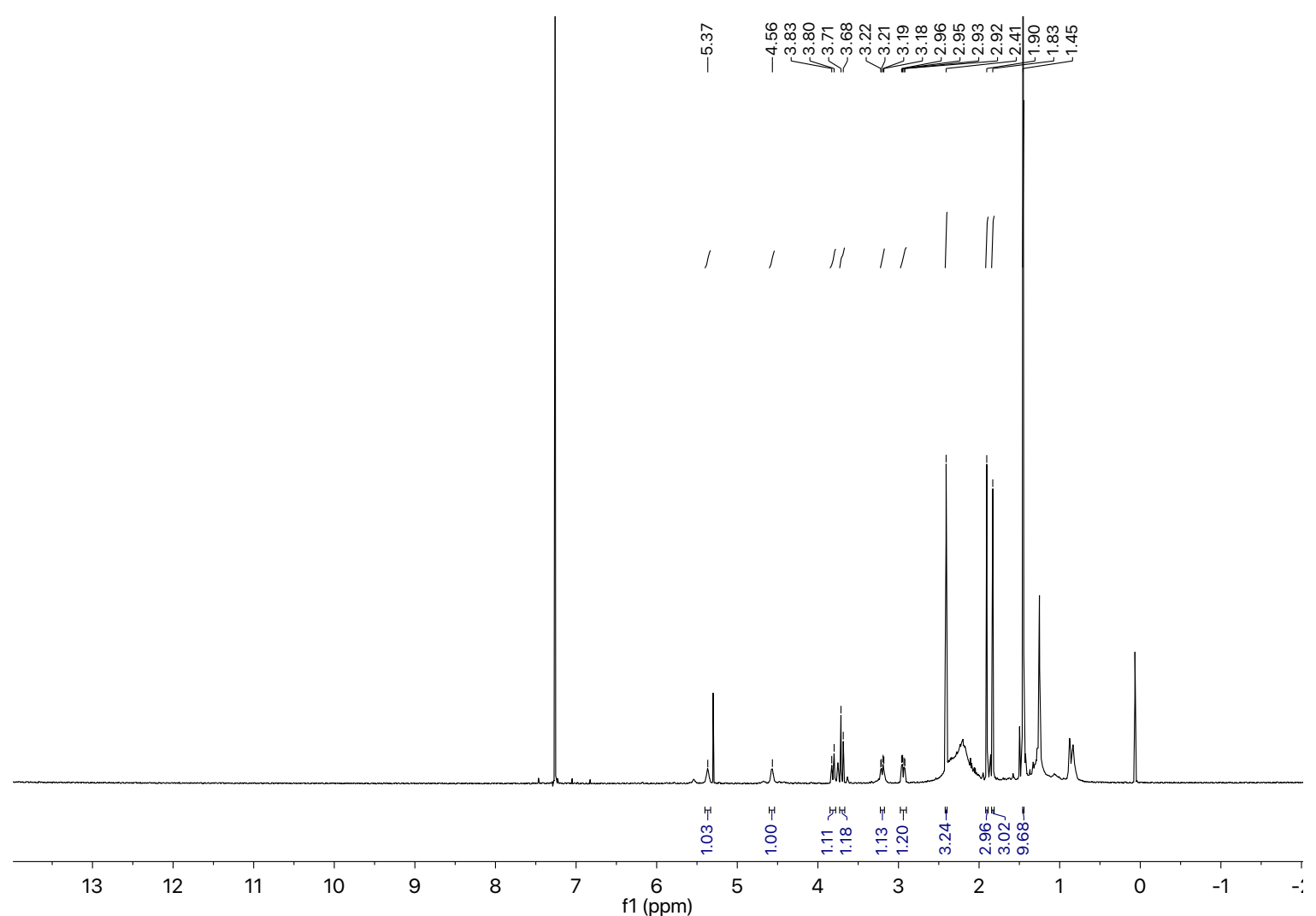

${ }^{1}$ H NMR of N-Boc-S-bimane-L-cysteine 9

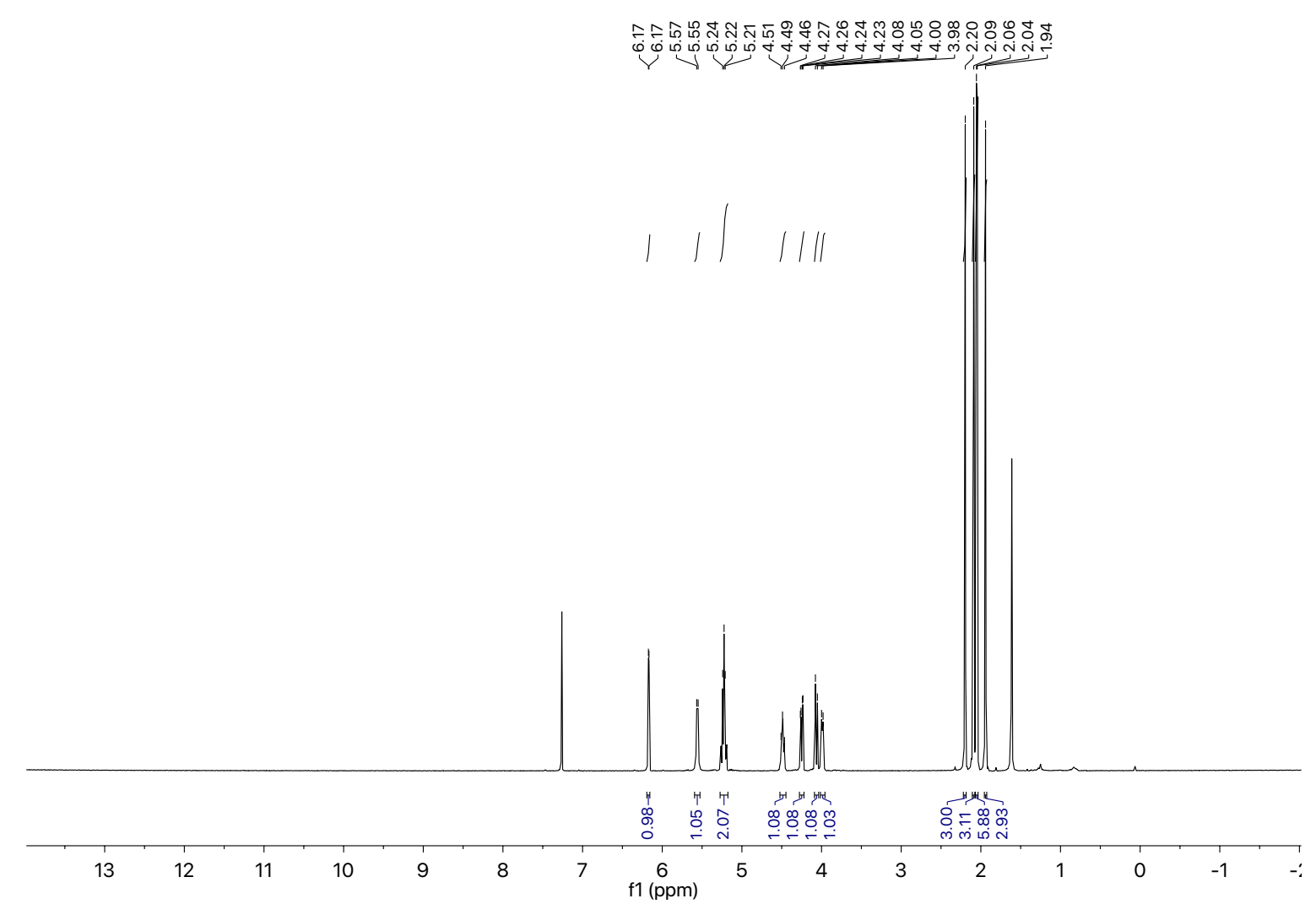

${ }^{1}$ H NMR of peracetylated glucosamine 13 


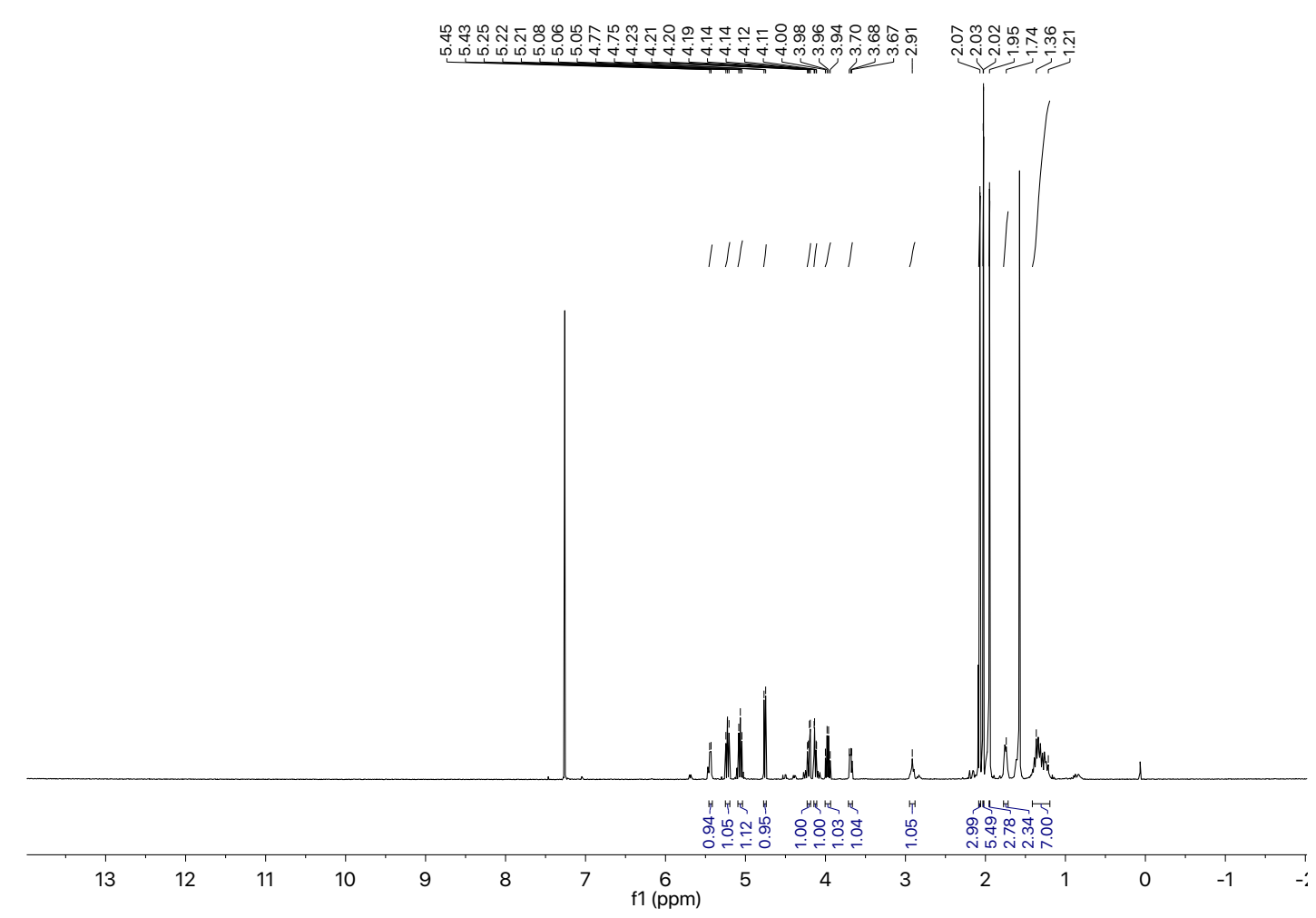

${ }^{1}$ H NMR of compound 14

商

"I," \|\|$,\|\| \|$

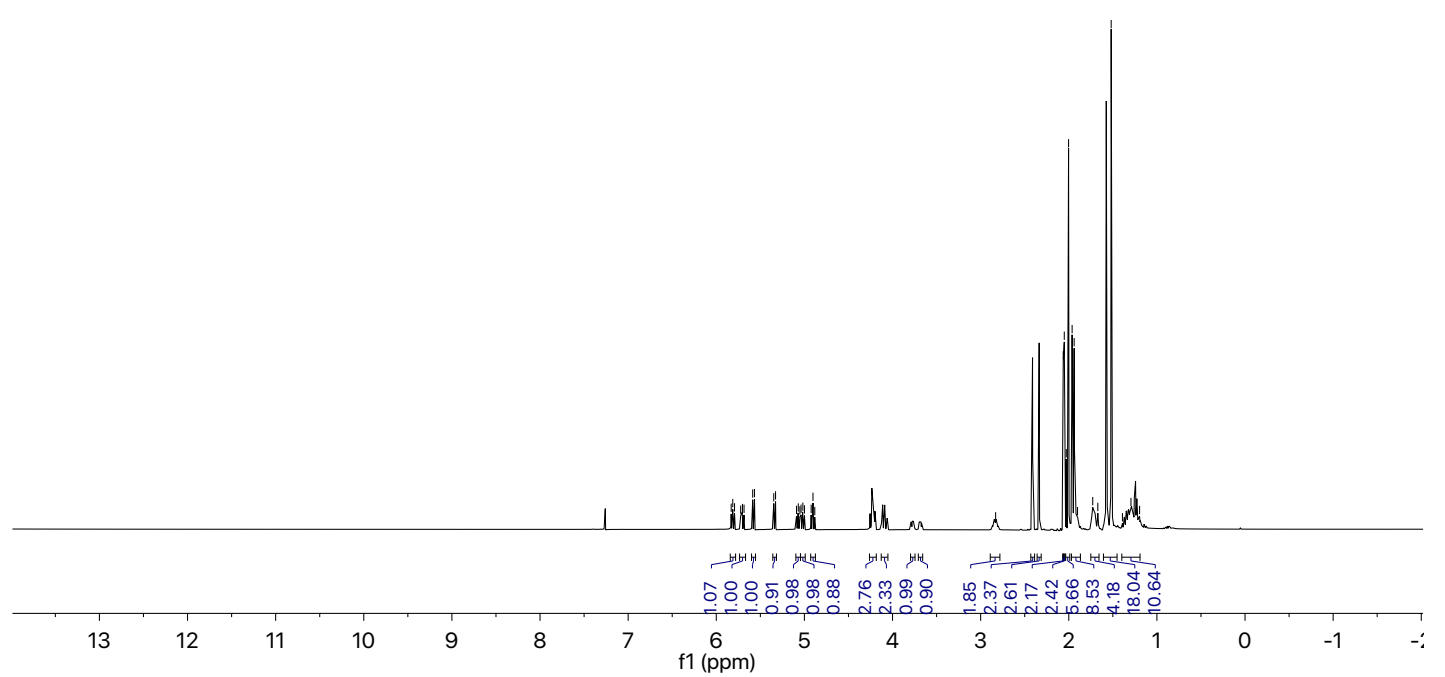

${ }^{1}$ H NMR of compound 15 


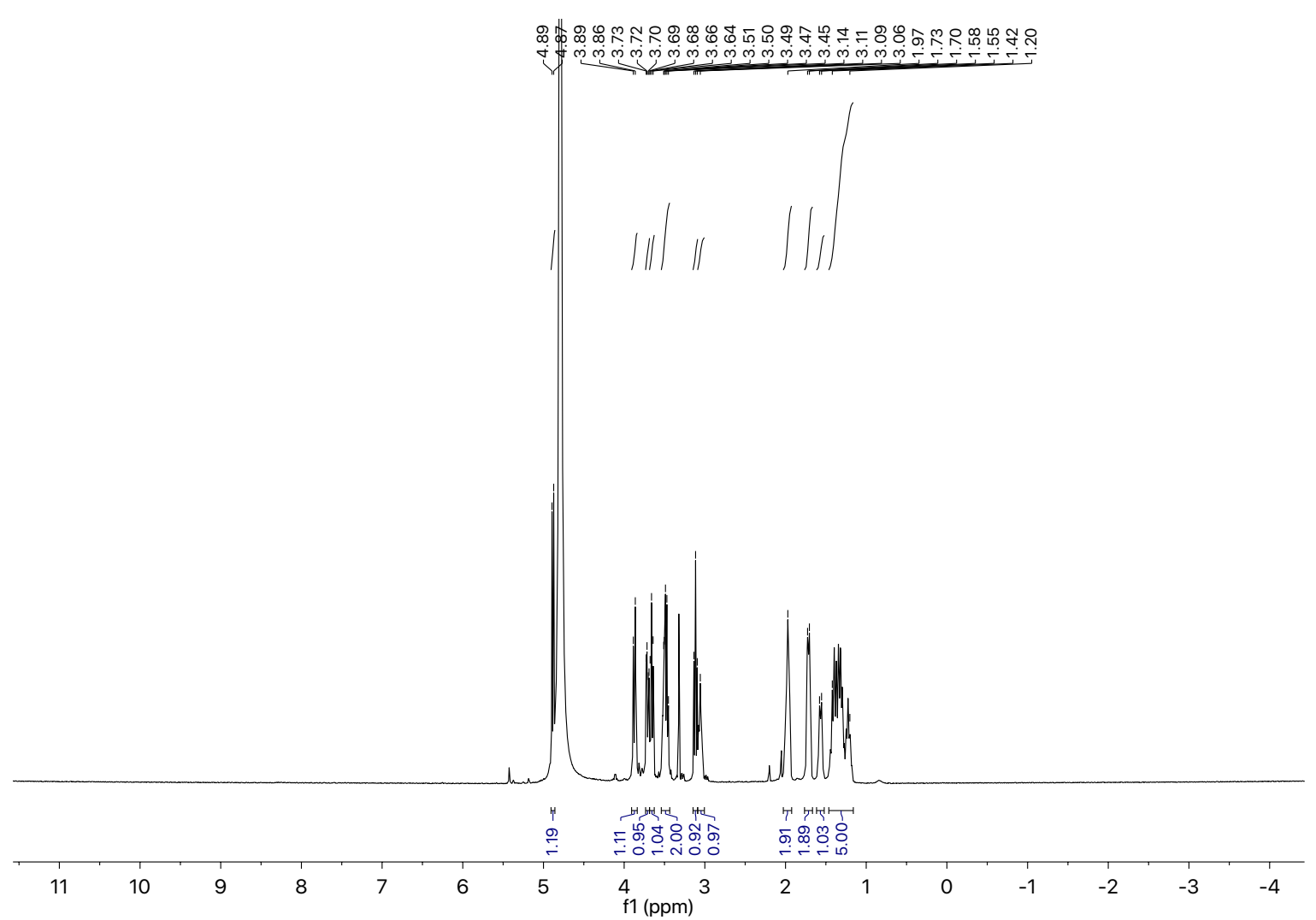

${ }^{1}$ H NMR of compound 11

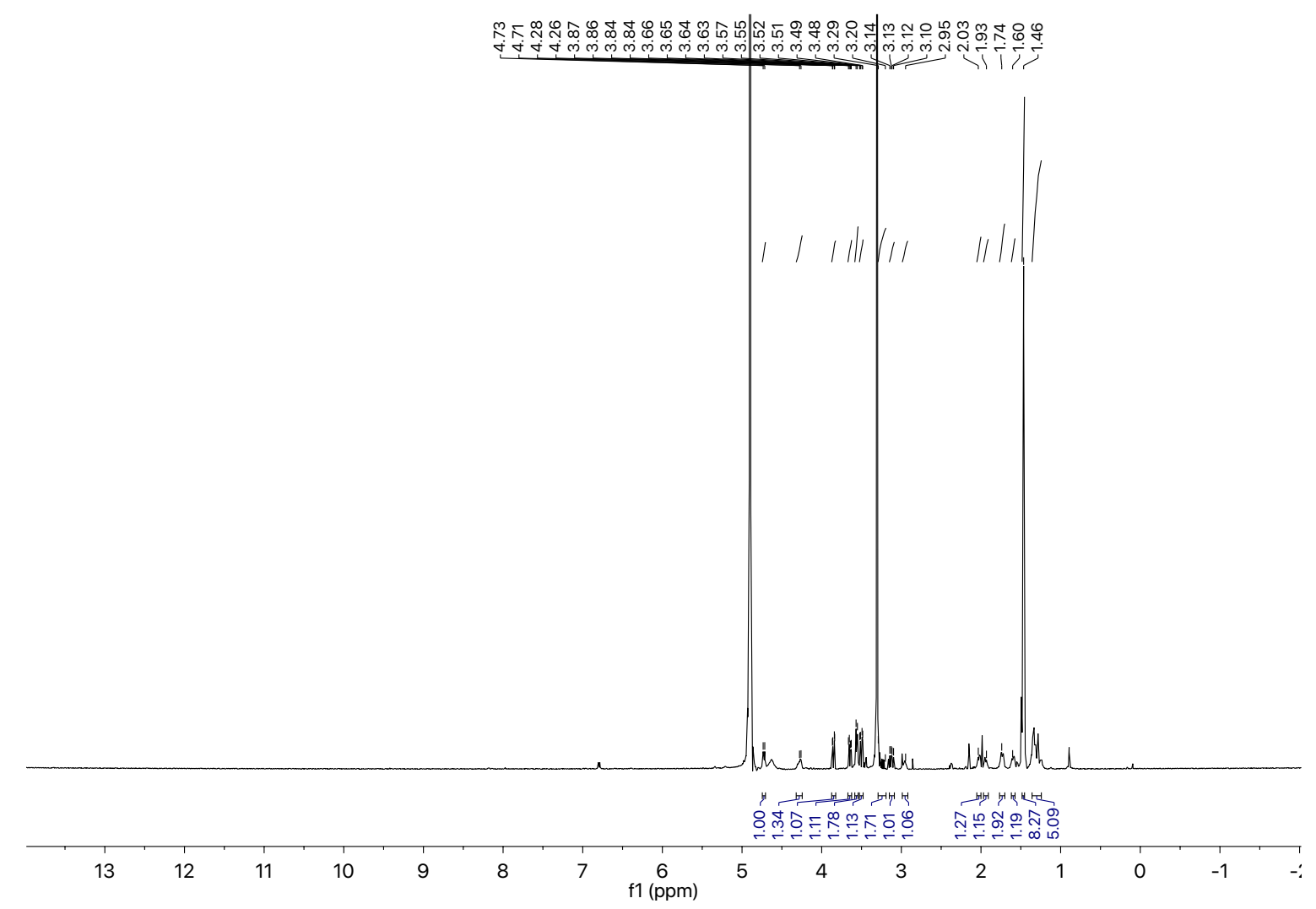

${ }^{1}$ H NMR of compound 1 


\section{References}

1. Newton, G. L., Leung, S. S., Wakabayashi, J. I., Rawat, M. \& Fahey, R. C. The DinB superfamily includes novel mycothiol, bacillithiol, and glutathione Stransferases. Biochemistry 50, 10751-10760 (2011).

2. Fan, F., Vetting, M. W., Frantom, P. A. \& Blanchard, J. S. Structures and mechanisms of the mycothiol biosynthetic enzymes. Curr. Opin. Chem. Biol. 13, 451-9 (2009).

3. Newton, G. L. et al. Characterization of Mycobacterium smegmatis Mutants Defective in 1-d-myo-Inosityl-2-amino-2-deoxy-d-glucopyranoside and Mycothiol Biosynthesis. Biomed. Biophys. Res. Commun. 255, 239-199 (1999).

4. Meister, A. \& Anderson, M. E. Glutathione. Ann. Rev. Biochem 52, 711-60 (1983).

5. Riordan, S. W. Synthesis of Antimycobacterial Agents that Harness Mycothiol and Cysteine conjugate $\beta$-lyase Metabolic Pathways. (Master's Thesis, Victoria University of Wellington, 2015).

6. Hernick. Targeting Mycothiol Biosynthesis and Mycothiol-Dependent Detoxification for the Treatment of Tuberculosis. J Anc Dis Prev Rem 1, (2013).

7. Gutierrez-Lugo, M.-T., Baker, H., Shiloach, J., Boshoff, H. \& Bewley, C. A. Dequalinium, a new inhibitor of Mycobacterium tuberculosis mycothiol ligase identified by high-throughput screening. J. Biomol. Screen. 14, 643-52 (2009).

8. IARC. IARC Monographs on the Evaluation of Carcinogenic Risks to Humans: Trichloroethylene, Tetrachloroethylene and Some Other Chlorinated Agents. (2014).

9. Guha, N. et al. Carcinogenicity of trichloroethylene, tetrachloroethylene, some other chlorinated solvents, and their metabolites. Lancet Oncol. 13, 1192-1193 (2012).

10. EPA, U. S. Toxicological Review of Tetrachloroethylene (Perchloroethylene). (2012).

11. California Environmental Protection Agency. Perchloroethylene Inhalation Cancer Unit Risk Factor Technical Support Document for Cancer Potency Factors, Appendix B, Public Review Draft. (2016).

12. Lock, E. A. \& Reed, C. J. Trichloroethylene: Mechanisms of Renal Toxicity and Renal Cancer and Relevance to Risk Assessment. Toxicol. Sci. 91, 313-331 
(2006).

13. Lash, L. H. et al. Glutathione Conjugation of Perchloroethylene in Rats and Mice in Vitro: Sex-, Species-, and Tissue-Dependent Differences Glutathione Conjugation of Perchloroethylene in Rats and Mice in Vitro: Sex-, Species-, and Tissue-Dependent Differences. Toxicol. Appl. Pharmacol. 150, 49-57 (1998).

14. Dekant, W., Berthold, K., Vamvakas, S., Henschler, D. \& Anders, M. W. Thioacylating intermediates as metabolites of S-(1,2-dichlorovinyl)-L-cysteine and S-(1,2,2-trichlorovinyl)-L-cysteine formed by cysteine conjugate beta-lyase. Chem. Res. Toxicol. 1, 175-178 (1988).

15. Gaskin, P. J., Adcock, H. J., Buckberry, L. D., Teesdale-Spittle, P. H. \& Shawl, P. N. The C-S lysis of L-cysteine conjugates by aspartate and alanine aminotransferase enzymes. Hum. Exp. Toxicol. 14, 422-427 (1995).

16. Adcock, H. J., Brophy, P. M., Teesdale-Spittle, P. H. \& Buckberry, L. D. Cysteine conjugate $\beta$-lyase activity in three species of parasitic helminth. Int. J. Parasitol. 29, 543-548 (1999).

17. Howlader, N. et al. SEER Cancer Statistics Review 1975-2013. (2016).

18. Burstein, H. J. et al. Clinical Cancer Advances 2017: Annual Report on Progress Against Cancer From the American Society of Clinical Oncology. J. Clin. Oncol. 35, 1341-1367 (2017).

19. Housman, G. et al. Drug resistance in cancer: an overview. Cancers (Basel). 6, 1769-92 (2014).

20. Kreipe, H. H. \& von Wasielewski, R. Beyond Typing and Grading: Target Analysis in Individualized Therapy as a New Challenge for Tumour Pathology. Recent Results Cancer Res. 176, 3-6 (2007).

21. Merin, N. M. \& Kelly, K. R. Clinical use of proteasome inhibitors in the treatment of multiple myeloma. Pharmaceuticals (Basel). 8, 1-20 (2014).

22. Conchon, M. et al. Dasatinib -clinical trials and management of adverse events in imatinib resistant/ intolerant chronic myeloid leukemia. Rev. Bras. Hematol.

Hemoter. 33, 131-139 (2011).

23. Diamantis, N. \& Banerji, U. Antibody-drug conjugates--an emerging class of cancer treatment. Br. J. Cancer 114, 362-7 (2016).

24. Espinosa, E., Zamora, P., Feliu, J. \& González Barón, M. Classification of anticancer drugs - a new system based on therapeutic targets. Cancer Treat. Rev. 29, 515-523 (2003). 
25. Hanahan, D. et al. Hallmarks of Cancer: The Next Generation. Cell 144, 646$674(2011)$.

26. Gatenby, R. A. \& Gillies, R. J. Why do cancers have high aerobic glycolysis? Nat. Rev. Cancer 4, 891-899 (2004).

27. Calvaresia, E. C. \& Hergenrother, P. J. Glucose conjugation for the specific targeting and treatment of cancer. Chem Sci 4, 2319-2333 (2013).

28. Hecht, S. M. Bleomycin Group Antitumor Agents. in Anticancer Agents from Natural Products (eds. Cragg, G. M., Kingston, D. G. I. \& Newman, D. J.) 451478 (CRC Press, 2011).

29. Schroeder, B. R. et al. The disaccharide moiety of bleomycin facilitates uptake by cancer cells. J. Am. Chem. Soc. 136, 13641-13656 (2014).

30. Khalil, D. N., Smith, E. L., Brentjens, R. J. \& Wolchok, J. D. The future of cancer treatment: immunomodulation, CARs and combination immunotherapy. Nat. Rev. Clin. Oncol. 13, 273-90 (2016).

31. Scott, A. M., Allison, J. P. \& Wolchok, J. D. Monoclonal antibodies in cancer therapy. Cancer Immun. 12, 14 (2012).

32. Perica, K., Varela, J. C., Oelke, M. \& Schneck, J. Adoptive T cell immunotherapy for cancer. Rambam Maimonides Med. J. 6, 1-8 (2015).

33. Marabelle, A. \& Gray, J. Tumor-targeted and immune-targeted monoclonal antibodies: Going from passive to active immunotherapy. Pediatr. Blood Cancer 62, 1317-1325 (2015).

34. Davis, L. \& Kuttan, G. Immunomodulatory activity of Withania somnifera. $J$. Ethnopharmacol. 71, 193-200 (2000).

35. Kuttan, G. \& Kuttan, R. Immunomodulatory Activity of a Peptide Isolated from Viscum Album Extract (NSC 635 089). Immunol. Invest. 21, 285-296 (1992).

36. Kuttan, G. Use of Withania somnifera Dunal as an adjuvant during radiation therapy. Indian J. Exp. Biol. 34, 854-856 (1996).

37. Vinay, D. S. et al. Immune evasion in cancer: Mechanistic basis and therapeutic strategies. Semin. Cancer Biol. 35, S185-S198 (2015).

38. Díaz- Zaragoza, M., Hernández-Ávila, R., Viedma-Rodriguez, R., ArenasAranda, D. \& Ostoa-Saloma, P. Natural and adaptive IgM antibodies in the recognition of tumor-associated antigens of breast cancer (Review). Oncol. Rep. 34, 1106-1114 (2015).

39. Haabeth, O. A. W. et al. Inflammation driven by tumour-specific Th1 cells 
protects against B-cell cancer. Nat. Commun. 2, 240 (2011).

40. Fabre, J. et al. Targeting the Tumor Microenvironment: The Protumor Effects of IL-17 Related to Cancer Type. Int. J. Mol. Sci. 17, (2016).

41. Steiner, G. E. et al. Expression and function of pro-inflammatory interleukin IL17 and IL-17 receptor in normal, benign hyperplastic, and malignant prostate. Prostate 56, 171-182 (2003).

42. Lyon, D. E., McCain, N. L., Walter, J. \& Schubert, C. Cytokine comparisons between women with breast cancer and women with a negative breast biopsy. Nurs. Res. 57, 51-8 (2008).

43. Tartour, E. et al. Interleukin 17, a T-cell-derived cytokine, promotes tumorigenicity of human cervical tumors in nude mice. Cancer Res. 59, 36983704 (1999).

44. Knapp, S., Gonzalez, S., Myers, D. S., Eckman, L. L. \& Bewley, C. A. Shortcut to Mycothiol Analogues. Org. Lett. 4, 4337-4339 (2002).

45. Hiremathad, A. et al. Tacrine-allyl/propargylcysteine-benzothiazole trihybrids as potential anti-Alzheimer's drug candidates. RSC Adv. 6, 53519-53532 (2016).

46. Rostovtsev, V. V., Green, L. G., Fokin, V. V. \& Sharpless, K. B. A Stepwise Huisgen Cycloaddition Process: Copper(I)-Catalyzed Regioselective 'Ligation' of Azides and Terminal Alkynes. Angew. Chemie Int. Ed. 41, 2596-2599 (2002).

47. Jothivasan, V. K. et al. Mycothiol: synthesis, biosynthesis and biological functions of the major low molecular weight thiol in actinomycetes. Nat. Prod. Rep. 25, 1091 (2008).

48. Eglen, R. \& Reisine, T. Primary Cells and Stem Cells in Drug Discovery: Emerging Tools for High-Throughput Screening. Assay Drug Dev. Technol. 9, 108-124 (2011).

49. Kaur, G. \& Dufour, J. M. Cell lines: Valuable tools or useless artifacts. Spermatogenesis 2, 1-5 (2012).

50. Magae, J. et al. Screening for Specific Inhibitors of Phagocytosis of Thioglycollate-elicited Macrophages. Biosci. Biotech. Biochem 58, 104-107 (1994).

51. Skoufias, D. A. et al. S-Trityl-L-cysteine Is a Reversible, Tight Binding Inhibitor of the Human Kinesin Eg5 That Specifically Blocks Mitotic Progression. J. Biol. Chem. 281, 17559-17569 (2006).

52. Petra, D. G. I., Kamer, P. C. J., Spek, A. L., Schoemaker, H. E. \& Van Leeuwen, 
P. W. N. M. Aminosulf(ox)ides as Ligands for Iridium(I)-Catalyzed Asymmetric Transfer Hydrogenation. J. Org. Chem 65, 3010-3017 (2000).

53. Johnson Ii, E. M. Design and Synthesis of Cysteine/Cystine Prodrugs and Bioisosteres Including Symmetrical and Unsymmetrical Disulfides Designed to Increase Cystine Levels in the CNS in Order to Drive the Cystine/Glutamate Antiporter: A Novel Treatment for Schizophrenia and Drug Addiction. (Ph.D. Thesis, University of Wisconsin, Milwaukee, 2012).

54. Hiremathad, A. et al. Tacrine-allyl/propargylcysteine-benzothiazole trihybrids as potential anti-Alzheimer's drug candidates. RSC Adv. 6, 53519-53532 (2016).

55. Conte, M. Lo, Pacifico, S., Chambery, A., Marra, A. \& Dondoni, A. Photoinduced Addition of Glycosyl Thiols to Alkynyl Peptides: Use of FreeRadical Thiol-Yne Coupling for Post-Translational Double-Glycosylation of Peptides. J. Org. Chem 75, 4644-4647 (2010).

56. Curran, T. P. et al. Synthesis and conformational behavior of metallacyclicdipeptides derived from coordination of side chain alkynylamino acids to tungsten. J. Organomet. Chem. 806, 12-21 (2016).

57. Valeur, E. \& Bradley, M. Amide bond formation: beyond the myth of coupling reagents. Chem. Soc. Rev. 38, 606-631 (2008).

58. Silva, D. G. et al. A comparative study of warheads for design of cysteine protease inhibitors. Bioorg. Med. Chem. Lett. 27, 5031-5035 (2017).

59. Montalbetti, C. A. G. N. \& Falque, V. Amide bond formation and peptide coupling. Tetrahedron 61, 10827-10852 (2005).

60. Lygo, B. \& Pelletier, G. 1-Hydroxybenzotriazole. Encyclopedia of reagents for organic synthesis (2013).

61. Pu, Y. J. et al. A Practical Method for Functionalized Peptide or Amide Bond Formation in Aqueous-Ethanol Media with EDC as Activator. Org. Process Res. Dev. 13, 310-314 (2009).

62. Wohlfarth, C. Dielectric constant of N,N-dimethylformamide. in Static Dielectric Constants of Pure Liquids and Binary Liquid Mixtures (ed. Lechner, M. D.) 175182 (Springer-Verlag Berlin Heidelberg, 2008).

63. Dunetz, J. R., Magano, J. \& Weisenburger, G. A. Large-Scale Applications of Amide Coupling Reagents for the Synthesis of Pharmaceuticals. Org. Process Res. Dev. 20, 140-177 (2016).

64. Van de Nes, J. A. P., Griewank, K. G., Schmid, K.-W. \& Grabellus, F. 
Immunocytochemical analysis of glucose transporter protein-1 (GLUT-1) in typical, brain invasive, atypical and anaplastic meningioma. Neuropathology $\mathbf{3 5}$, 24-36 (2015).

65. Ma, X. et al. Clinical significance of COX-2, GLUT-1 and VEGF expressions in endometrial cancer tissues. Pakistan J. Med. Sci. 31, 280-284 (2015).

66. Abdou, A. G., Eldien, M. M. S. \& Elsakka, D. GLUT-1 Expression in Cutaneous Basal and Squamous Cell Carcinomas. Int. J. Surg. Pathol. 23, 447-453 (2015).

67. Panda, S. \& Ding, J. L. Natural antibodies bridge innate and adaptive immunity. J. Immunol. 194, 13-20 (2015).

68. Stavnezer, J., Guikema, J. E. J. \& Schrader, C. E. Mechanism and regulation of class switch recombination. Annu. Rev. Immunol. 26, 261-92 (2008).

69. Boes, M. Role of natural and immune IgM antibodies in immune responses. Mol. Immunol. 37, 1141-1149 (2000).

70. Couper, K. N., Blount, D. G. \& Riley, E. M. IL-10: The master regulator of immunity to infection. J. Immunol. 180, 5771-5777 (2008).

71. Kühn, R., Löhler, J., Rennick, D., Rajewsky, K. \& Müller, W. Interleukin-10deficient mice develop chronic enterocolitis. Cell 75, 263-74 (1993).

72. Kelchtermans, H., Billiau, A. \& Matthys, P. How interferon-g keeps autoimmune diseases in check. Trends Immunol. 29, 479-486 (2008).

73. Schoenborn, J. R. \& Wilson, C. B. Regulation of Interferon- $\gamma$ During Innate and Adaptive Immune Responses. in Advances in Immunology (ed. Frederick Alt) 41-101 (Elsevier Inc., 2007).

74. Choi, P. \& Reiser, H. IL-4: role in disease and regulation of production. Clin. Exp. Immunol. 113, 317-9 (1998).

75. Ishigame, H. et al. Differential Roles of Interleukin-17A and -17F in Host Defense against Mucoepithelial Bacterial Infection and Allergic Responses. Immunity 30, 108-119 (2009).

76. Waitzman, J. S. \& Rice, S. E. Mechanism and regulation of kinesin-5, an essential motor for the mitotic spindle. Biol. Cell 106, 1-12 (2014).

77. Kapellos, T. S. et al. A novel real time imaging platform to quantify macrophage phagocytosis. Biochem. Pharmacol. 116, 107-19 (2016).

78. Johansson, M., Denardo, D. G. \& Coussens, L. M. Polarized immune responses differentially regulate cancer development. Immunol. Rev. 222, 145-54 (2008).

79. Kennedy, R. \& Celis, E. Multiple roles for CD4 T cells in anti-tumor immune 
responses. Immunol. Rev. 222, 129-144 (2008).

80. Berridge, M. V., Tan, A. S., McCoy, K. D. \& Wang, R. The biochemical and cellular basis of cell proliferation assays that use tetrazolium salts. Biochemica 4, 14-19 (1996). 